\title{
CHARACTERISTICS AND TRAVEL PATTERNS OF NEW YORK RESIDENTS: Subpopulations of Persons with a Disability in 2009
}

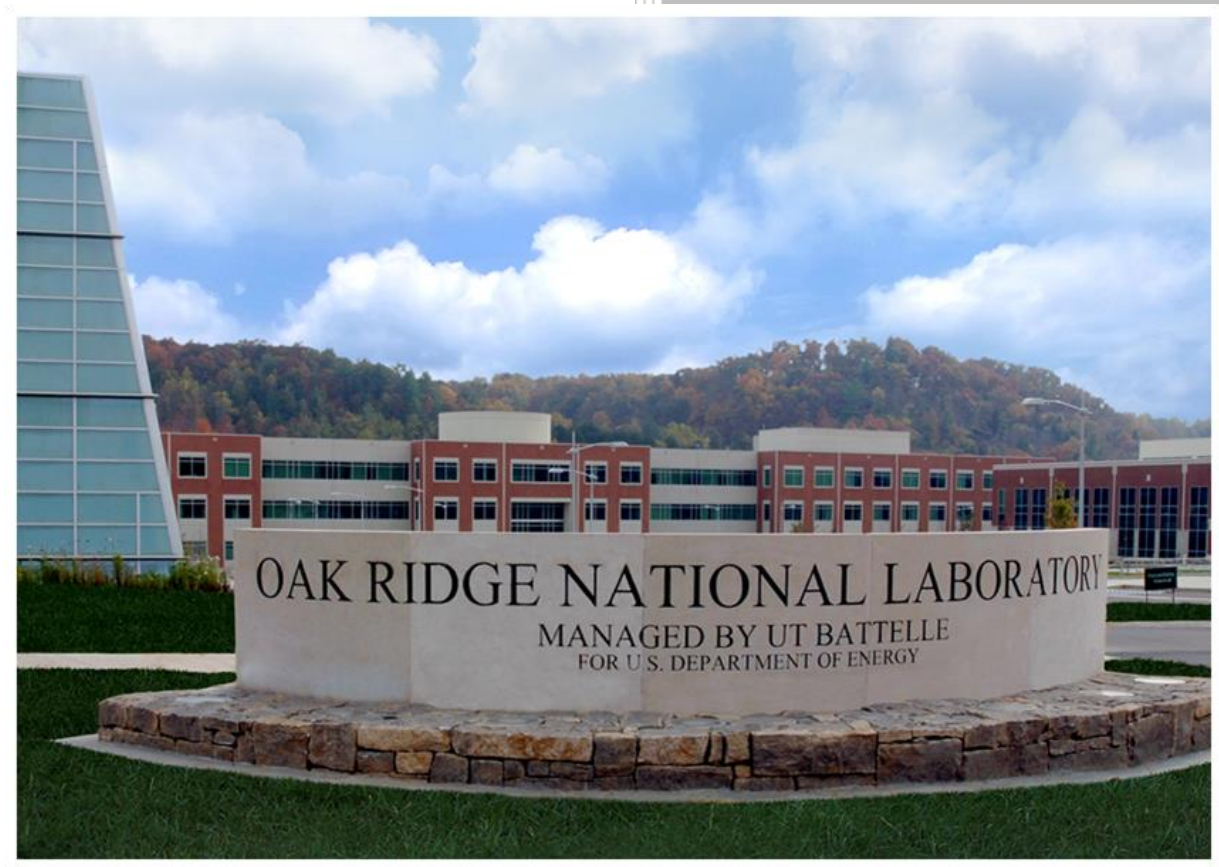

Approved for public release Distribution is unlimited
Ho-Ling Hwang, Ph.D. Tim Reuscher Daniel Wilson

August 2016 


\section{DOCUMENT AVAILABILITY}

Reports produced after January 1,1996, are generally available free via US Department of Energy (DOE) SciTech Connect.

Website http://www.osti.gov/scitech/

Reports produced before January 1, 1996, may be purchased by members of the public from the following source:

National Technical Information Service

5285 Port Royal Road

Springfield, VA 22161

Telephone 703-605-6000 (1-800-553-6847)

TDD 703-487-4639

Fax 703-605-6900

E-mail info@ntis.gov

Website http://www.ntis.gov/help/ordermethods.aspx

Reports are available to DOE employees, DOE contractors, Energy Technology Data Exchange representatives, and International Nuclear Information System representatives from the following source:

Office of Scientific and Technical Information

PO Box 62

Oak Ridge, TN 37831

Telephone 865-576-8401

Fax 865-576-5728

E-mail reports@osti.gov

Website http://www.osti.gov/contact.html

This report was prepared as an account of work sponsored by an agency of the United States Government. Neither the United States Government nor any agency thereof, nor any of their employees, makes any warranty, express or implied, or assumes any legal liability or responsibility for the accuracy, completeness, or usefulness of any information, apparatus, product, or process disclosed, or represents that its use would not infringe privately owned rights. Reference herein to any specific commercial product, process, or service by trade name, trademark, manufacturer, or otherwise, does not necessarily constitute or imply its endorsement, recommendation, or favoring by the United States Government or any agency thereof. The views and opinions of authors expressed herein do not necessarily state or reflect those of the United States Government or any agency thereof. 
Engineering and Transportation Science Division | Center for Transportation Analysis

\section{CHARACTERISTICS AND TRAVEL PATTERNS OF NEW YORK RESIDENTS: SUBPOPULATIONS OF PERSONS WITH A DISABILITY IN 2009}

Final Technical Memorandum for Task 14

August 2016

Ho-Ling Hwang, Ph.D.

Tim Reuscher

Daniel Wilson

Prepared for

New York State Department of Transportation

Prepared by

OAK RIDGE NATIONAL LABORATORY

Oak Ridge, TN 37831-6283

managed by

UT-BATTELLE, LLC

for the

US DEPARTMENT OF ENERGY

under contract DE-AC05-00OR22725 



\section{TABLE OF CONTENTS}

LIST OF FIGURES ............................................................................................................. vii

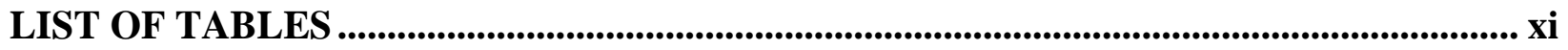

ACRONYMS xiii

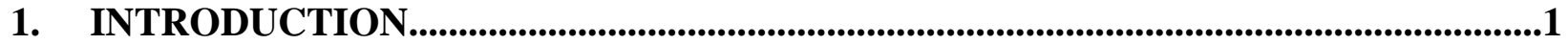

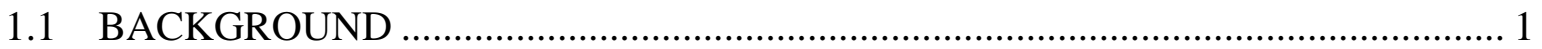

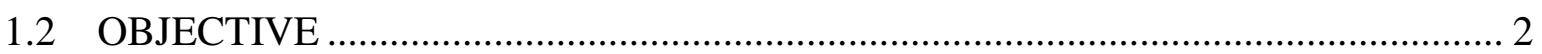

1.3 ORANIZATION OF THIS REPORT ............................................................... 2

2. DEFINITION OF DISABILITY AND INFORMATION SOURCES..................................3

2.1 NATIONAL HOUSEHOLD TRAVEL SURVEY ………....................................... 3

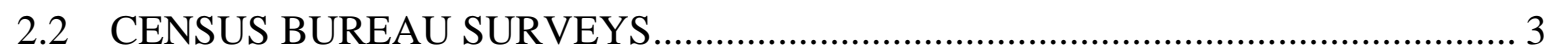

2.2.1 American Community Survey Data............................................................. 4

2.2.2 Survey of Income and Program Participation ................................................... 4

2.3 CENTERS FOR DISEASE CONTROL AND PREVENTION STATISTICS ............. 5

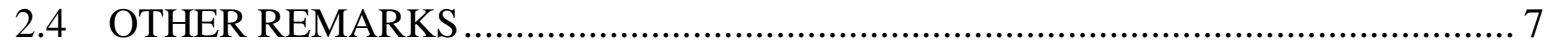

3. OVERVIEW OF DISABLED POPULATION - ANALYSIS OF ACS DATA ...............9

3.1 THE PREVALENCE OF DISABILITY ……......................................................... 9

3.1.1 Disability Type ................................................................................. 10

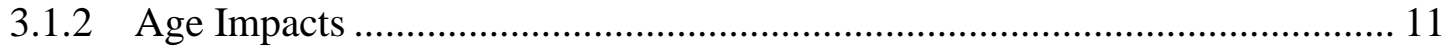

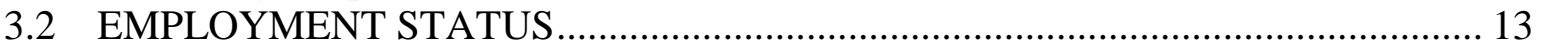

3.2.1 Disability Status and Employment............................................................. 14

3.2.2 Impacts of Disability Types on Employment Status....................................... 17

3.3 WORK LIMITATIONS FOR PEOPLE WITH A DISABILITY ………………..... 21

3.3.1 Work Experience by Disability Status .......................................................... 22

3.3.2 Type of Disability Influence on Work Status ............................................... 24

3.4 MODE CHOICES FOR COMMUTING TO WORK ……………........................ 29

4. NHTS-BASED STATISTICS ON DISABLED PERSONS IN NYS ................................31

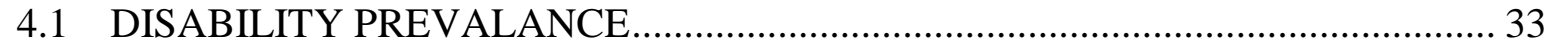

4.1.1 Age and Gender Factors............................................................................. 33

4.1.2 Difference in Vehicle Ownership ................................................................. 35

4.1.3 Household Income Gap.......................................................................... 36

4.1.4 Driving Status ........................................................................................ 37

4.1.5 Worker Status..................................................................................... 37

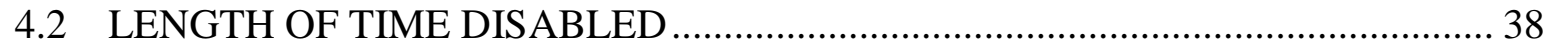

4.2.1 Population Distribution by Length of Time Disabled..................................... 38

4.2.2 Age Impacts on Length of Time Disabled ...................................................... 39

4.3 TRAVEL LIMITATIONS DUE TO DISABILITY ……….................................. 43

5. MOBILITY OF NYS DISABLED PERSONS …...............................................................47

5.1 IMPACTS OF DISABILITY ON TRIP PURPOSES …..................................... 47

5.2 INFLUENCE OF DISABILITY ON MODE CHOICES ………................................ 48

5.2.1 Overview of Mode Share by Disability Status …………………………...... 48

5.2.2 Mode Choices among Zero-Vehicle Households by Disability Status........... 50

5.3 HOUSEHOLD SIZE IMPACTS ON MODE CHOICE BY DISABILITY STATUS51

5.3.1 One-Person Households. 


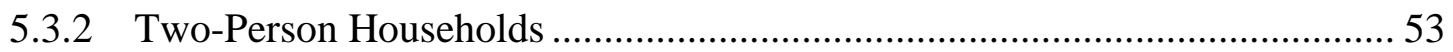

5.3.3 Households with Three or More Persons........................................................ 54

5.4 OVERVIEW ON IMPACTS OF DISABILITY ON TRIP RATES …………........... 56

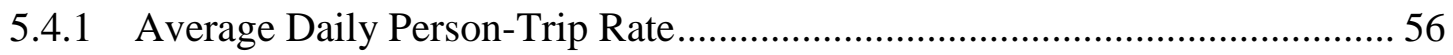

5.4.2 Average Person Trip Length .................................................................... 57

5.4.3 Average Daily Vehicle-Trip Rate ................................................................... 58

5.4.4 Average Vehicle Trip Length .................................................................... 59

5.5 TRAVEL STATISTICS FOR ZERO-VEHICLE HOUSEHOLDS BY DISABILITY

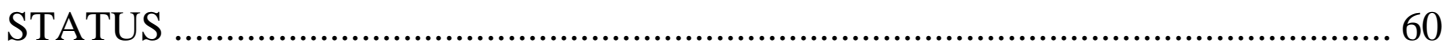

5.6 TRAVEL STATISTICS BY HOUSEHOLD SIZE AND DISABILITY STATUS ... 61

5.6.1 Impacts of Household Size on Trip Frequencies by Disability Status............. 61

5.6.2 Impacts of Household Size on Trip Length for Disabled Households ............ 63

6. SUMMARY ................................................................................................................69

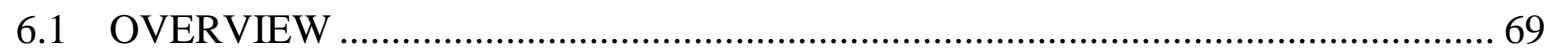

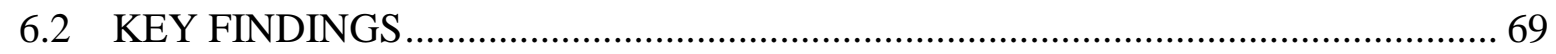

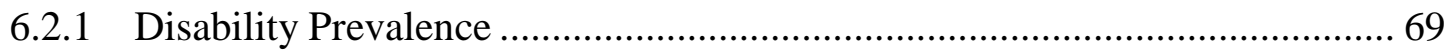

6.2.2 Age and Gender Characteristics.................................................................. 69

6.2.3 Economic Wellbeing ................................................................................. 70

6.2.4 Employment Opportunity ………………………………………………. 70

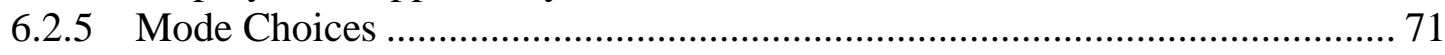

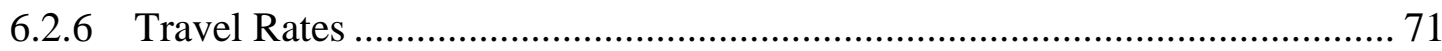

6.2.7 Zero-Vehicle Disabled Households ………………...................................... 72

6.2.8 Influence of Household Size .................................................................... 72

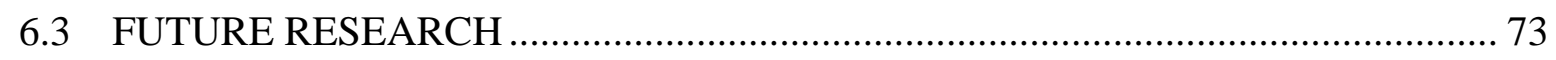

APPENDIX A GLOSSARY.............................................................................................75

APPENDIX B CDC DISABILTY STATISTICS ...................................................................87

APPENDIX C ADDITIONAL DISABILITY STATISTICS FROM ACS:

ECONOMIC WELLBEING ........................................................................99

APPENDIX D SUPPLEMENTAL STATISTICS FROM 2009 NHTS ...............................105 


\section{LIST OF FIGURES}

Figure

Page

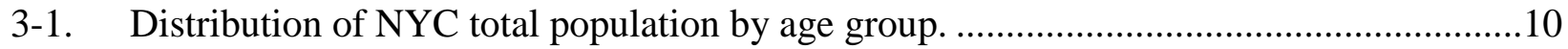

3-2. Distribution of NYC disabled population by age group. ............................................10

3-3. Percent of population with disabilities by type and region...........................................11

3-4. Percent of population with a given type of disability by elderly status by region.............12

3-5. Percent of disabled population by disability type and age group (note: only hearing and vision were asked to those under age 5, and independent living was only asked

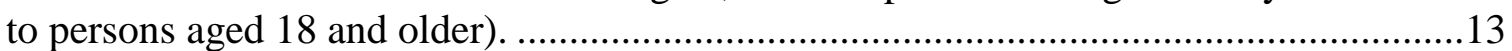

3-6. Employment status for non-disabled population of $18-64$ years old. .............................15

3-7. Employment status for 18-64 years old with any types of disabilities. .........................15

3-8. Non-disabled working age population who were in the labor force...............................16

3-9. Disabled working age population who were in the labor force. ....................................16

3-10. Percent of working age population with disabilities by employment status by region.

3-11. Employment status for working age population with a hearing difficulty. ....................18

3-12. Employment status for working age population with a vision difficulty.........................18

3-13. Employment status for working age population with a cognitive difficulty. ...................19

3-14. Employment status for working age population with an ambulatory difficulty. ..............20

3-15. Employment status for working age population with a self-care difficulty....................20

3-16. Employment status for working age population with an independent living difficulty.

3-17. Share of working age population with a disability by worker status and region..............23

3-18. Work experience for working age population with a disability...................................23

3-19. Work experience for non-disabled working age population.....................................24

3-20. Work status for working age population with a hearing difficulty..............................25

3-21. Work status for working age population with a vision difficulty. ................................25

3-22. Work status for working age population with a cognitive difficulty............................26

3-23. Work status for working age population with an ambulatory difficulty.........................27

3-24. Work status for working age population with a self-care difficulty. ............................27

3-25. Work status for working age population with an independent living difficulty..............28

4-1. Distribution of sample households with a disabled person, 2009 NHTS. .......................31

4-2. Map showing the geographic boundaries for New York City (NYC) and the New

York Metropolitan Transportation Council (NYMTC) ..............................................32

4-3. Length of time with medical condition that made it difficult to travel, 2009 NHTS. .......33

4-4. Distribution of population by disabled status, gender, and age group (2009 NHTS).......34

4-5. Percent of disabled population by age group, 2009 NHTS. .............................................34

4-6. Distribution of vehicle ownership by disability status and region (2009 NHTS).............35

4-7. Distribution of household income by disability status and region (2009 NHTS).............36

4-8. Percent of persons age 16 years and over reported as a driver and by disability status (2009 NHTS).

4-9. Percent of persons age 16 years and over who are workers (2009 NHTS). .....................38

4-10. Distribution of disabled person by length of time disabled. ............................................39

4-11. Share of elderly population within a given length of time disabled. ..............................40 
4-12. Distribution of length of disability within elderly and non-elder group.

4-13. Shares of disabled population with given travel limitations by elderly status and region.

4-14. Percent of populations that lived in urban area, by disability status and region...............45

5-1. Distribution of trips by trip purpose, by disability status and region. ............................47

5-2. Mode shares by disability status and region (2009 NHTS). .......................................49

5-3. Mode shares for zero-vehicle households by disability status and region.......................51

5-4. Mode share among one-person households by disability status and region.....................52

5-5. Mode shares among two-person households by disability status and region. ..................54

5-6. Mode shares among three-or-more person households by disability status and region.

5-7. Mode shares by major mode of transportation over household size, region, and

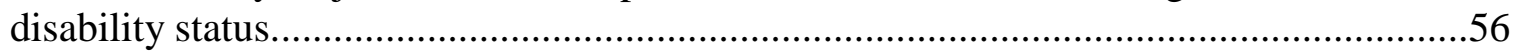

5-8. Average daily person-trip rates by disability status and region (2009 NHTS)................57

5-9. Average person trip length by disability status and region (2009 NHTS)......................58

5-10. Average daily vehicle-trip rate by disability status and region (2009 NHTS). ................58

5-11. Average vehicle trip length by disability status and region (2009 NHTS)....................59

5-12. Person-trip per person by household size, disability status, and region (2009 NHTS).

5-13. Vehicle-trip per driver by household size, disability status, and region (2009 NHTS)

5-14. PMT per person (in miles) by household size, disability status, and region (2009 NHTS).

5-15. Average person-trip length in miles, by household size, disability status, and region (2009 NHTS).

5-16. VMT per driver by household size, disability status, and region (2009 NHTS). ............66

5-17. Average VT length by household size, disability status, and region (2009 NHTS).........67

B-1. Screenshot of the homepage for the CDC DHDS online tool. .......................................8

B-2. Example of the "Maps \& Data Tables" feature provided by the DHDS. ........................89

B-3. Choices of maps and tables provided under the "Disability Status and Types" option.

B-4. Example of an interactive map for disability statistics shown with high contrast............91

B-5. Disability estimates displayed under the "Interactive Comparison Map" option. ............92

B-6. Example of the "Interactive Comparison Map" option for the Northeast Census

Region......

B-7. Information available for viewing under the "State Profiles" feature in DHDS..............94

B-8. Example of the resulting State Profile report for NYS . .........................................95

B-9. Screenshot of the Dual Area Profiles option in the DHDS tool. ...................................96

B-10. Example of a Dual Area Profile report under the subject of "Disability Status and Types," where disability statistics for NYS and the entire U.S. were compared. ............97

B-11. Example of a summary table produced as a part of the "Dual Area Profiles" report. .......98

C-1. Median earning rates by disability status, gender, and region (where "male no disability" $=100 \%$ ).

C-2. Annual earnings of workers age 16 years and older by disability status and region.......101

C-3. 2009 poverty rates by disability status and region..... 
C-4. Education distribution for population age 25 years and older by disability status and

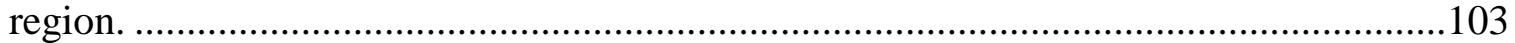

C-5. Share of households (HH) that received Food Stamp/SNAP by disability status in 2009 


\section{LIST OF TABLES}

Table

Page

3-1. Census ACS 2009 Estimates on Population with a Disability by Age Group...................9

3-2. Employment Standing by Disability Status (2009 ACS) .............................................14

3-3. Employment Rates for Working Age Population with a Disability by Region ................21

3-4. Work Experience for Working Age Population With/Without a Disability .....................22

3-5. Percent of Working Age Individuals with a Given Disability Who Worked in 2009 by Disability Type (Including Full-Time and Less Than Full-Time) ............................28

4-1. NYS Population and Disability Rate by Disability Status and Age (2009 NHTS) ...........33

4-2. Population by Length of Time Having a Disability Condition by Region (2009 NHTS)

4-3. Age Distributions of Disabled Persons by Region within Each Length-Of-Time Disabled Category....

4-4. Distribution of Disabled Population by Length-of-Time Disabled Within Given Age Group by Region

4-5. Population by Urban/Rural Type by Disability Status (2009 NHTS) ...........................45

5-1. Trip Statistics for Zero-Vehicle Households by Disability Status (2009 NHTS).............60

C-1. Median Earnings in 2009 by Disability Status and Region ..........................................99

C-2. Number of Households by Food Stamps/SNAP Receipt Status, Disability Status, and Region for 2009

D-1. Travel Statistics by Household Size, Disability Status, and Region (2009 NHTS) ........105

D-2. Mode Shares by Household Size, Disability Status, and Region (2009 NHTS) .............106 


\section{ACRONYMS}

ACS American Community Survey

ADA Americans with Disabilities Act

ADLs Activities of Daily Living

BRFSS Behavioral Risk Factor Surveillance System

CDC Center for Disease Control and Prevention

DHDS Disability and Health Data System

DHHS Department of Health and Human Services

DOT Department of Transportation

NCHS National Center for Health Statistics

NHIS National Health interview Survey

NHIS-D National Health interview Survey on Disability

NHTS National Household Travel Survey

NYC New York City

NYMTC New York Metropolitan Transportation Council

NYS New York State

ORNL Oak Ridge National Laboratory

POV Privately Owned Vehicle

SIPP Survey of Income and Program Participation

SNAP Supplemental Nutrition Assistance Program

SSA Social Security Administration 


\section{INTRODUCTION}

\subsection{BACKGROUND}

According to Census Bureau, the total number of persons with a disability accounted for nearly $12.6 \%$ of the total U.S. population ${ }^{1}$ in 2013 . For the same year, it estimated that $11.2 \%$ of the over 19 million "total civilian non-institutionalized" population in New York State (NYS) was disabled. The percent with a disability among the NYS population increased to $11.5 \%$ in 2014 , while the U.S. overall percentage remained at the same level (12.6\%). Because of the significant percentage of population with disabilities, understanding and addressing issues associated with all aspects of the disabled population, including livability of the community, factors affecting travel behavior, and mobility, etc., have become higher priorities for public policy makers and planners throughout the nation.

The term "disability" does not often refer to a single definition. It can be used in different contexts by various government agencies or among different professions. For instance, disability would be viewed as a physiological condition requiring treatment by medical professions, while certain federal programs could define it as the impairment or activity limitation that leads to the need for certain program benefits. Because of the differences in definitions, an individual might be considered to have a disability under one set of criteria but not by others. Consequently, caution should be taken when comparing estimates or statistics on disabilities across different data sources.

In this study, Oak Ridge National Laboratory (ORNL) was tasked by the NYS Department of Transportation (DOT) to conduct a detailed examination of travel behaviors, and identify patterns and trends, on several NYS subpopulations, including disabled persons. Unlike other studies that concentrated on national level statistics, this research is focused on examining issues associated with travelers among NYS residents only. For each special subpopulation group, ORNL will identify differences, if any, in travel patterns that are attributable to demographic characteristics, household characteristics, modal characteristics, geographic location, and other concepts. Focus will be given to trip frequency, trip chaining, as well as travel by time of day, trip purpose, and mode choice.

\footnotetext{
${ }^{1}$ Disability Characteristics, American Fact Finder, U.S. Census Bureau, see: http://factfinder.census.gov/faces/tableservices/jsf/pages/productview.xhtml?pid=ACS_14_1YR_S1810\&prodType =table.
} 


\subsection{OBJECTIVE}

The objective of this study is to examine persons with disabilities in NYS, including their characteristics and travel behaviors using data from the 2009 National Household Travel Survey (NHTS) and Census Bureau. The NHTS data was used as the primary data source to analyze subjects and address questions such as:

- Are there differences in traveler demographics between the disabled population and others who lived in the same NYS regions (e.g., New York City or other urban areas of NYS)?

- How do they compare with the population at large?

- Are there any regional differences (e.g., urban versus rural) or gender differences?

- Do any unique travel characteristics or patterns exist within the disabled population?

\subsection{ORANIZATION OF THIS REPORT}

Major information and data sources utilized in this study, including Census Bureau and NHTS, are briefly described in Section 2 of this report. Definitions of "disability" as used in different data sources are also discussed in this Section. Results generated from examining the Census Bureau data, specifically the 2009 American Community Survey (ACS) data, are presented in Section 3. Discussions on disability statistics produced from analyses conducted using the 2009 NHTS data follow in Section 4. Mobility patterns of the disabled population discovered by analyzing the 2009 NHTS data is addressed in Section 5. Finally, a summary of highlights on the findings from this research is presented in Section 6. Several appendices are included at the end of the report to provide supplemental information, such as a Glossary and other related materials that might be beneficial for future research on a similar subject. 


\section{DEFINITION OF DISABILITY AND INFORMATION SOURCES}

Depending on the focus of data providers, the term "disability" can be used in different contexts. Consequently, the word disability can be referred to in multiple definitions. While medical models and health professionals might view disability as a physiological condition, certain advocates can view disability as the result of societal forces on impairment. For instance, the Social Security Disability Insurance program defines disability as the impairment or limitation that leads to the need for benefit, that is, income support to individuals who are not able "to engage in any substantial gainful activity."

This section provides a brief description of major data sources available for conducting disability-related research and is not limited to those actually applied to this report. Disability definitions applied to each of the data sources are also discussed where appropriate.

\subsection{NATIONAL HOUSEHOLD TRAVEL SURVEY}

Overall, the travel related statistics presented in this report were mainly produced using data from the 2009 NHTS. The NHTS is a Federal Highway Administration-sponsored national travel survey of over 150,000 U.S. households in 2009, with over 16,000 of those households residing in NYS. ${ }^{3}$ The NHTS database is the authoritative source of national data on the travel behavior of the American public. The NHTS includes questions about trip frequency, distance, travel time, and modes of transportation, including walking and bicycling.

In the 2009 NHTS, a "disabled person" was defined as one who answers "yes" to the question of: Do you have a temporary or permanent condition or handicap that makes it difficult to travel outside of the home? A "disabled household" in this context would be defined as a household that has one or more persons reporting "yes" to the above question.

Note that the NHTS collected information from populations that were age 5 years old and older at the survey time only. Most importantly, questions on disabilities were not asked of persons under 16 years old.

\subsection{CENSUS BUREAU SURVEYS}

In addition to the 2009 NHTS data, other supplemental information and data sources were also used in this study to examine mobility and economic issues and patterns associated with the disabled population in NYS. Datasets from the Census Bureau, including the ACS and the

\footnotetext{
${ }^{2}$ Definition of disability from the Social Security Act, 42 U.S.C. part 423(d)(1).

${ }^{3}$ U.S. Territories are not included in the NHTS sampling frame.
} 
Survey of Income and Program Participation (SIPP) provide bountiful statistics and information that could support in-depth studies on disability subjects. They are especially useful in examining the size of the disabled population and investigating any impacts on performing participatory activities by people with disabilities. These two Census Bureau data sources are briefly discussed below. Note that only ACS data was utilized in this study, mainly due to resource limitations. The SIPP data will be examined under a separate research subject.

\subsubsection{American Community Survey Data}

The ACS is a survey conducted by the U.S. Census Bureau of about 3 million households annually (250 thousand per month), and is subject to the constraint that households should not be surveyed more than one time in any five-year period. Thus, the ACS is very intensive - about 20 times as large as the NHTS (three million versus one-hundred fifty thousand) - and it is repeated annually. Each year's ACS sample includes, on average, almost 50 households per Census Tract and almost 15 households per Block Group. Data on demographic, social, and economic characteristics on all ages of the U.S. populations is collected in the ACS. The ACS also collects data on commuting, i.e., the Journey to Work (JTW), including mode of transportation and travel time to work.

Specifically relevant to this research is that the ACS provides estimates of persons with disabilities in all states and regions within the United States. The Census Bureau used six questions to identify persons with disabilities, thus covering six disability types ${ }^{4}$ - hearing difficulty, vision difficulty, cognitive difficulty, ambulatory difficulty, self-care difficulty, and independent-living difficulty. Per the ACS definition, a response of "yes" to any one of those questions would designate that person as having a disability. However, only the hearing and vision questions are asked for individuals under 5 years old, and the independent-living question is not used for those under 18 years old. Note that a person could answer "yes" to one or more of the disability questions.

\subsubsection{Survey of Income and Program Participation}

The SIPP $^{5}$ is a household-based survey conducted by the Census Bureau, which collects information from a continuous series of national panels. Each panel consists of a nationally representative sample of households interviewed over a multiple-year period, lasting approximately two to four years. The SIPP panel interviews are conducted in waves; each wave lasts four months. The most current 2014 SIPP panel began in February 2014 with a sample of approximately fifty-three thousand households, selected based on the 2010 Decennial Census.

\footnotetext{
${ }^{4}$ Definition of disability types can be found at: http://www.census.gov/people/disability/methodology/acs.html.

${ }^{5}$ Survey of Income and Program Participation, U.S. Census Bureau, see http://www.census.gov/programssurveys/sipp/about.html.
} 
The SIPP is the premier source of information for income and program participation. It collects data and measures changes for many topics, such as economic well-being, family dynamics, education, assets, health insurance, childcare, and food security. The disability section of SIPP gathers information about the difficulty of performing certain activities due to a physical, mental, or emotional condition. It uses a set of six standard disability questions, which were implemented across multiple government surveys including the ACS. These six functional limitation questions cover difficulties with hearing, vision, cognitive activities, ambulatory activities, self-care, and independent living. For many activities, if a respondent answered "yes" to a given disability question, a follow up question was asked to determine the severity of the limitation.

For example, for those who had a hearing/seeing difficulty, an answer of "yes" to the follow-up question of "Was deaf, blind, or was unable to see, hear, or have speech understood (age 6 years and older)" will classify the response as having a severe disability condition. Based on a 2012 study conducted by the Census Bureau ${ }^{6}$, which used the 2008 SIPP panel data collected from May through August 2010, it was concluded that nearly 57 million people (18.7\%) of the about 304 million civilian non-institutionalized population had a disability in 2010. Among those with a disability, about 38 million people (12.6\% of total 304 million) were considered as having a severe disability.

\subsection{CENTERS FOR DISEASE CONTROL AND PREVENTION STATISTICS}

The Center for Disease Control and Prevention (CDC) is one of the major operating components of the Department of Health and Human Services (DHHS). To assist in fulfilling its mission to "protect Americans from health, safety and security threats," the CDC collects and maintains several health-related survey programs and produces many statistics regarding public health and wellbeing. The CDC also routinely conducts critical analyses and provides important health information to increase public awareness of potentially dangerous health threats, as well as responds when needs arise.

The CDC/DHHS defines disability as "any condition of the body or mind that makes it more difficult for the person with the condition to do certain activities and interact with the world around them."7 The CDC data that specifically address disabilities includes the following:

- Behavioral Risk Factor Surveillance System (BRFSS) ${ }^{8}$ is an annual state-based system of health surveys that collects information on health risk behaviors, preventive health

\footnotetext{
6 “Table 1 Prevalence of Disability for Selected Age Groups," Americans with Disabilities: 2010, U.S. Census, issued July 2012, available at: https://www.census.gov/prod/2012pubs/p70-131.pdf.

${ }^{7}$ What is disability? Impairments, Activity Limitations, and Participation Restrictions, Disability and Health, Center for Disease Control and Prevention, see http://www.cdc.gov/ncbddd/disabilityandhealth/disability.html.
} 
practices, and health care access primarily related to chronic disease and injury. The 2013 BRFSS survey included questions on five disability types: vision, cognition, mobility, self-care, and independent living. Responses of "yes" to at least one of the five disability questions the respondents were identified as having a disability. Prior to the 2013 survey, disability status of a person was not explicitly identified and information on disability type was not collected. A User's Guide ${ }^{9}$ for the annual disability statistics produced from the BRFSS was prepared and published by the Rehabilitation and Training Center on Employment Policy for Persons with Disabilities of the Cornell University.

- Disability and Health Data System (DHDS) ${ }^{10}$ is an online, interactive data tool developed and maintained by the CDC on the health and wellness of adults with disabilities. The DHDS statistics are available in national and state tables. This tool uses the 2013 BRFSS collected data, since it was the first year that the CDC started to collect disability information by five disability types. Therefore, compatible statistics for the 2009 NHTS year were not available. A more detailed discussion on the DHDS data tool is included in Appendix B at the end of this report.

- National Health Interview Survey (NHIS) ${ }^{11}$ is a survey conducted by the National Center for Health Statistics (NCHS) within the CDC, which has monitored the health of Americans since 1957. The survey data covers a broad range of health topics and are collected through large-scale in-person household interviews. The Americans with Disabilities Act (ADA), which was signed into law in July 1990, prompted the awareness of needs for data on disabled persons. Many offices within several federal agencies, including CDC/DHHS, Social Security Administration (SSA), Health Resources Administration, Bureau of Transportation Statistics in the U.S. Department of Transportation, etc., participated in developing a survey that was included in the NHIS (i.e., NHIS on Disability, or NHIS-D) for two consecutive years in 1994-1995 ${ }^{12}$. Using the data collected in the NHIS-D, NCHS has released a report on disability, entitled Trends and Differential Use of Assistive Technology Devices: United States, 1994, in November 1997. This special supplement on disability has not been repeated in the NHIS since then, however.

\footnotetext{
${ }^{8}$ Behavioral Risk Factor Surveillance System, Centers for Disease Control and Prevention, http://www.cdc.gov/BRFSS/.

${ }^{9}$ Erickson, W. and Dumoulin-Smith, A. (2009), User Guide: A guide to disability statistics from the Behavioral Risk Factors Surveillance System (http://digitalcommons.ilr.cornell.edu/edicollect/1263/), Rehabilitation and Training Center on Employment Policy for Persons with Disabilities, Ithaca, New York.

${ }^{10}$ To access the Disability and Health Data System (DHDS) go to http://dhds.cdc.gov/.

${ }^{11}$ About the National Health Interview Survey, National Center for Health Statistics, Center for Disease Control and Prevention, accessed February 2016: http://www.cdc.gov/nchs/nhis/about_nhis.htm.

${ }^{12}$ Overview of National Health Interview Survey on Disability, see http://www.cdc.gov/nchs/nhis/nhis disability.htm\#microdata.
} 
Although no specific information was provided as in the NHIS-D, general health questions that might be in some degree associated with disabilities were covered in the annual NHIS reports. For example, based on statistics published in the "Early Release of Selected Estimates Based on Data from the 2009 NHIS," the NCHS reported that in 2009, 6.4\% of adults aged 65 years and older needed help with personal care from other persons. The NHIS noted that personal care needs, or activities of daily living (ADLs), include eating, bathing, dressing, or getting around inside the person's home. Furthermore, about 3\% of adults aged 18 years and over experienced serious psychological distress during the past 30 days in that same year (2009).

\subsection{OTHER REMARKS}

Information on disability-related topics is also available from organizations outside the mainstream sources listed above (Section 2.3), including the SSA and academic research centers.

The SSA publishes annual statistics about the Social Security disability insurance program. Note that Social Security pays benefits only for total disability; it does not pay benefits for partial disability or for short-term disability. Social Security program rules assume that working families have access to other resources to provide support during periods of short-term disabilities. For this specific purpose, the definition of disability under SSA rules is different from that used by other disability programs. A "Disability" defined under Social Security is based on an individual's inability to work ${ }^{13}$. A person is considered disabled under Social Security rules if:

- The person cannot do work that he/she did before;

- SSA decides that the person cannot adjust to other work because of his/her medical condition(s); and

- The person's disability has lasted (or is expected to last) for at least one year, or to result in death.

The Disability Statistics and Demographics Rehabilitation Research and Training Center within the Institute on Disability, University of New Hampshire, published a 2014 Disability Statistics Annual Report that provides national-level statistics about people with disabilities. This organization also compiled a 2014 Compendium report providing state-level disability statistics. Sources used in compiling their statistics tables included several mentioned above including Census Bureau's ACS data and SSA reported statistics.

\footnotetext{
${ }^{13}$ Disability Planner: What we mean by disability, Social Security website, https://www.ssa.gov/planners/disability/dqualify4.html.
} 


\section{OVERVIEW OF DISABLED POPULATION - ANALYSIS OF ACS DATA}

As mentioned earlier in this report, the Census Bureau identifies a population with disabilities by six disability types: hearing difficulty, vision difficulty, cognitive difficulty, ambulatory difficulty, self-care difficulty, and independent-living difficulty. Note that, populations of different disability types are not mutually exclusive groups, because a disabled person could have one or more types of disabilities. Recall that in the ACS only the hearing and vision questions were asked for individuals under five years old and the independent-living question was not used for those under 18 years old.

To be consistent with the 2009 NHTS, statistics presented in this Section were produced using 2009 ACS data, unless otherwise specified. In this context, national- and state-level (i.e., NYS) ACS data, along with aggregated county-level data for New York City (NYC) which consists of five boroughs: Bronx, Brooklyn (Kings County), Manhattan (New York County), Queens, and Staten Island (Richmond County), were summarized.

\subsection{THE PREVALENCE OF DISABILITY}

Table 3-1 shows statistics produced using the 2009 ACS data as published in "Table S1810: Disability Characteristics." Of the total 301 million U.S. population, about 36 million of all age ranges reported having at least one type of disability (hearing, vision, cognitive, ambulatory, self-care, or independent living) during 2009. During the same year, over 2 million of the total 19 million New Yorkers (including residents of NYC and other parts of NYS) had disabilities. Overall, about $11-12 \%$ of the U.S. population had disabilities, no matter where they lived in the U.S. (i.e., NYC, other parts of NYS, or outside NYS).

Table 3-1. Census ACS 2009 Estimates on Population with a Disability by Age Group

\begin{tabular}{|c|c|c|c|c|c|c|}
\hline \multirow[b]{2}{*}{$\begin{array}{c}\text { Population age } \\
\text { group }\end{array}$} & \multicolumn{3}{|c|}{ NYC } & \multicolumn{3}{|c|}{ Rest of NYS } \\
\hline & Total & $\begin{array}{c}\text { With a } \\
\text { disability }\end{array}$ & $\begin{array}{c}\% \\
\text { disabled }\end{array}$ & Total & $\begin{array}{c}\text { With a } \\
\text { disability }\end{array}$ & $\begin{array}{c}\% \\
\text { disabled }\end{array}$ \\
\hline All ages & $8,320,856$ & 886,704 & $11 \%$ & $10,943,518$ & $1,238,666$ & $11 \%$ \\
\hline Age under 5 & 581,099 & 3,046 & $1 \%$ & 637,282 & 6,202 & $1 \%$ \\
\hline Age 5-17 years & $1,307,975$ & 52,402 & $4 \%$ & $1,887,532$ & 97,939 & $5 \%$ \\
\hline Age $18-64$ years & $5,448,210$ & 445,906 & $8 \%$ & $6,889,703$ & 637,461 & $9 \%$ \\
\hline Age $65+$ years & 983,572 & 385,350 & $39 \%$ & $1,529,001$ & 497,064 & $33 \%$ \\
\hline \multirow[b]{2}{*}{$\begin{array}{c}\text { Population age } \\
\text { group }\end{array}$} & \multicolumn{3}{|c|}{$\begin{array}{ll}\text { Rest of U.S. } \\
\end{array}$} & \multicolumn{3}{|c|}{ Total U.S. } \\
\hline & Total & $\begin{array}{l}\text { With a } \\
\text { disability }\end{array}$ & $\begin{array}{c}\% \\
\text { disabled }\end{array}$ & Total & $\begin{array}{c}\text { With a } \\
\text { disability }\end{array}$ & $\begin{array}{c}\% \\
\text { disabled }\end{array}$ \\
\hline All ages & $282,207,700$ & $34,025,340$ & $12 \%$ & $301,472,074$ & $36,150,710$ & $12 \%$ \\
\hline Age under 5 & $19,988,142$ & 149,345 & $1 \%$ & $21,206,523$ & 158,593 & $1 \%$ \\
\hline Age 5-17 years & $49,956,323$ & $2,598,183$ & $5 \%$ & $53,151,830$ & $2,748,524$ & $5 \%$ \\
\hline Age $18-64$ years & $176,843,311$ & $17,971,220$ & $10 \%$ & $189,181,224$ & $19,054,587$ & $10 \%$ \\
\hline Age $65+$ years & $35,419,924$ & $13,306,592$ & $38 \%$ & $37,932,497$ & $14,189,006$ & $37 \%$ \\
\hline
\end{tabular}


The significantly higher percentage of elderly persons (age 65 years and over) with a disability is evident from Table 3-1, regardless of their region of residency. In all areas, at least one-third to nearly $40 \%$ of the elderly populations had disabilities. Using NYC as an example, the share of population by age group (Figure 3-1) shows the elderly population (i.e., age 65 years and over) accounted for about $12 \%$ of the total NYC population. When considering only those with a disability (Figure 3-2), the share of the elderly population in NYC jumps to $44 \%$.

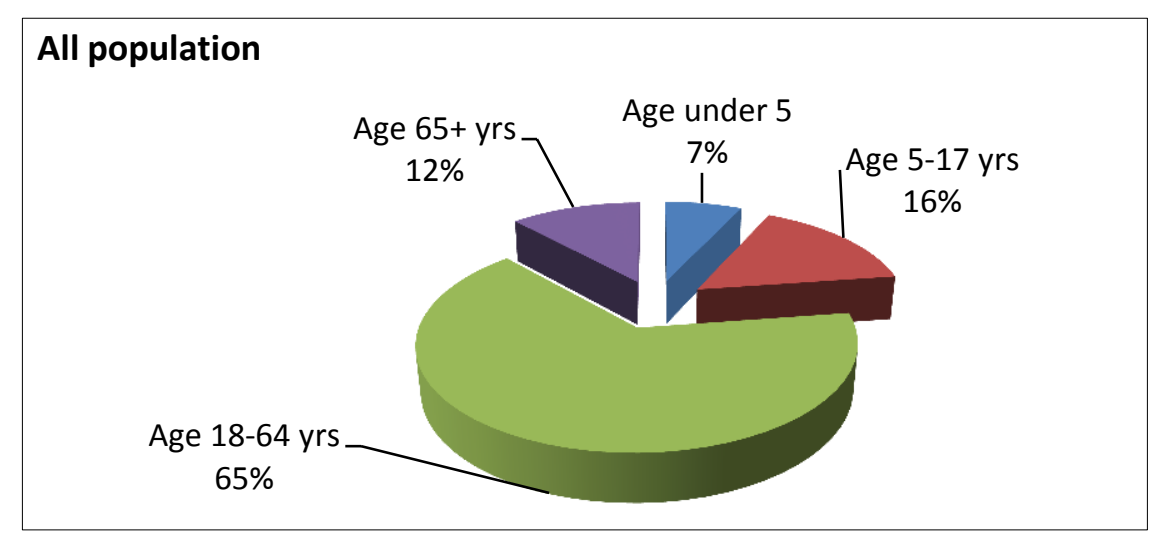

Figure 3-1. Distribution of NYC total population by age group.

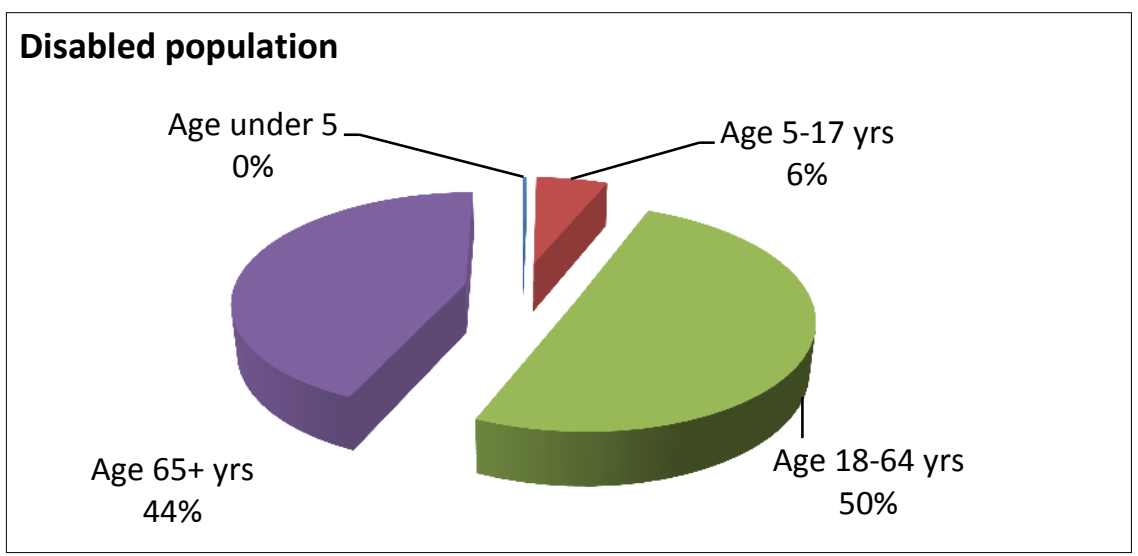

Figure 3-2. Distribution of NYC disabled population by age group.

\subsubsection{Disability Type}

When examining by the different disabilities types, Figure 3-3 shows that difficulty in "independent living" was the most common disability type in all regions, accounting for over 5\% of the total population in each region. Statistics presented in Figure 3-3 also show that the percent of population with any type of disability among NYS residents who lived outside NYC (i.e., rest of NYS) in most cases is lower than those who lived in NYC or other parts of the U.S. The only exception was for people with hearing difficulties — only $2 \%$ of NYC residents had a hearing difficulty while over $3 \%$ of those who lived outside NYC had a hearing difficulty in 2009. Overall, the shares of population with vision difficulty and self-care difficulty are noticeably smaller than other disability types. 


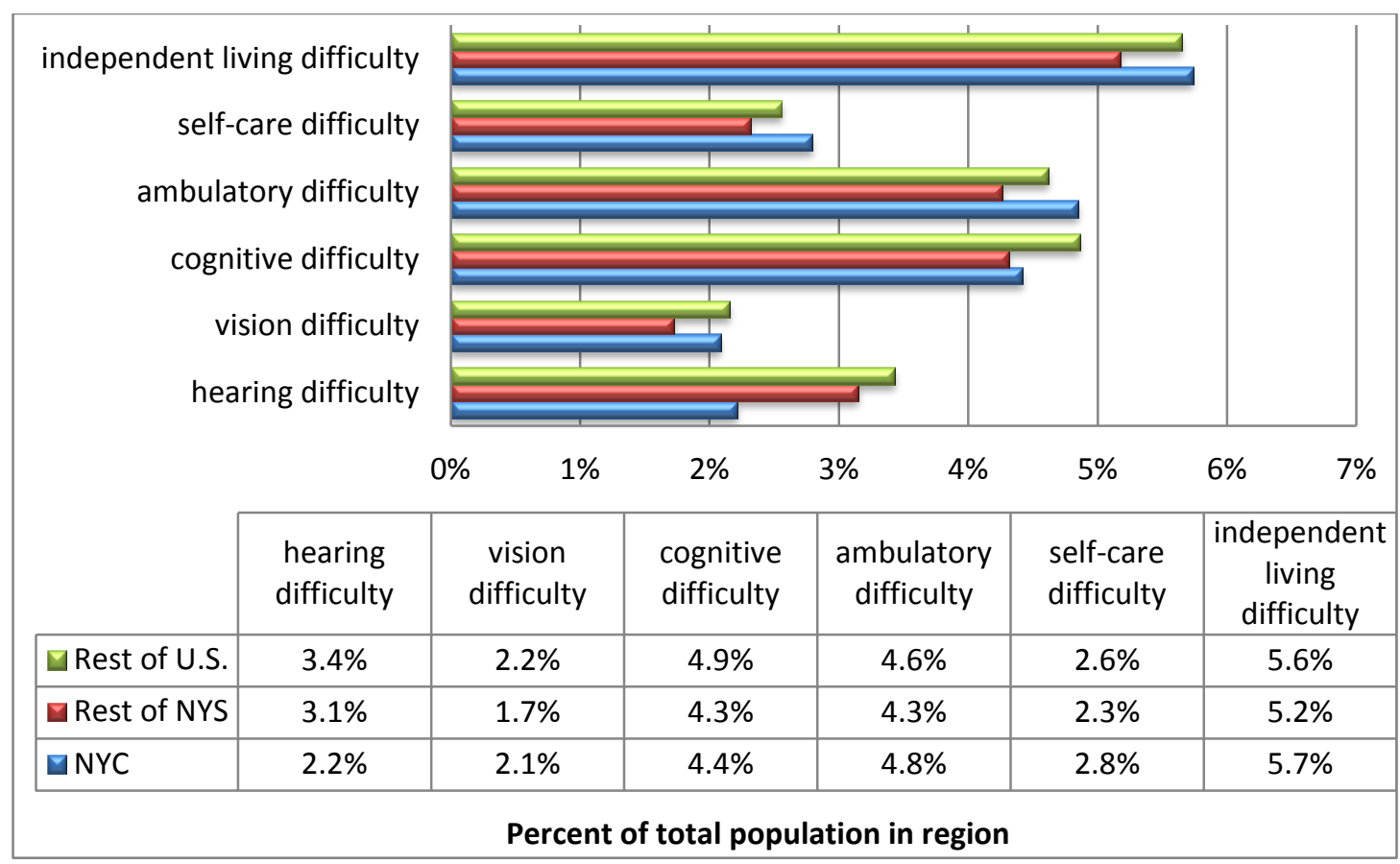

Figure 3-3. Percent of population with disabilities by type and region.

\subsubsection{Age Impacts}

As seen in Table 3-1, the elderly population is more likely to having a disability than their younger counterparts. Although Figure 3-3 indicates that only a relatively small portion of the population in all regions has a disability $(2 \%-6 \%)$, the rate of population with a disability was in fact much larger among the elderly population. Statistics shown in the lower portion of Figure 3-4 confirm this.

It is evident in Figure 3-4 that the most common disability types reported among the elderly population are "ambulatory" and "independent living" difficulties. Specifically, Figure 3-4 shows that about $21 \%-28 \%$ of the elderly population has ambulatory difficulties, while only about $7 \%$ of the non-elderly population (ages 5-64 years old) reported the same type of disability. Furthermore, around $14 \%-21 \%$ of the elderly population has difficulties in independent living, while less than $4 \%$ of their younger counterparts reported having this difficulty (ages 18 to 64 years and older). Similarly, the elderly population reported significantly higher rates of having other types of disabilities (hearing, vision, cognitive, self-care) than their younger neighbors within the same regions. 


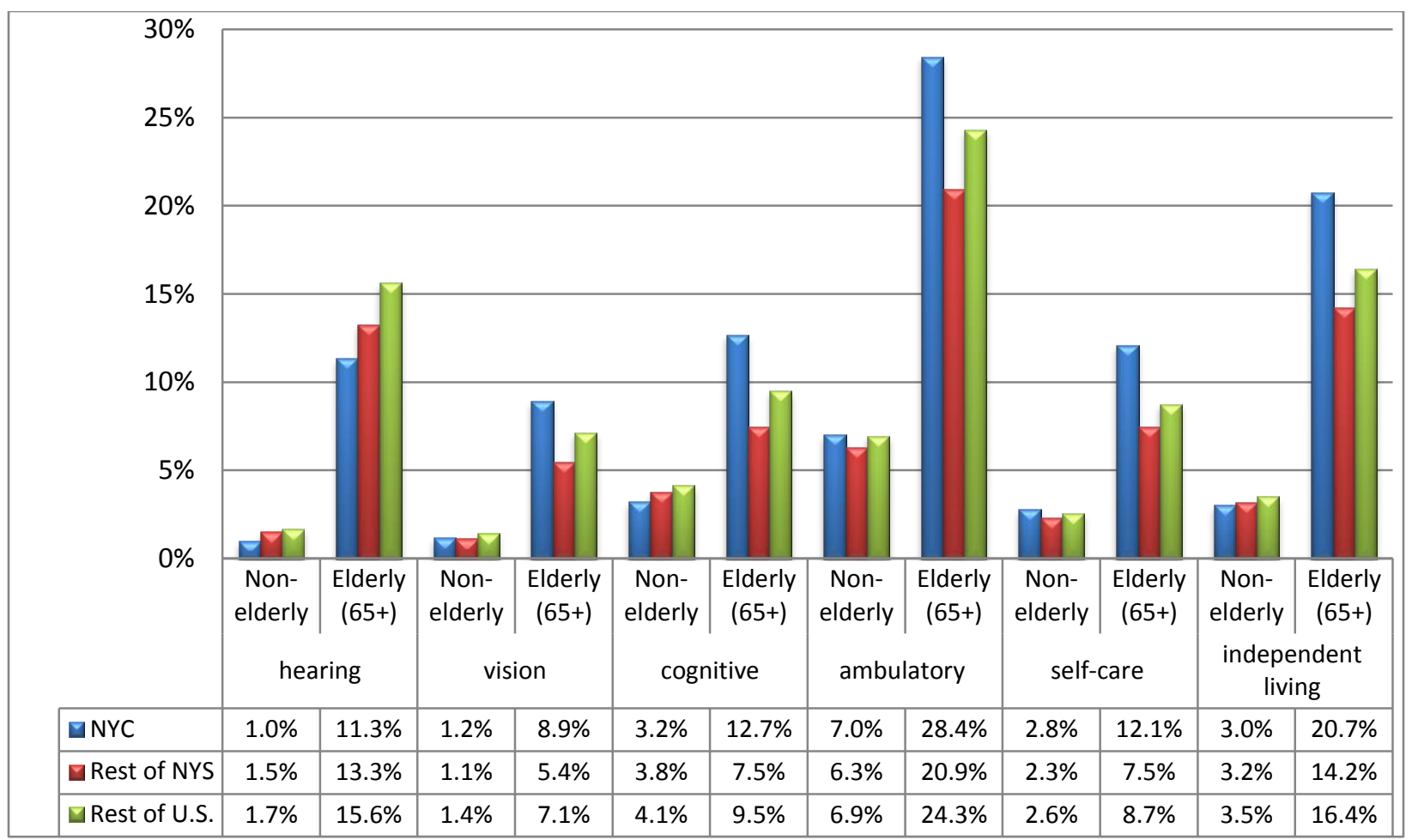

Figure 3-4. Percent of population with a given type of disability by elderly status by region.

According to the 2009 ACS data, Figure 3-5 shows that consistently in all regions over $70 \%$ of "disabled" 5-17 year olds had cognitive difficulties. For disabled persons 18 years and older, the most common issue was ambulatory difficulty, occurring in about 50-70\% of the disabled population in this age group. The next most common disability issues facing the disabled 18 years and older population were difficulties in cognitive and independent living. As seen in Figure 3-5, self-care difficulty was also more significant for the disabled elderly population living outside NYC. 


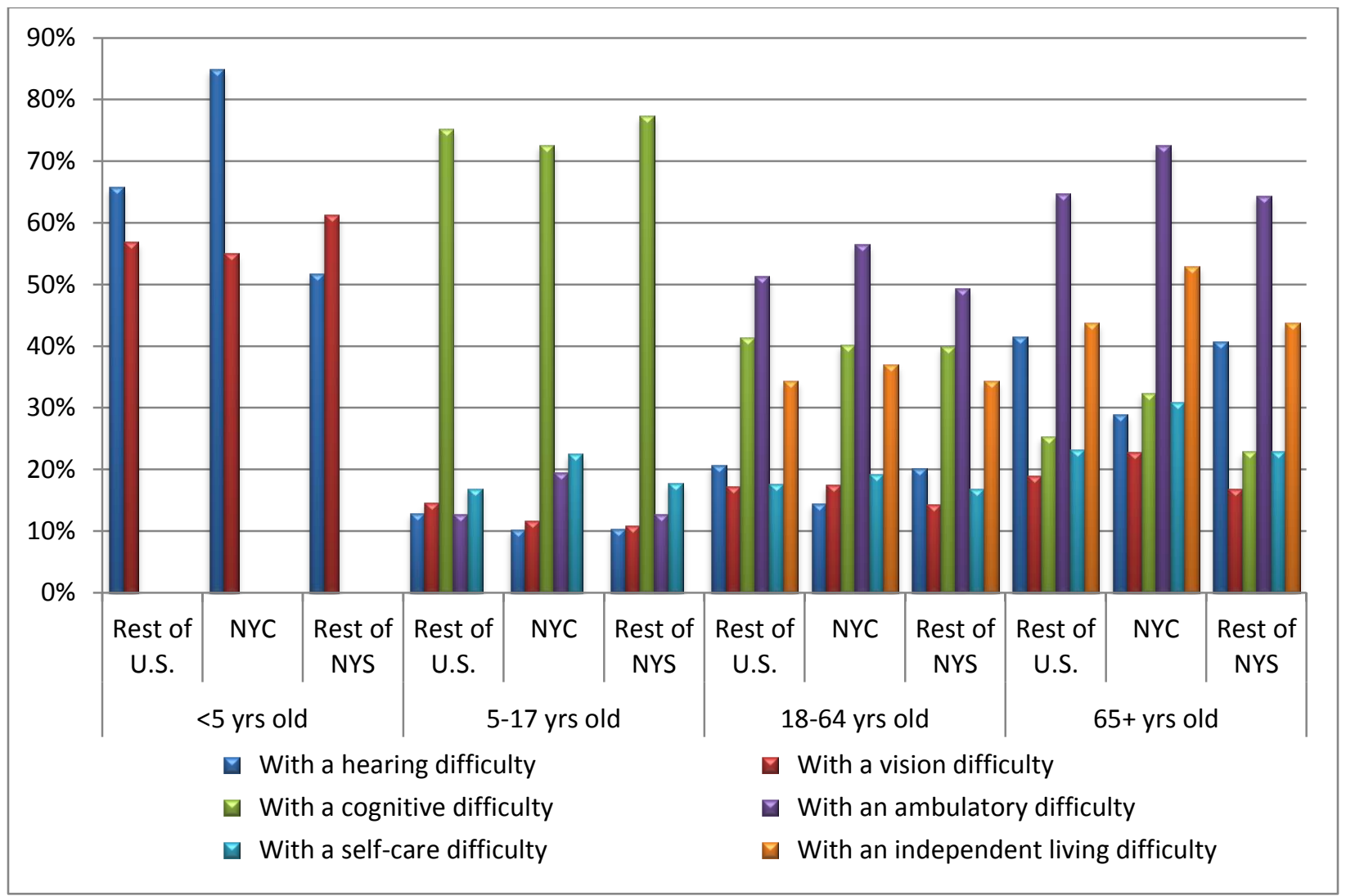

Figure 3-5. Percent of disabled population by disability type and age group (note: only hearing and vision were asked to those under age 5 , and independent living was only asked to persons aged 18 and older).

Note that only hearing and vision questions were asked to the "under age 5" population, thus both disability types were expected to have accounted for over half of the corresponding population (i.e., under-5 population with a disability), as shown in Figure 3-5.

\subsection{EMPLOYMENT STATUS}

The ACS employment-related survey questions were asked of all people ages 15 years and over. Summary statistics tables published in the American Fact Finder are based on people ages 18 to 64 years old only, and are referred to as the "working age group" in this Section. This study analyzed 2009 ACS data with respect to employment status of populations with/without a disability. The goal of this research was to determine whether disability status has any impacts on a person's employment standing and to identify how disability type influences one's employment status. 


\subsubsection{Disability Status and Employment}

The Census Bureau publishes information regarding employment status by disability status ${ }^{14}$ for all civilian noninstitutionalized population ages 18 to 64 years old, at national, state, and county levels. Based on 2009 ACS data (see Table 3-2), about 148 million (78\%) of the total 189 million U.S. population, and 77\% (9.5 million out of 12 million) of NYS residents, were in the labor force. Among the employed population in the U.S., only about $5 \%$ were persons with a disability; while about $4 \%$ of those employed NYS residents were disabled. When considering the U.S. population who were not in the labor force during 2009, the data reveals that over a quarter of those people (11 million out of 42 million, or $26 \%$ ) had a disability. Similarly, about $23 \%$ of New Yorkers who were not in the labor force were disabled.

Table 3-2. Employment Standing by Disability Status (2009 ACS)

\begin{tabular}{|c|r|r|}
\hline \multicolumn{1}{|c|}{ Status } & United States & \multicolumn{1}{c|}{ NYS } \\
\hline Total population (18-64 years old) & $189,181,224$ & $12,337,913$ \\
\hline In the labor force: & $147,563,389$ & $9,475,823$ \\
\hline Employed: & $133,202,340$ & $8,640,457$ \\
\hline With a disability & $6,723,694$ & 361,173 \\
\hline No disability & $126,478,646$ & $8,279,284$ \\
\hline Unemployed: & $14,361,049$ & 835,366 \\
\hline With a disability & $1,479,136$ & 65,415 \\
\hline No disability & $12,881,913$ & 769,951 \\
\hline Not in labor force: & $41,617,835$ & $2,862,090$ \\
\hline With a disability & $10,851,757$ & 656,779 \\
\hline No disability & $30,766,078$ & $2,205,311$ \\
\hline
\end{tabular}

Roughly $20 \%$ of the "no-disability" working age population (referred to as the "non-disabled population" in this report) from each region (NYC, rest of NYS, or rest of U.S.) was not in the labor force during 2009, as presented in Figure 3-6. However, Figure 3-7 shows that more than half of the working age population with any type of disability was not in the labor force. This seems to reflect that a disability condition might have prevented a person from working (thus out of the labor force). A higher rate of "not in labor force" for the NYC working age population can be observed in both Figure 3-6 and Figure 3-7, when compared to residents of other states or New Yorkers living outside of NYC. Furthermore, only about 30\%-36\% (depending on region) of the working age population with a disability were employed, versus about $71 \%-76 \%$ for those non-disabled working age population.

\footnotetext{
${ }^{14}$ American Fact Finder Table B18120: Employment Status by Disability Status and Type; based on 2009 ACS 1year estimates, U.S. Census.
} 


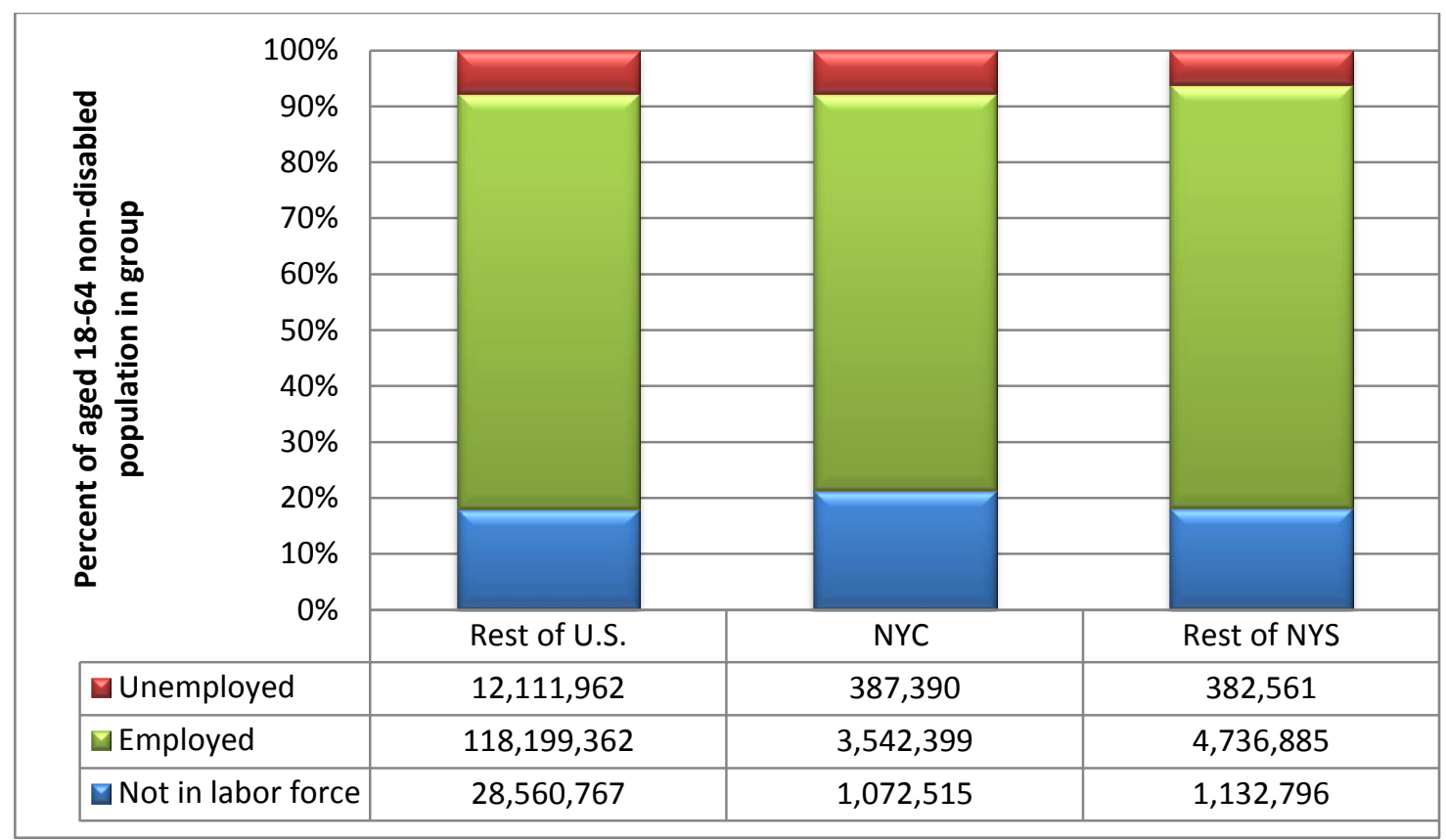

Figure 3-6. Employment status for non-disabled population of 18-64 years old.

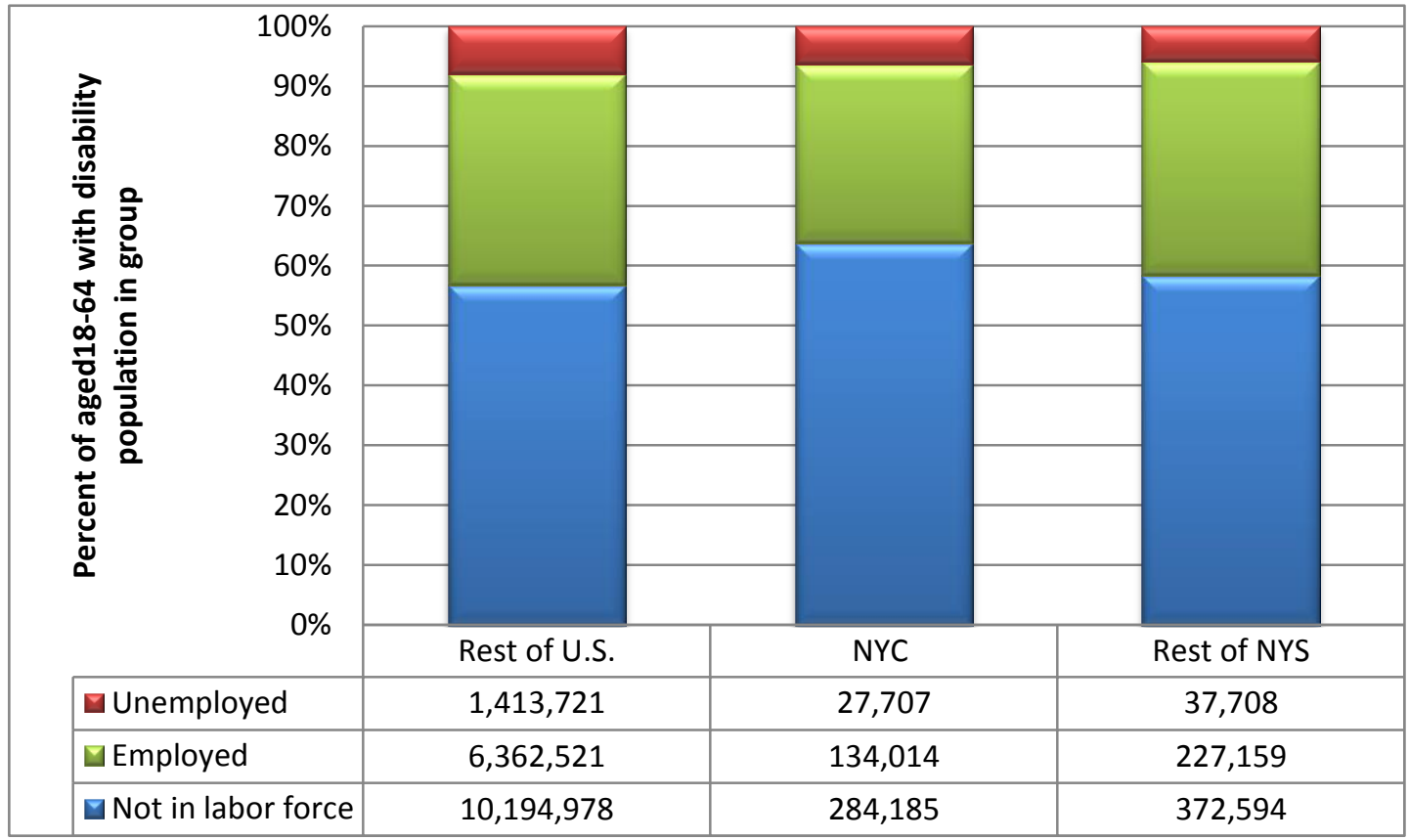

Figure 3-7. Employment status for 18-64 years old with any types of disabilities.

Unemployment rates among the working age population who were in the labor force, for nondisabled and disabled populations, are presented in Figure 3-8 and Figure 3-9 respectively. Clearly visible is that the unemployment rate for disabled populations (who were in the labor force) is about twice as high as for their non-disabled counterparts in 2009. 


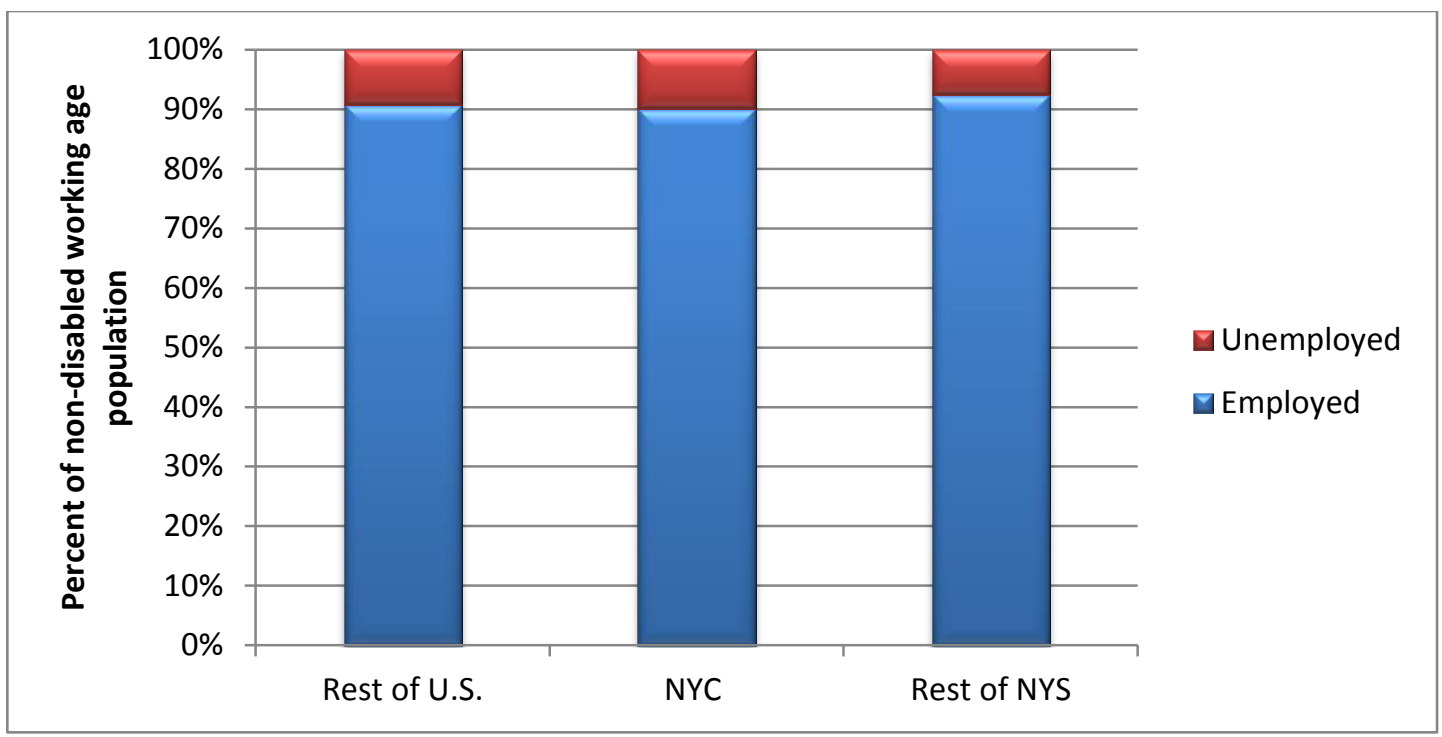

Figure 3-8. Non-disabled working age population who were in the labor force.

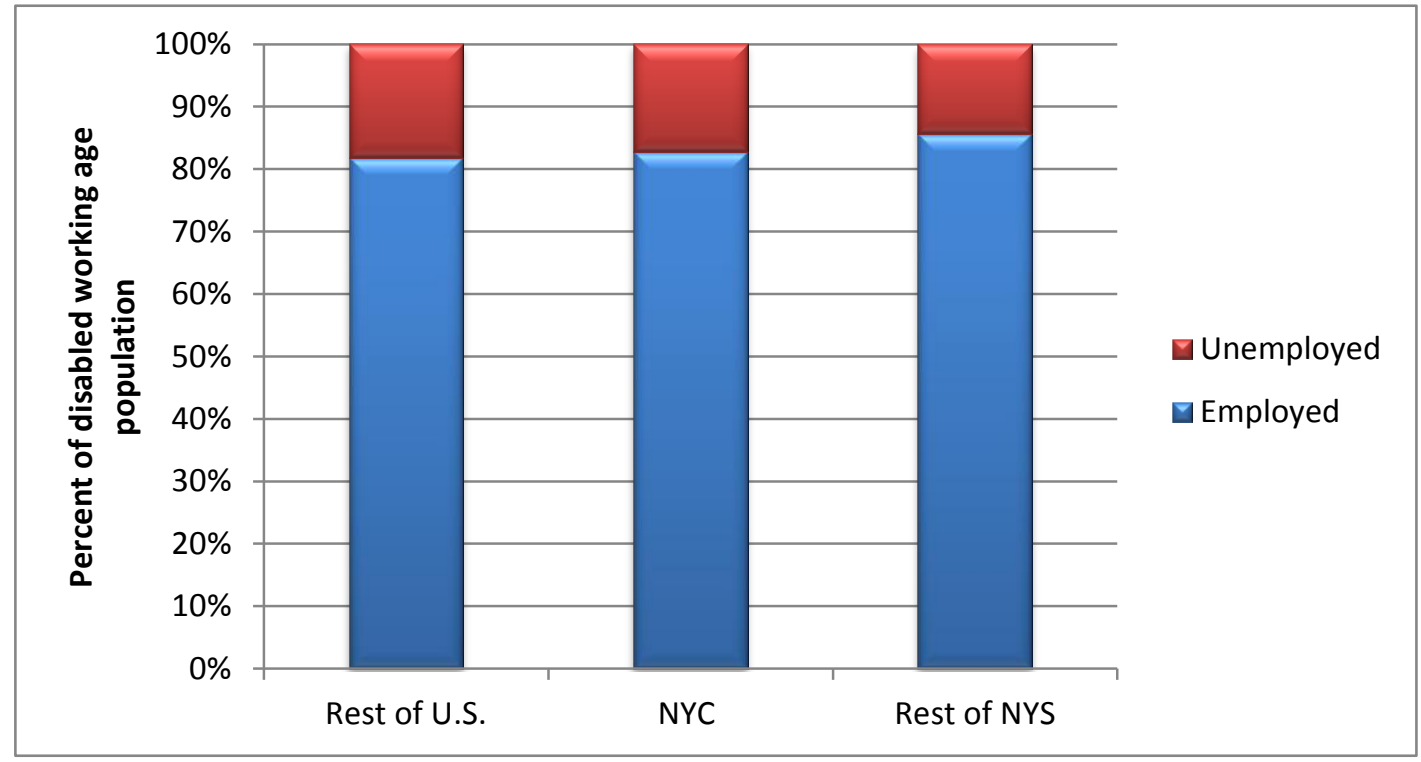

Figure 3-9. Disabled working age population who were in the labor force.

The 2009 ACS data shows that approximately one in four working age persons who lived outside NYC and were not in labor force had a disability, while the rate of disability for the NYC working age population not in labor force was one in five (see Figure 3-10). The rates of disability among the unemployed working age population dropped to about $10 \%$ for those who lived outside NYC and around 6\% for NYC residents. Within the employed populations, however, the rates of disability were under $5 \%$ in all regions. 


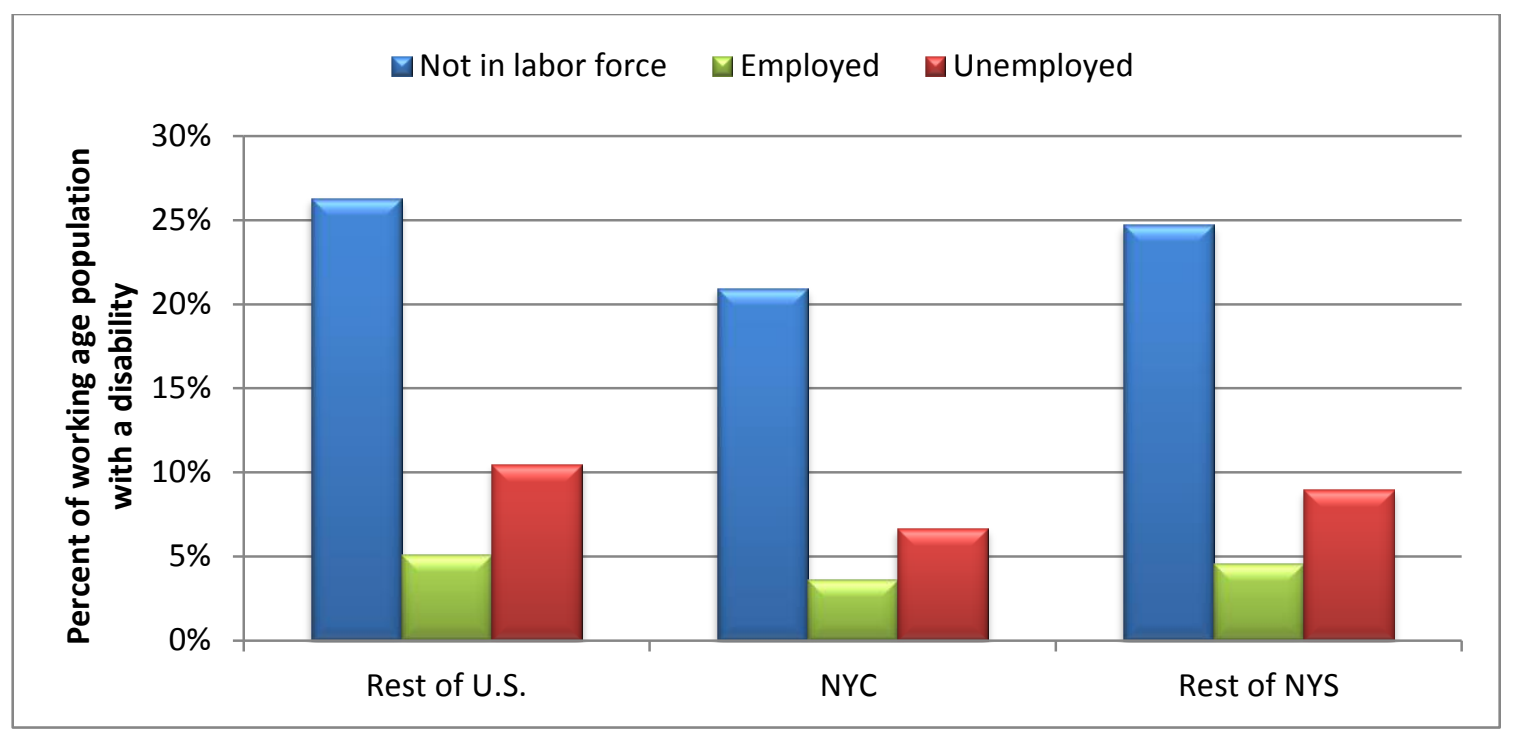

Figure 3-10. Percent of working age population with disabilities by employment status by region.

\subsubsection{Impacts of Disability Types on Employment Status}

Statistics summarized thus far have shown an employment gap between the respective employment rates of people with and without disabilities. Additional analysis, using 2009 ACS data, for identifying any employment gaps due to disability type is addressed next.

\section{Hearing Difficulty}

This category includes individuals who are deaf or have serious difficulty in hearing. Figure 3-11 shows that about $40 \%$ of the working age population with a hearing difficulty who lived outside NYC was not in the labor force; and $50 \%$ of their counterpart NYC residents were the same. Compared to overall results shown in Figure 3-7, the rate of employment for working age people with hearing difficulties was more than $15 \%$ higher, regardless of where they lived. Specifically, a NYC resident with hearing difficulty would have a $43 \%$ chance of being employed while $52 \%-54 \%$ of their counterparts living outside NYC were employed. Based on 2009 ACS data, a person with a hearing difficulty, on average, had a much better employment opportunity than people with other types of disabilities. 


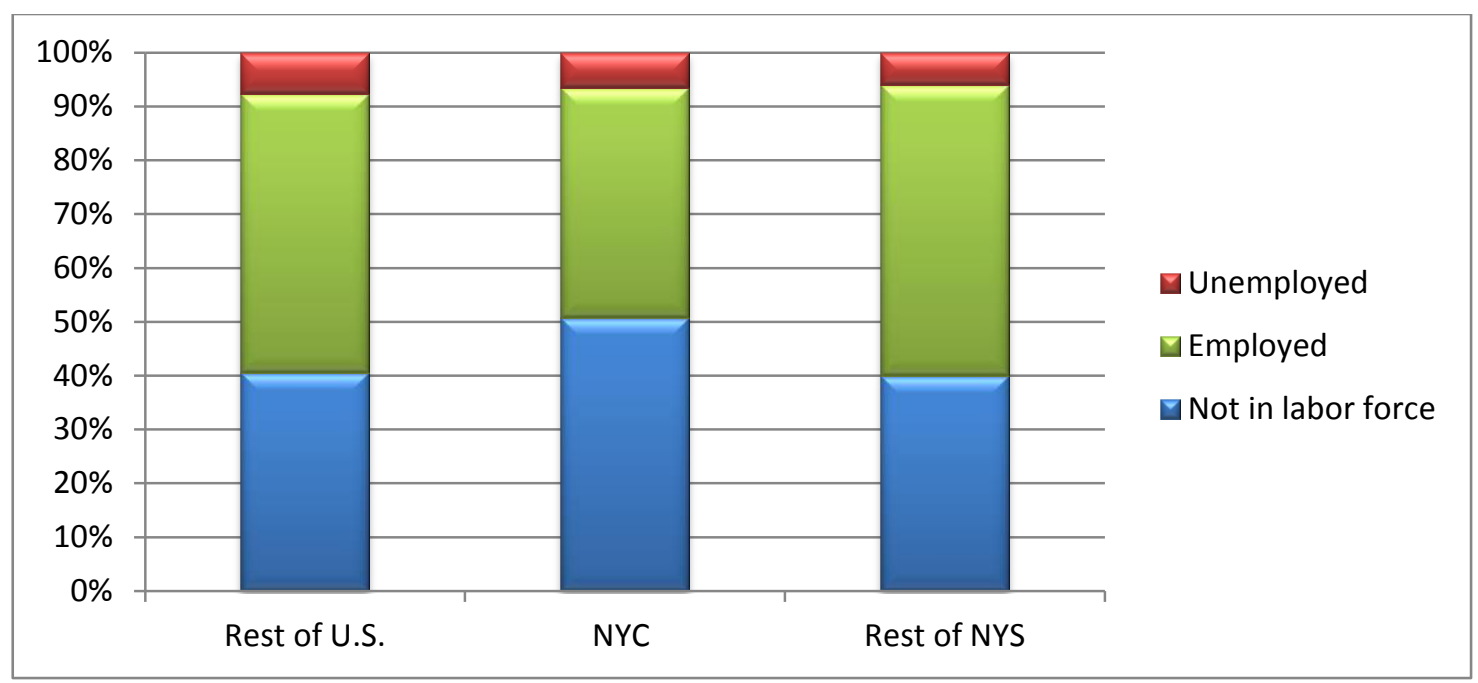

Figure 3-11. Employment status for working age population with a hearing difficulty.

\section{Vision Difficulty}

For people with vision difficulties (i.e., blind or having serious difficulty seeing even with glasses), the employment opportunity was not as good as for those with hearing difficulties. As shown in Figure 3-12, only about 36\%-38\% of those with vision difficulties were employed, slightly higher than overall employment rates presented in Figure 3-7. The majority of those with vision difficulties (over half of the total population), however, appeared to stay out of the labor force, especially for NYS residents. The unemployment rates for persons with vision difficulties are similar to those with hearing difficulties.

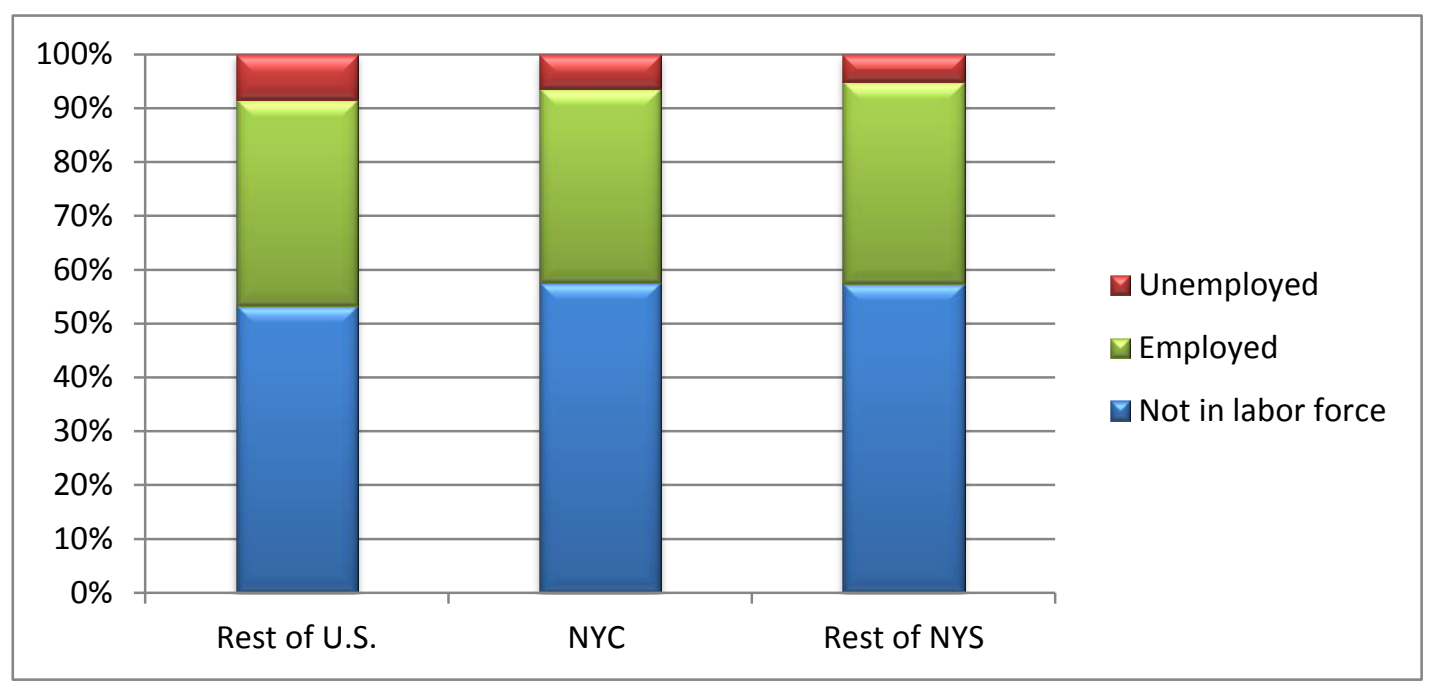

Figure 3-12. Employment status for working age population with a vision difficulty. 


\section{Cognitive Difficulty}

In the 2009 ACS data, individuals (ages 5 years and older) who answered "yes" to the question asking if they had "serious difficulty concentrating, remembering, or making decisions" due to a physical, mental, or emotional condition, were identified as having a cognitive disability. As seen in Figure 3-13, over two-thirds of the population with a cognitive disability from the three regions analyzed was not in labor force. Over three-quarters of residents from NYC with a cognitive disability were not in labor force. Only $18 \%$ of the NYC population with a cognitive difficulty was employed, while outside NYC, the working age population with a cognitive disability had an employment rate of $25 \%$.

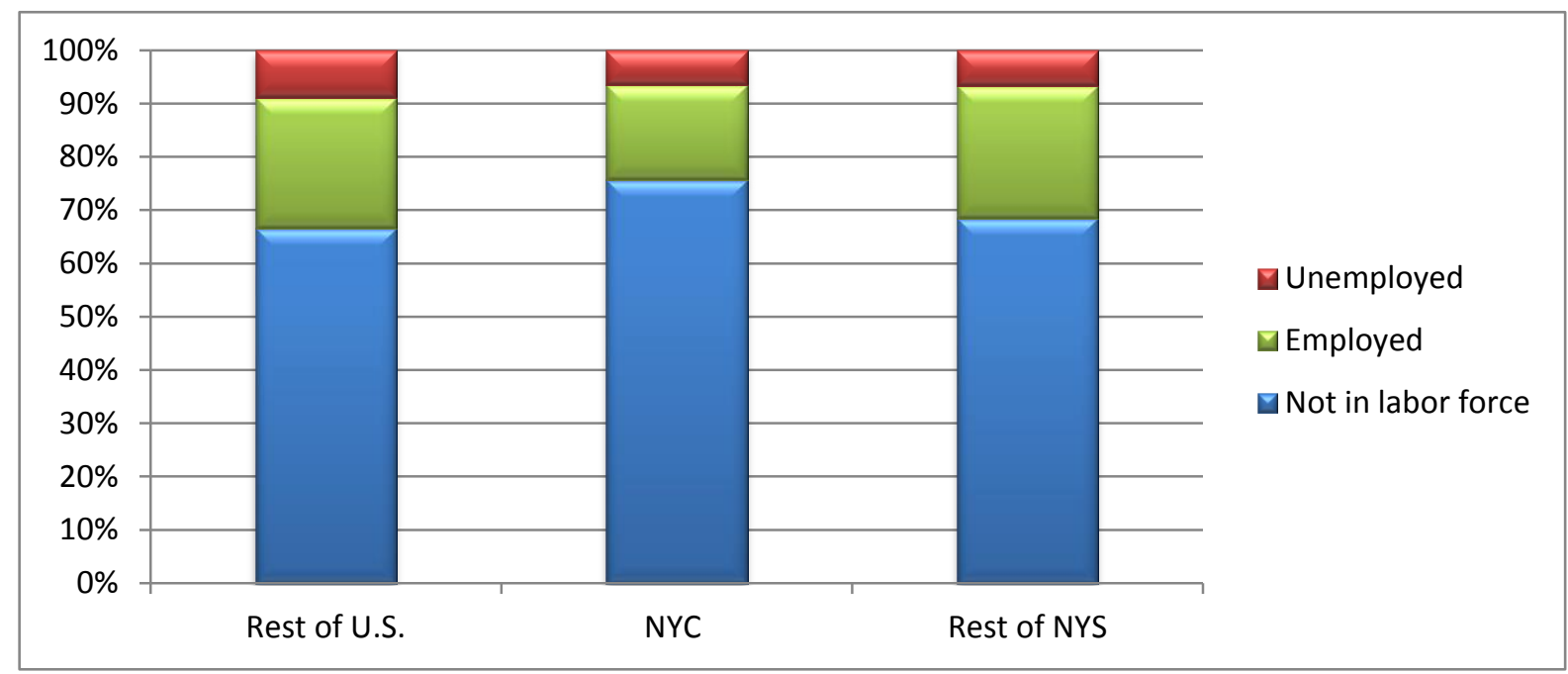

Figure 3-13. Employment status for working age population with a cognitive difficulty.

\section{Ambulatory Difficulty}

This category includes 2009 ACS survey respondents (ages 5 years and older) that indicated having "serious difficulty walking or climbing stairs," which measures the mobility of a person. Result seen in Figure 3-14 does not present any noticeable regional differences, neither in employment rates nor for the in-labor-force status. For all regions, the employment rates were at $26 \%$ for the population with an ambulatory disability; while nearly $70 \%$ of the population with an ambulatory disability was not in the labor force during 2009. 


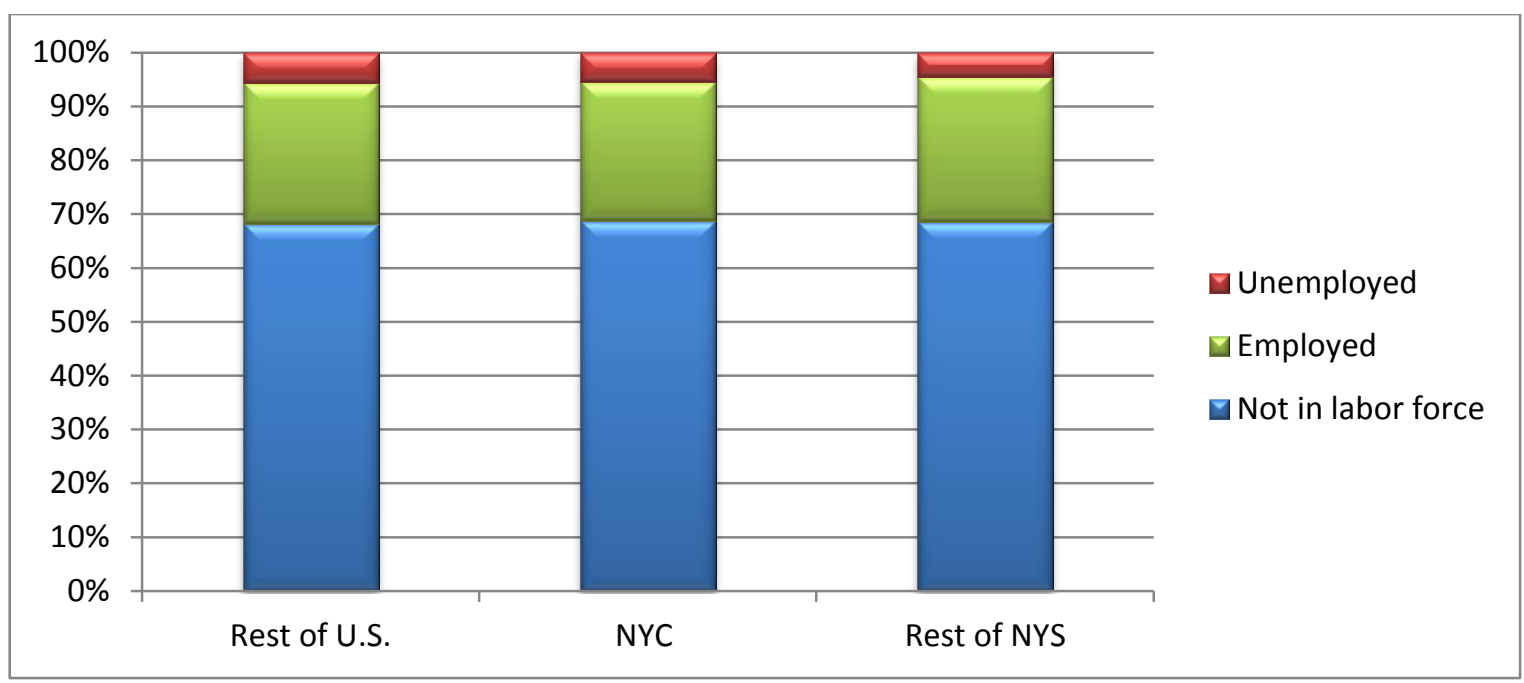

Figure 3-14. Employment status for working age population with an ambulatory difficulty.

\section{Self-care Difficulty}

Individuals age 5 and older who had difficulty bathing or dressing were classified as having a self-care difficulty by the 2009 ACS. Due to the nature of this disability, it is not a surprise to see that about $80 \%$ of the working age population with a self-care difficulty was not in the labor force. According to 2009 ACS (see Figure 3-15), less than $20 \%$ of the working age population with a self-care disability was employed in 2009.

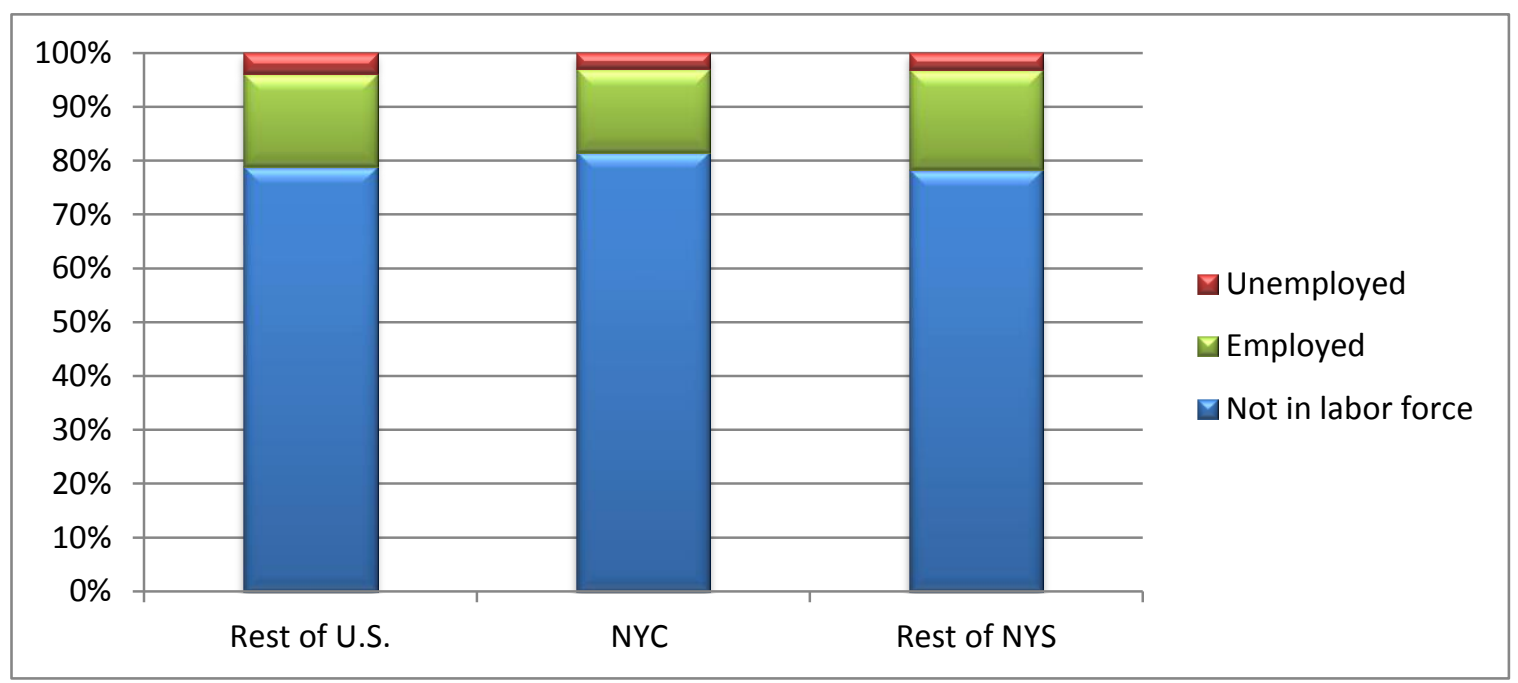

Figure 3-15. Employment status for working age population with a self-care difficulty.

\section{Independent Living Difficulty}

The question associated with the difficulty of "independent living" was only asked to 2009 ACS survey respondents age 18 years and older. An individual who is having difficulty doing errands alone such as visiting a doctor's office or shopping due to a physical, mental, or emotional problem, was categorized as having "independent living difficulty" by the 2009 ACS. Similar to 
"self-care difficulty" above, approximately $80 \%$ of the working age population with an independent living difficulty was not in the labor force, and less than $20 \%$ of this population was employed during 2009 (see Figure 3-16).

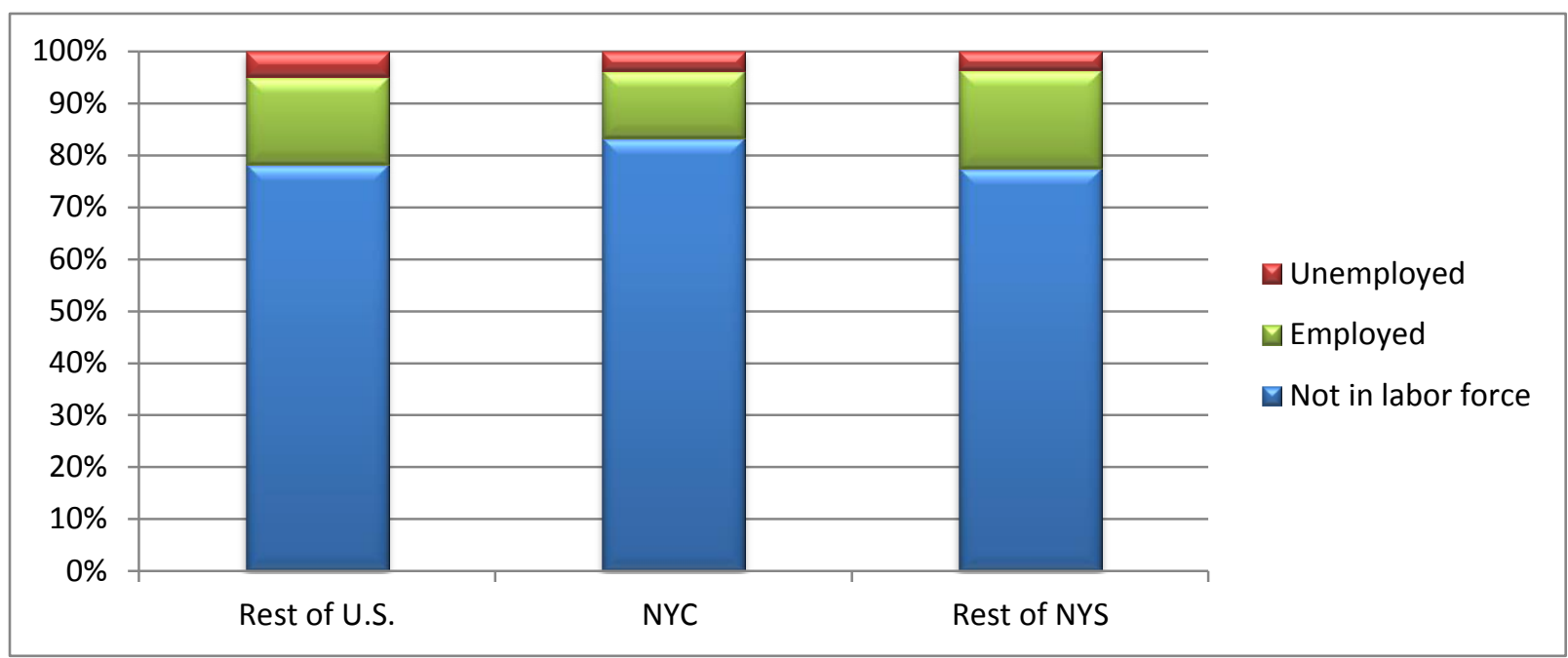

Figure 3-16. Employment status for working age population with an independent living difficulty.

Table 3-3 summarizes the employment rates for the working age population with a disability by type of difficulty and by region, as discussed above. Overall, employment rates for working area population with a disability who lived in the rest of NYS and those from the rest of the U.S. are very similar. Working age population from NYC with a disability generally had a lower employment rate when compared to those that lived outside NYC, except for those with an ambulatory difficulty.

Table 3-3. Employment Rates for Working Age Population with a Disability by Region

\begin{tabular}{|l|c|c|c|}
\hline Disability type & Rest of U.S. & NYC & $\begin{array}{c}\text { Rest of } \\
\text { NYS }\end{array}$ \\
\hline Hearing difficulty & $52 \%$ & $43 \%$ & $54 \%$ \\
\hline Vision difficulty & $38 \%$ & $36 \%$ & $38 \%$ \\
\hline Cognitive difficulty & $25 \%$ & $18 \%$ & $25 \%$ \\
\hline Ambulatory difficulty & $26 \%$ & $26 \%$ & $27 \%$ \\
\hline Self-care difficulty & $17 \%$ & $15 \%$ & $19 \%$ \\
\hline Independent living difficulty & $17 \%$ & $13 \%$ & $19 \%$ \\
\hline
\end{tabular}

\subsection{WORK LIMITATIONS FOR PEOPLE WITH A DISABILITY}

Similar to the employment opportunity, work limitations influence one's need/decision to travel, and the frequencies of making such trips (i.e., commuting to work). In addition to investigating employment status of populations with a disability, the 2009 ACS data was also used to examine work experience (e.g., work full time, work less than full time, or not working) for people with/without a disability. Several questions were asked of the ACS survey respondents to gather information related to work status in the past 12 months, weeks worked in the past 12 months, 
and usual hours per week worked in the past 12 months. With this work status information, the Census Bureau derives statistics associated with work experience of people in the U.S. and publishes summary tables on the American Fact Finder website. Most relevant to this research is data from Table B18121 (entitled Work Experience by Disability Status and Type ${ }^{15}$ ) that provides disability statistics for the working age population (i.e., ages 18 to 64 years old) at national, state, and county levels.

\subsubsection{Work Experience by Disability Status}

Table 3-4 below presents summary statistics extracted from Table B18121 of the 2009 ACS data. Of the total 189 million working age population in the U.S., about half of them (95 million) worked full-time during 2009, while another 56 million ( 30\%) worked less than full-time in the same year. In NYS, over half (6 million out of 12 million) of its working age population worked full-time and roughly $28 \%$ worked less than full-time in 2009. Statistics presented in Table 3-4 also show that only a small portion of individuals with a disability worked during 2009, either on a full time or part time basis. Clearly evidenced is the fact that the majority of individuals with a disability did not work.

Table 3-4. Work Experience for Working Age Population With/Without a Disability

\begin{tabular}{|c|c|r|}
\hline \multicolumn{1}{|c|}{ Work Status } & United States & \multicolumn{1}{c|}{ NYS } \\
\hline Total population age 18-64 years & $\mathbf{1 8 9 , 1 8 1 , 2 2 4}$ & $\mathbf{1 2 , 3 3 7 , 9 1 3}$ \\
\hline Worked full-time & $94,718,682$ & $6,276,061$ \\
\hline With a disability & $4,092,171$ & $\mathbf{2 2 1 , 4 0 9}$ \\
\hline No disability & $90,626,511$ & $6,054,652$ \\
\hline Worked less than full-time & $55,706,011$ & $3,371,643$ \\
\hline With a disability & $4,354,606$ & 221,617 \\
\hline No disability & $51,351,405$ & $3,150,026$ \\
\hline Did not work & $38,756,531$ & $2,690,209$ \\
\hline With a disability & $10,607,810$ & 640,341 \\
\hline No disability & $28,148,721$ & $2,049,868$ \\
\hline
\end{tabular}

When focusing on the working age population that had a disability within each work status, Figure 3-17 shows that over one in four persons $(27 \%)$ who lived outside NYC did not work in 2009. During the same time period, NYC residents who had a disability about $21 \%$ did not work. In all regions, less than 5\% of the people who worked full-time in 2009 had a disability. Among part-time workers for each region, less than $8 \%$ were disabled persons. Again, this confirms the statement made earlier that most individuals with a disability did not work in 2009 , regardless of where they lived.

\footnotetext{
${ }^{15}$ American Fact Finder Table Viewer, B18121 Work Experience by Disability Status and Type, U.S. Census; see http://factfinder.census.gov/faces/tableservices/jsf/pages/productview.xhtml?pid=ACS_09_1YR_B18121\&prodTyp $\mathrm{e}=$ table.
} 


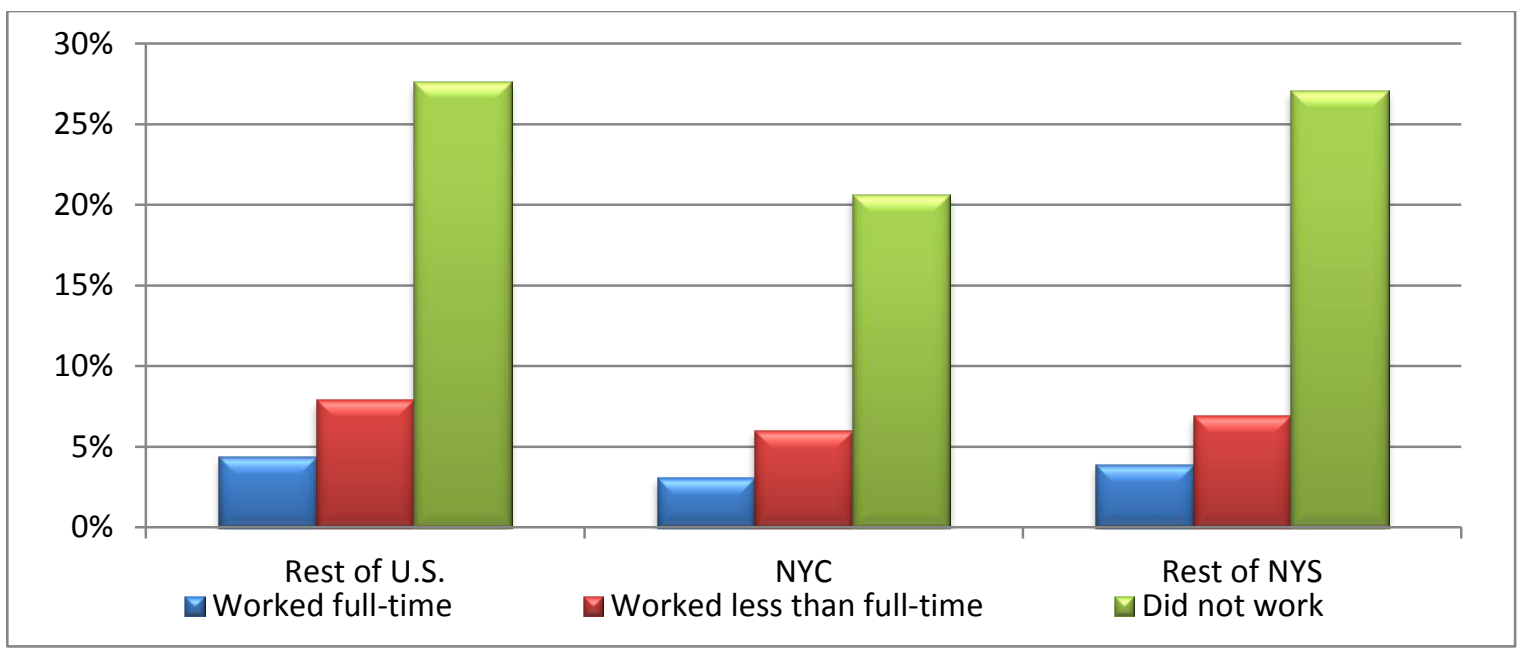

Figure 3-17. Share of working age population with a disability by worker status and region.

As seen in Figure 3-18, 55\% of the working age population with a disability living outside of NYC did not work in 2009, while $63 \%$ of their counterparts in NYC did not work. When considering the shares of full-time workers, only around $20 \%(19 \%-22 \%)$ of the population with a disability in each region worked full time. On the contrary, Figure 3-19 shows that about 15\% of the non-disabled population living outside of NYC and $22 \%$ of non-disabled NYC residents did not work during 2009. In fact, the patterns shown in Figure 3-19 nearly mirror those presented in Figure 3-18. Over 53\% of the non-disabled working age population in the regions worked full time in 2009 , verses over $55 \%$ with a disability did not work at all during the same year.

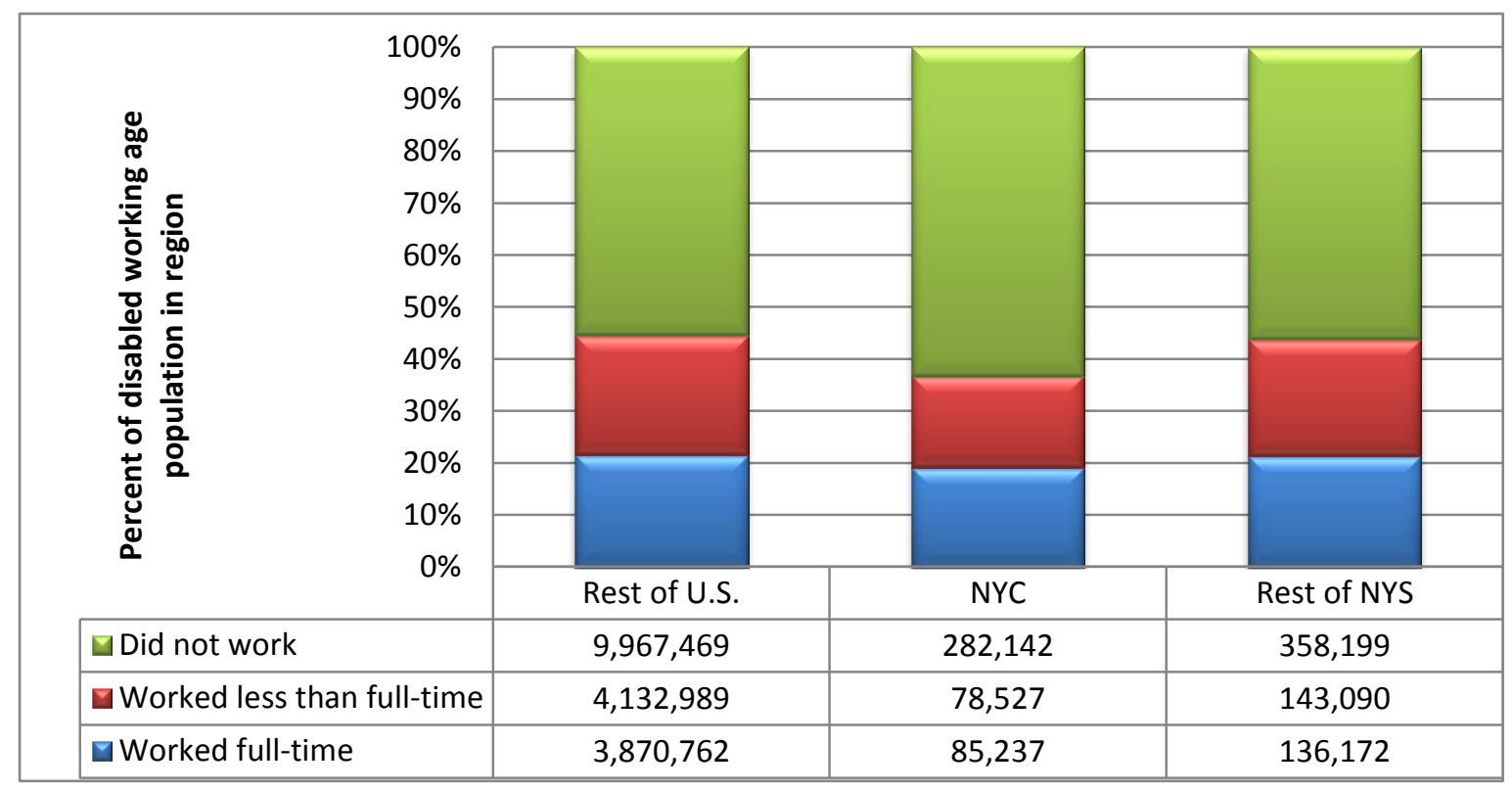

Figure 3-18. Work experience for working age population with a disability. 


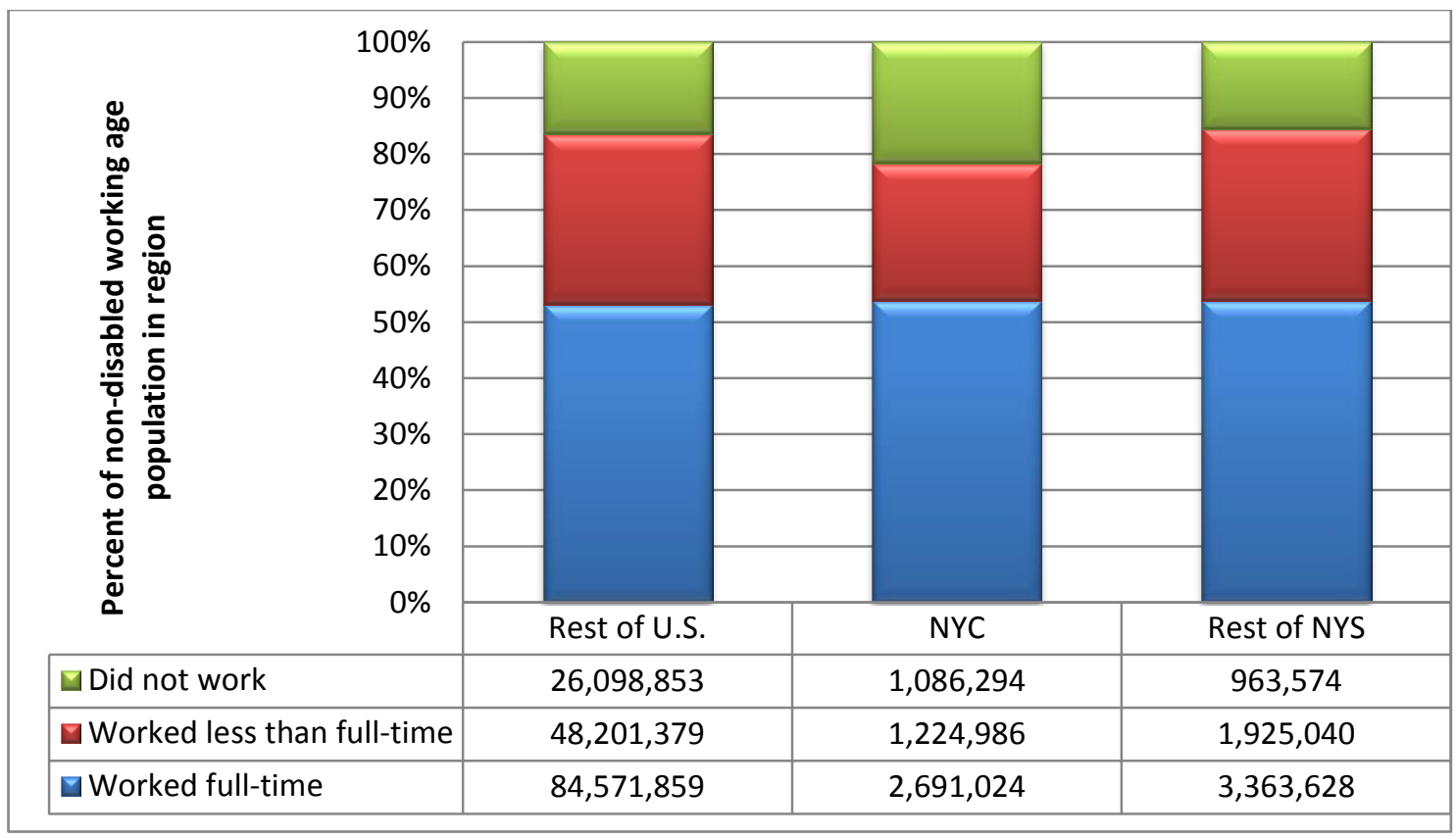

Figure 3-19. Work experience for non-disabled working age population.

\subsubsection{Type of Disability Influence on Work Status}

Similar to examining effects of disability type on one's employment status (Section 3.2.2), results from a brief investigation to determine whether the disability type imposed different influences on worker limitation for those with a disability are presented in the following subsections.

\section{Hearing Difficulty}

Figure 3-20 shows that among the working age population with a hearing difficulty who lived outside NYC about $60 \%$ worked either full-time or part-time in 2009. For their counterpart NYC residents, slightly less than $50 \%$ worked on a full-time or part time basis during the same year. In other words, work limitations seem more significant for individuals with a hearing disability who lived in NYC, than those that lived outside the NYC region. 


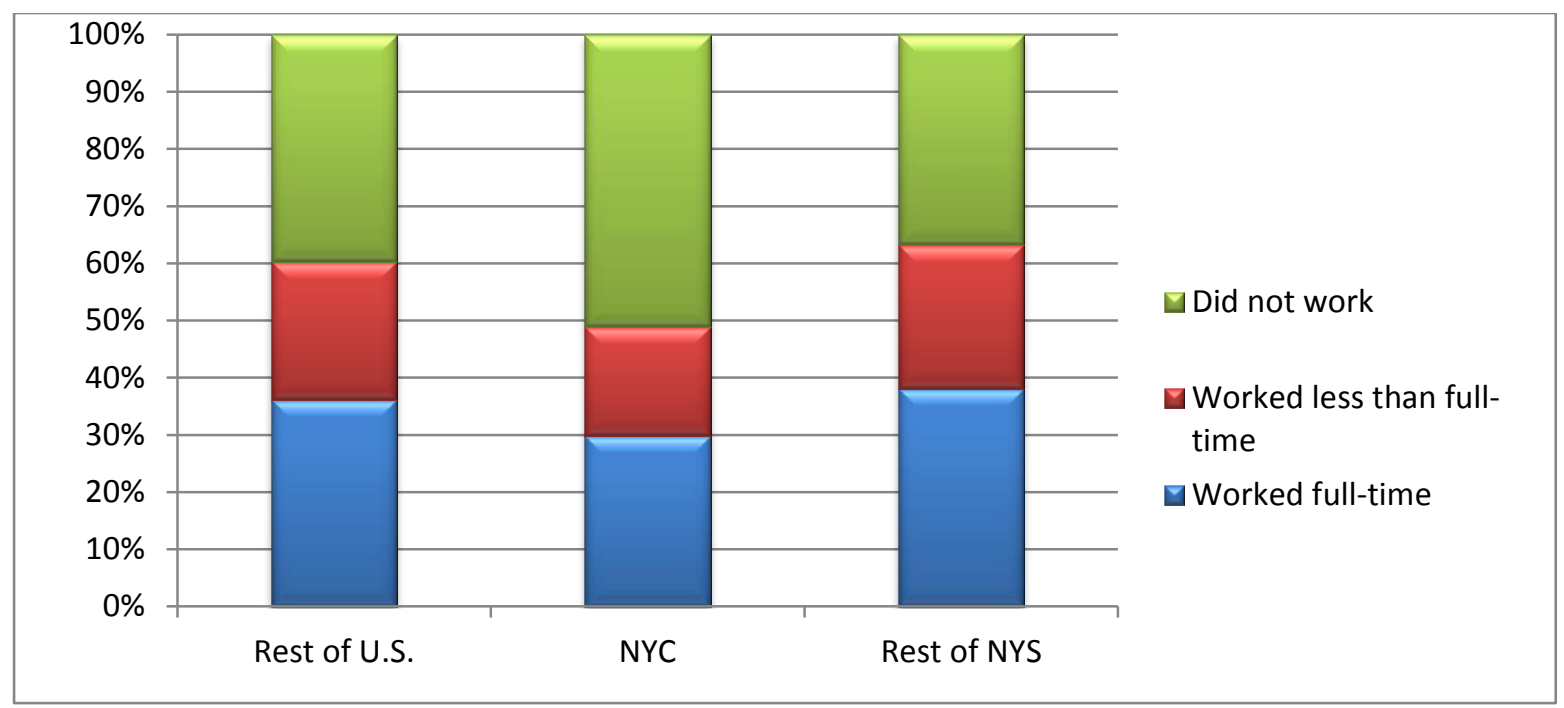

Figure 3-20. Work status for working age population with a hearing difficulty.

\section{Vision Difficulty}

A regional influence on work limitation seems less visible among individuals with a vision disability. As presented in Figure 3-21, about $43 \%$ of NYS residents with a vision difficulty worked in 2009, either full-time or part-time, while $47 \%$ of their counterparts living elsewhere in the U.S. worked in the same year. As for the employment status, work limitations for individuals with a vision disability were higher when compared to people with a hearing disability.

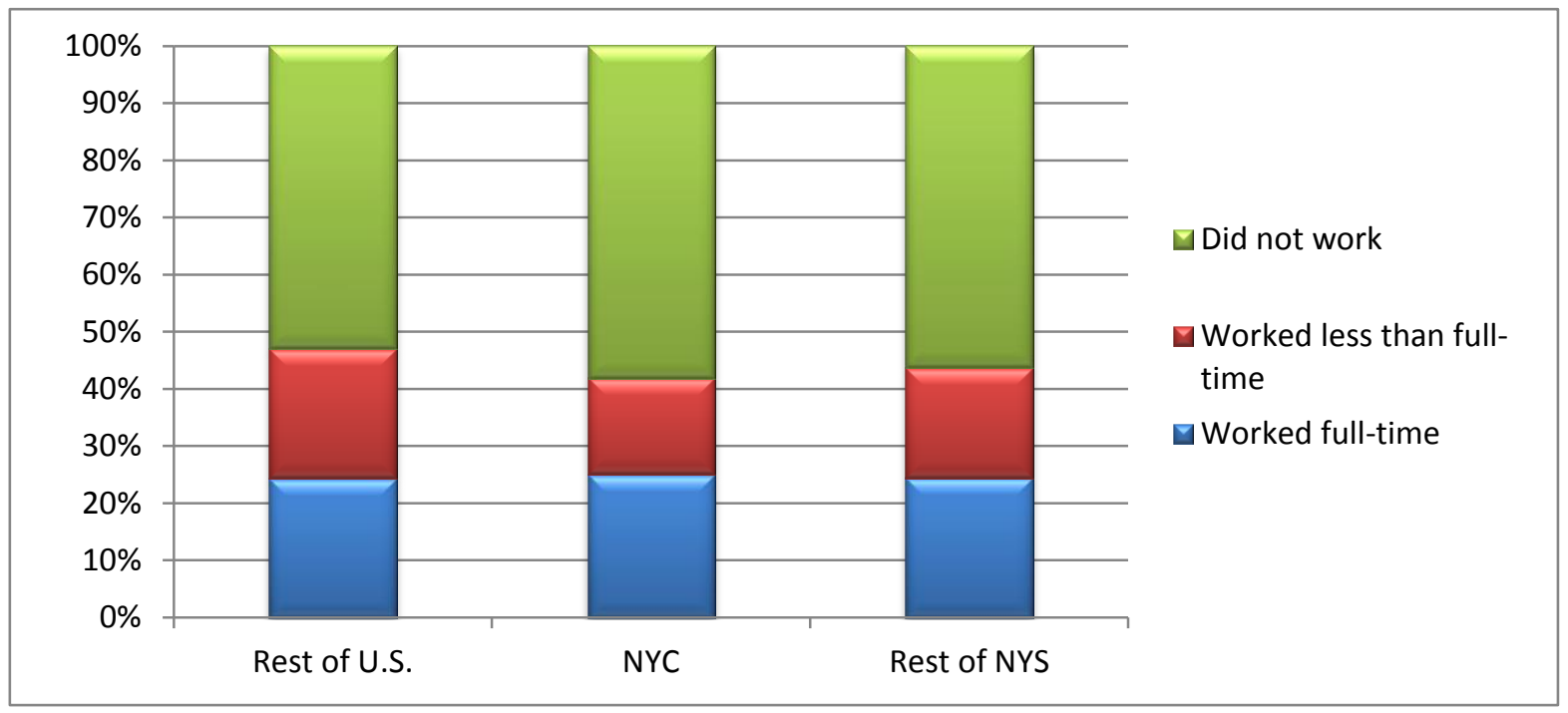

Figure 3-21. Work status for working age population with a vision difficulty. 


\section{Cognitive Difficulty}

Because people with a cognitive disability typically have serious difficulty concentrating, remembering, or making decisions, it was not anticipated that many of these individuals would work on a regular basis (i.e., full time). Figure 3-22 indicates that only about 10\% of the working age population with a cognitive difficulty worked full-time in 2009, regardless of where they lived. Those working part time was slightly larger for the working age population who lived outside NYC, than their colleagues that lived in the city, about $25 \%$ verse $15 \%$, respectively. Overall, about three out of four working age NYC residents with a cognitive disability did not work at all during 2009; while two in three working age individuals with the same disability living outside NYC did not work.

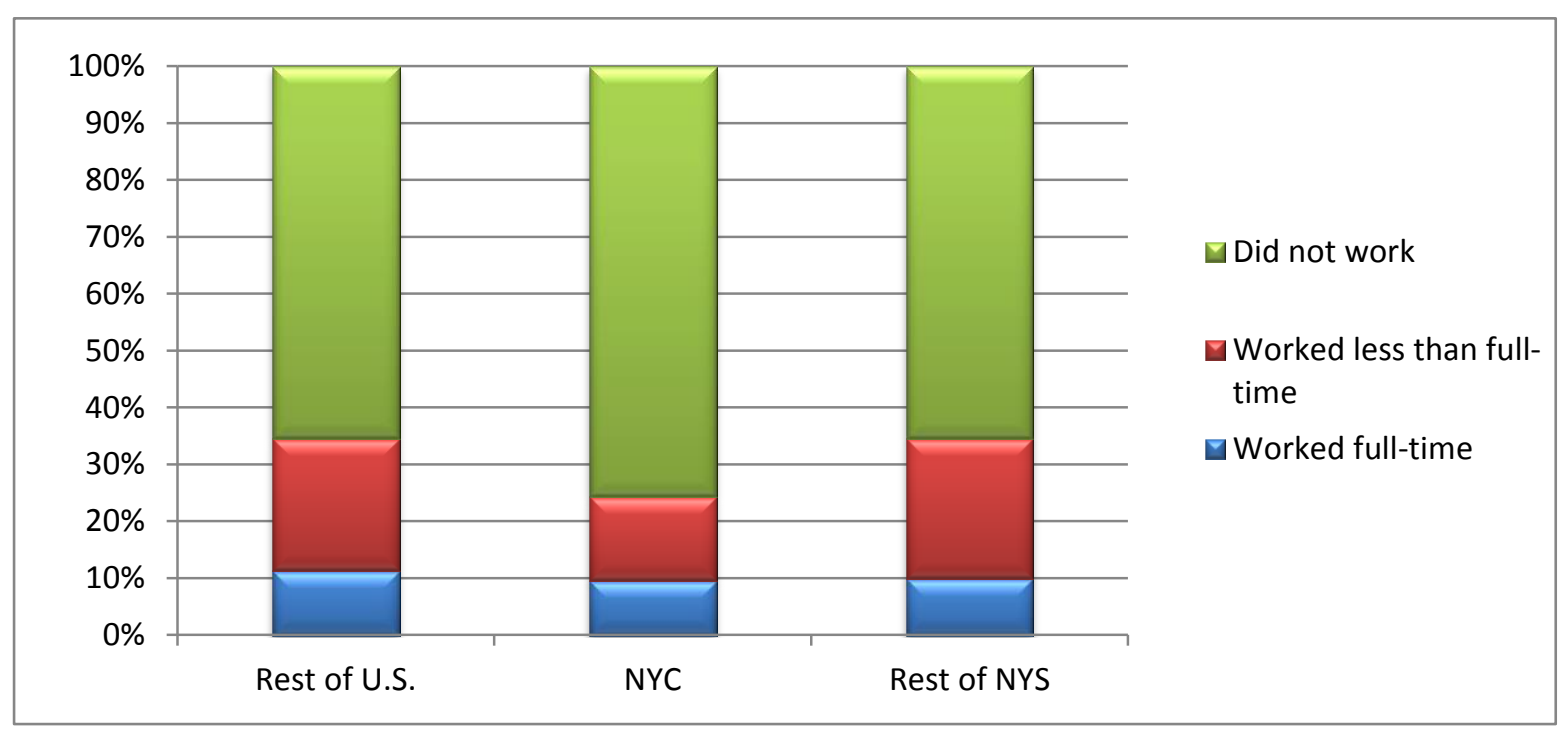

Figure 3-22. Work status for working age population with a cognitive difficulty.

\section{Ambulatory Difficulty}

Work limitations for working age individuals with an ambulatory difficulty were rather consistent across all regions. Figure 3-23 shows that about $70 \%$ of these individuals did not work in 2009, no matter where they lived. Of those who worked in 2009 about half worked fulltime while the remaining half worked less than full-time. 


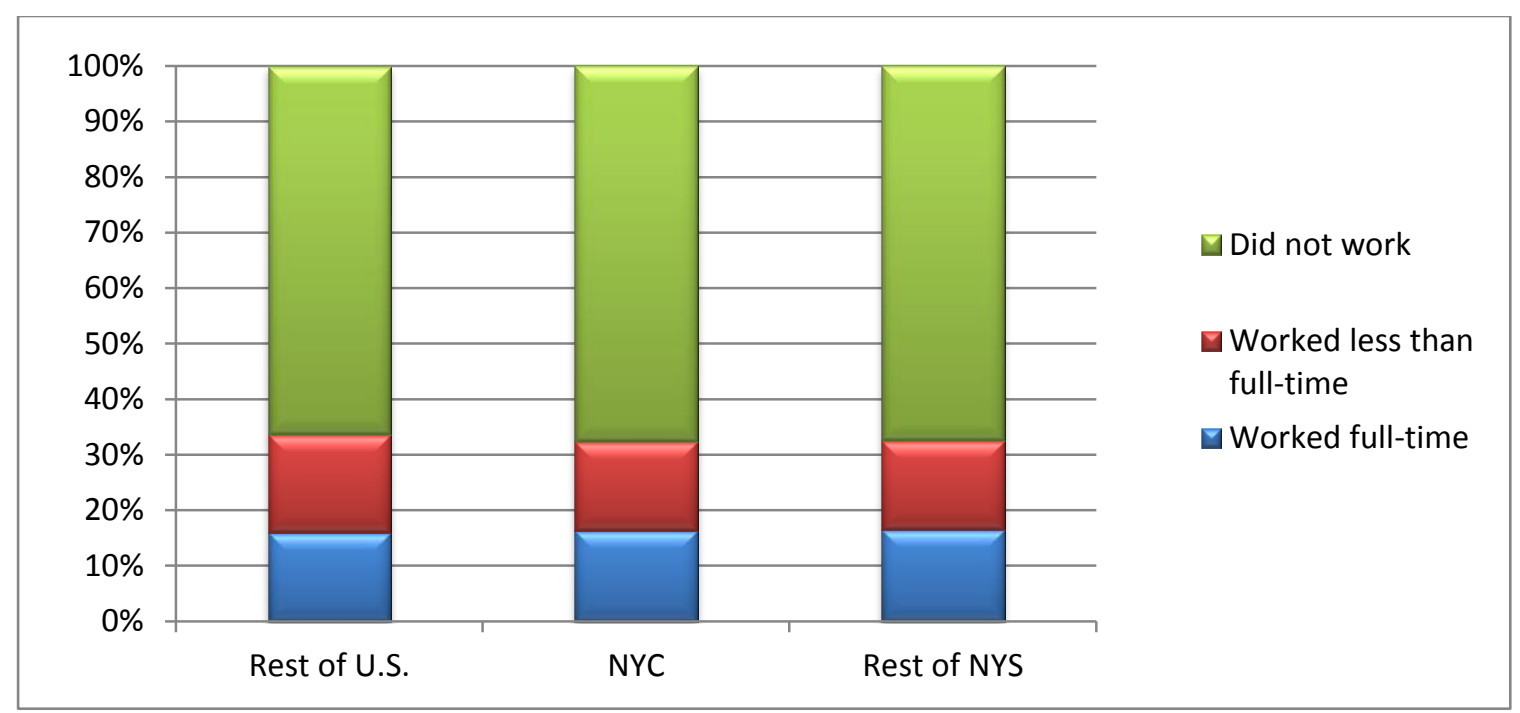

Figure 3-23. Work status for working age population with an ambulatory difficulty.

\section{Self-Care Difficulty}

People with a self-care disability encounter challenges in performing simple activities of daily living, such as dressing, bathing, or getting around inside the home. Understandably, work limitations for working age individuals with a self-care disability are much higher than other types of disabilities discussed thus far. As seen in Figure 3-24, less than $25 \%$ of working age individuals with a self-care difficulty worked during 2009 (either full-time or part-time) in all regions. Work limitations for NYC residents with a self-care disability were slightly higher, only about $20 \%$ of NYC individuals with a self-care difficulty worked in 2009. Furthermore, in all regions, only about $10 \%$ of individuals with a self-care disability worked full-time during 2009.

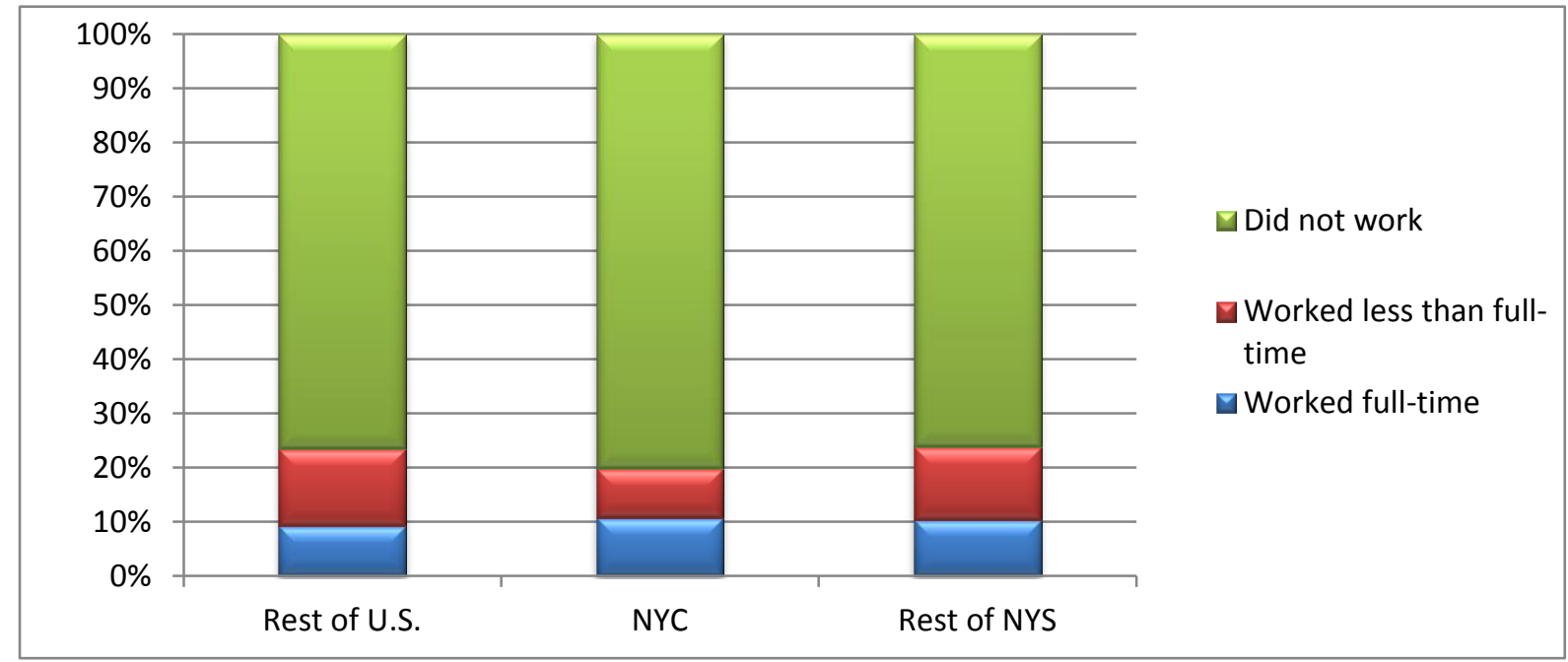

Figure 3-24. Work status for working age population with a self-care difficulty. 


\section{Independent Living Difficulty}

Individuals with an independent living disability have difficulties conducting daily errands alone. Similar to those with a self-care disability, working age people with an independent living disability encountered considerable work-limitation challenges. Figure 3-25 shows that, over $80 \%$ of working age individuals with an independent living difficulty who lived in NYC did not work at all in 2009, while about $75 \%$ of their counterparts from regions outside the NYC did not work in the same year. Even when they worked, most of these working age persons with an independent living disability worked less than full-time. In fact, as observed from Figure 3-25, only $8 \%$ of all working age individuals with an independent living difficulty worked full-time during 2009. This $8 \%$ rate is consistent across all three regions.

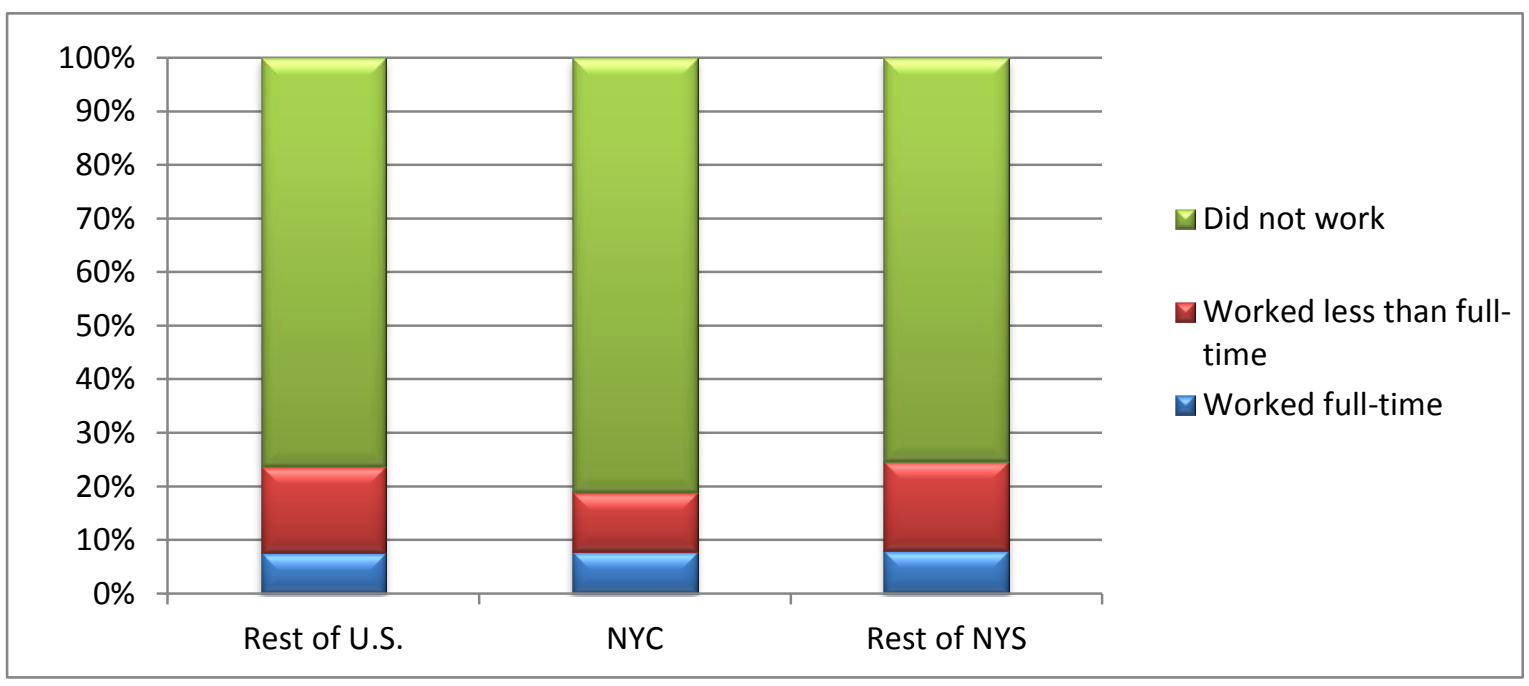

Figure 3-25. Work status for working age population with an independent living difficulty.

Table 3-5 summarizes the shares of working age individuals with a disability and disability type who worked during 2009. The data presented in this table includes both full-time and part-time work status for those working age individuals. Results related to work limitations were found to closely resemble those from the previous employment status discussion (Section 3.2). Noticeably regional differences between the working age population by disability type for those living in NYC and those from the other areas are also presented.

Table 3-5. Percent of Working Age Individuals with a Given Disability Who Worked in 2009 by Disability Type (Including Full-Time and Less Than Full-Time)

\begin{tabular}{|l|c|c|c|}
\hline Disability type & Rest of U.S. & NYC & Rest of NYS \\
\hline Hearing difficulty & $60 \%$ & $49 \%$ & $63 \%$ \\
\hline Vision difficulty & $47 \%$ & $42 \%$ & $44 \%$ \\
\hline Cognitive difficulty & $34 \%$ & $24 \%$ & $34 \%$ \\
\hline Ambulatory difficulty & $34 \%$ & $32 \%$ & $33 \%$ \\
\hline Self-care difficulty & $24 \%$ & $20 \%$ & $24 \%$ \\
\hline Independent living difficulty & $24 \%$ & $19 \%$ & $25 \%$ \\
\hline
\end{tabular}




\subsection{MODE CHOICES FOR COMMUTING TO WORK}

For the working population age 16 years and older, the 2009 ACS also collected information regarding mode choices for their commuting to work. Figure 3-6 presents mode shares by disability status of the worker and by region of residency for those age 16 years and older in 2009. The most striking difference, although expected, is the use of public transportation among NYC workers verses workers from other regions, regardless of their disability status. NYC has an extensive public transportation network that allows riders to reach jobs, schools, and other places for conducting daily activities. Thus, as Figure 3-26 shows more than half of NYC workers utilized public transportation for commuting to work, even for workers with a disability.

Outside NYC, commuting to work mostly relied on personal vehicles. No matter what the disability status was workers in most cases drove alone for their commuting. Roughly, $70 \%$ of disabled workers drove to work, while about $77 \%-78 \%$ of their non-disabled co-workers used the same mode. About $13 \%$ of the disabled workers that lived outside NYC traveled to work by carpooling while $9 \%-10 \%$ of their non-disabled co-workers carpooled to work.

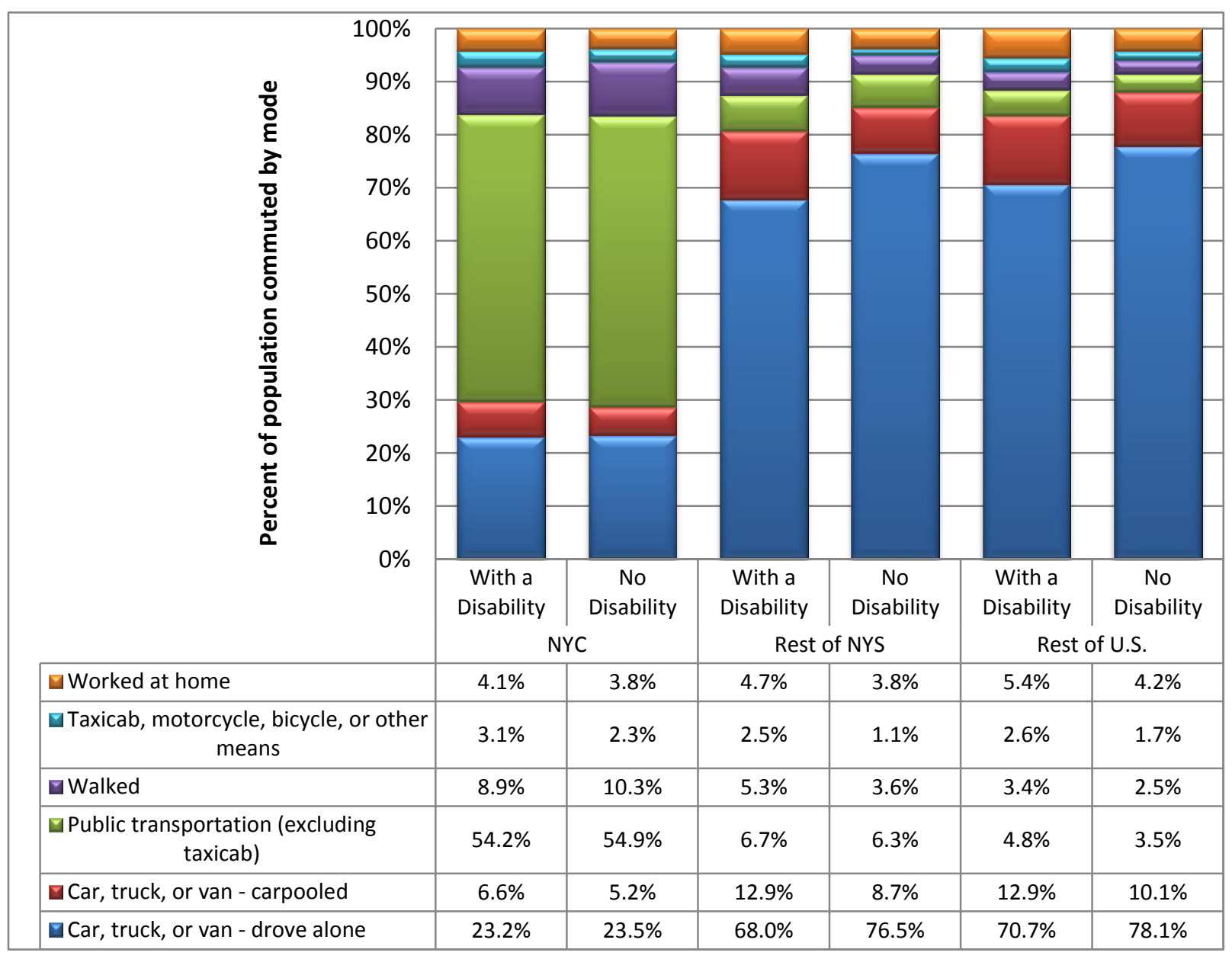

Figure 3-26. Share of mode use for commuting to work by disability status and region. 
In addition to statistics presented above, statistics on several other interesting aspects of disabled populations can also be obtained from the ACS. A summary of these disability statistics is included in Appendix $\mathrm{C}$ of this report. 


\section{NHTS-BASED STATISTICS ON DISABLED PERSONS IN NYS}

Unlike the 2009 ACS that collected disability data by six different types, disability status was rather loosely defined in the 2009 NHTS. As pointed out in Section 2 of this report, this study defines a "disabled person" in the 2009 NHTS as one who answers "yes" to the question of "Do you have a temporary or permanent condition or handicap that makes it difficult to travel outside of the home?" Also different from the ACS is that the 2009 NHTS collected travel information on all trip types and purposes, while travel data is only available for "commuting to work" trips under the ACS.

Within this research context, a "disabled household" is defined as one that contains one or more disabled persons within the household. Due to sample size constraints of the 2009 NHTS, households within population-concentrated urban areas are more likely to be selected for the survey. Figure 4-1 shows such a pattern of disabled households clustering around major cities in NYS.

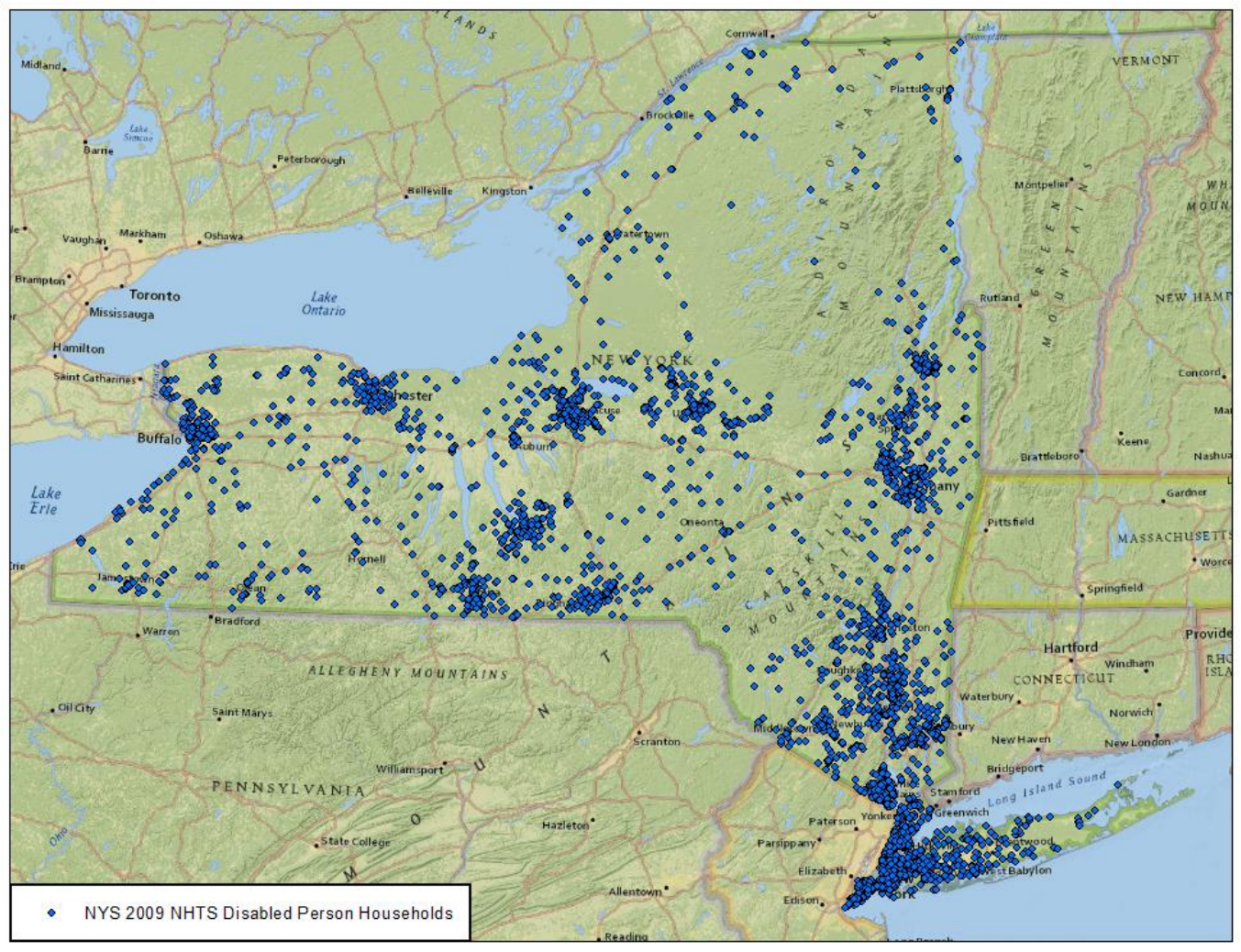

Figure 4-1. Distribution of sample households with a disabled person, 2009 NHTS.

Statistics summarized in this section were generated from analyses of the 2009 NHTS data. The 2009 NHTS did not collect any information about the severity of a disability nor the type of disabilities. In addition, the questions about disabilities were not asked of persons under 16 years of age in the 2009 NHTS. The NHTS did ask its survey respondents to identify the length 
of time he/she had such a "condition or handicap," however. Note that for statistical comparisons and tabulations within the NHTS context, the area of New York Metropolitan Transportation Council (NYMTC) is used instead of the 5-county NYC region that was used in 2009 ACS-based analyses (Section 3). Figure 4-2 shows the geographic boundary differences between NYC and NYMTC.

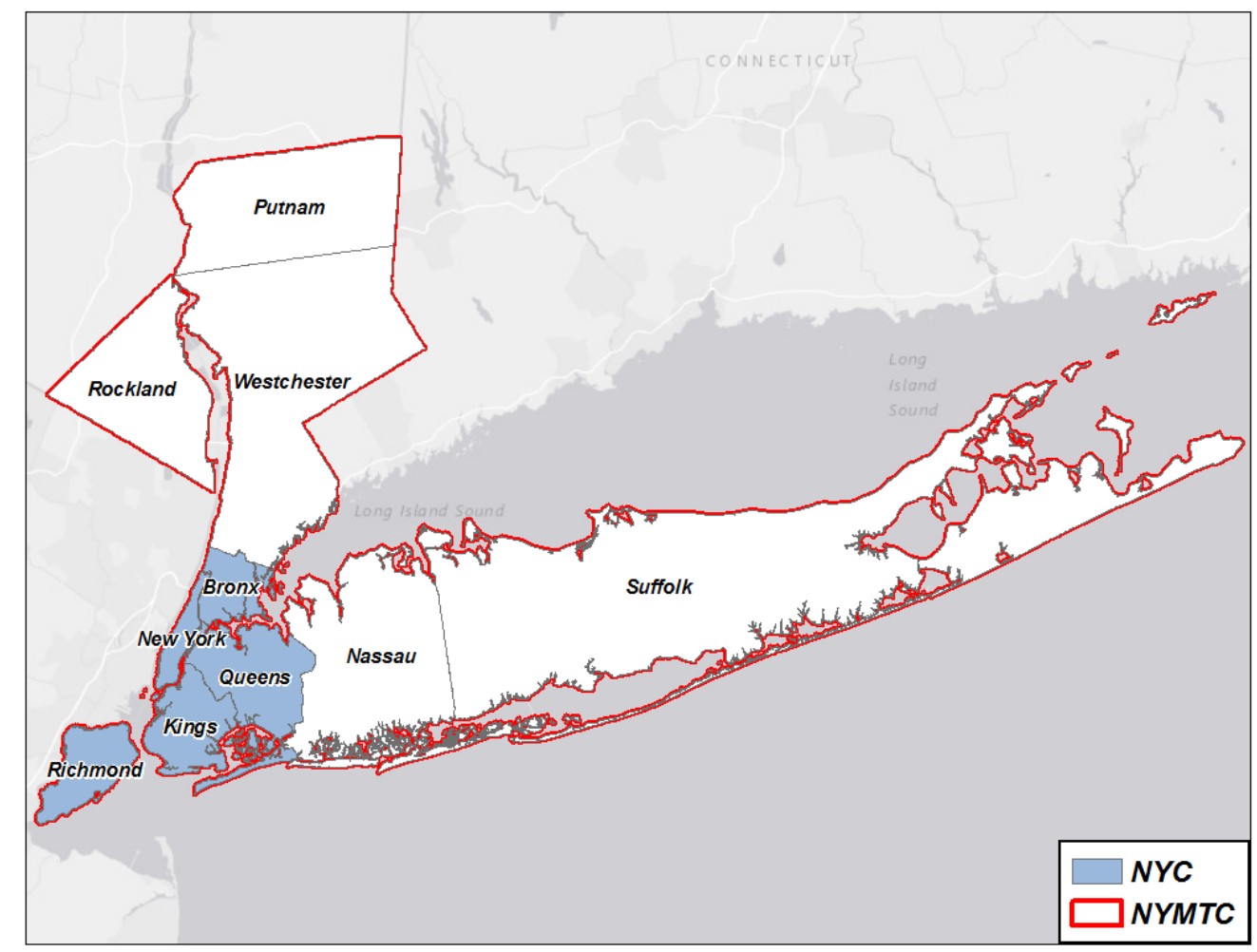

Figure 4-2. Map showing the geographic boundaries for New York City (NYC) and the New York Metropolitan Transportation Council (NYMTC)

Among New Yorkers who responded having "medical conditions that made it difficult to travel outside of the home" over $31 \%$ of respondents reported 10 or more years of having such conditions; nearly $27 \%$ indicated the length of time with the conditions was within 1-4 years (Figure 4-3). Only about $8 \%$ of the respondents from NYS reported having such medical conditions for their entire lives. Overall, there appears to be no significant differences in the length of time a person had a disability condition between New Yorkers and those that lived outside NYS. 


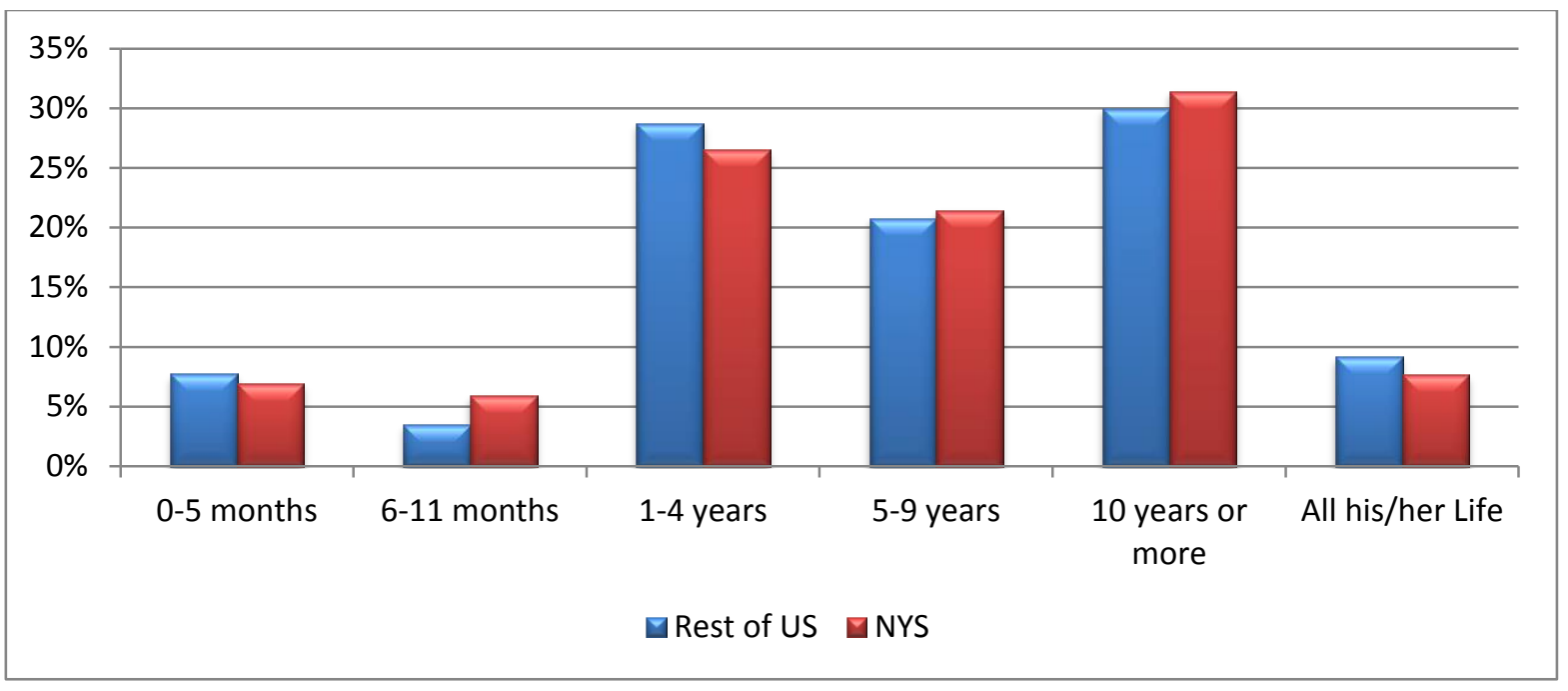

Figure 4-3. Length of time with medical condition that made it difficult to travel, 2009 NHTS.

\subsection{DISABILITY PREVALANCE}

Of all 16 million NYS residents age 16 years and older in 2009, NHTS captured 1.7 million with a disability (i.e., responded "yes" to the NHTS disability question). This is equivalent to a disability rate (i.e., number of disabled persons divided by total population) of about $11 \%$ of the NYS population age 16 years and over (Table 4-1), which is consistent with the 2009 ACS results reported in Section 3.1.

Table 4-1. NYS Population and Disability Rate by Disability Status and Age (2009 NHTS)

\begin{tabular}{|l|c|r|r|r|c|}
\hline \multicolumn{1}{|c|}{ Age group } & Disabled & Not Disabled & Unreported & \multicolumn{1}{c|}{ Total } & Disability Rate \\
\hline $16-64$ yrs. & 904,505 & $12,133,102$ & 16,281 & $13,053,887$ & $7 \%$ \\
\hline $65+$ yrs. & 793,723 & $1,806,375$ & 7,572 & $2,607,670$ & $31 \%$ \\
\hline $65-69$ yrs. & 152,945 & 564,121 & 1,892 & 718,959 & $21 \%$ \\
\hline $70-74$ yrs. & 156,321 & 440,229 & 1,234 & 597,783 & $26 \%$ \\
\hline $75-79$ yrs. & 137,029 & 369,544 & 746 & 507,319 & $27 \%$ \\
\hline $80-84$ yrs. & 166,695 & 280,487 & 630 & 447,812 & $37 \%$ \\
\hline $85+$ yrs. & 180,733 & 151,994 & 3,070 & 335,797 & $54 \%$ \\
\hline Total & $\mathbf{1 , 6 9 8 , 2 2 8}$ & $\mathbf{1 3 , 9 3 9 , 4 7 7}$ & $\mathbf{2 3 , 8 5 3}$ & $\mathbf{1 5 , 6 6 1 , 5 5 8}$ & $\mathbf{1 1 \%}$ \\
\hline
\end{tabular}

\subsubsection{Age and Gender Factors}

As summarized in Table 4-1, the non-elderly group (age 16 to 64 years old) had a rate of $7 \%$ of the disability population while the elderly group as a whole had a $31 \%$ disability rate. Table 4-1 also shows that the disability rate increases with elderly ages, from about $21 \%$ for those age 65 69 years old to over half (54\%) of the oldest elderly group (85+). Considering gender, the NHTS 2009 data indicated that elderly males have an overall disability rate of $26 \%$ while $34 \%$ of elderly females have a disability (Figure 4-4). 


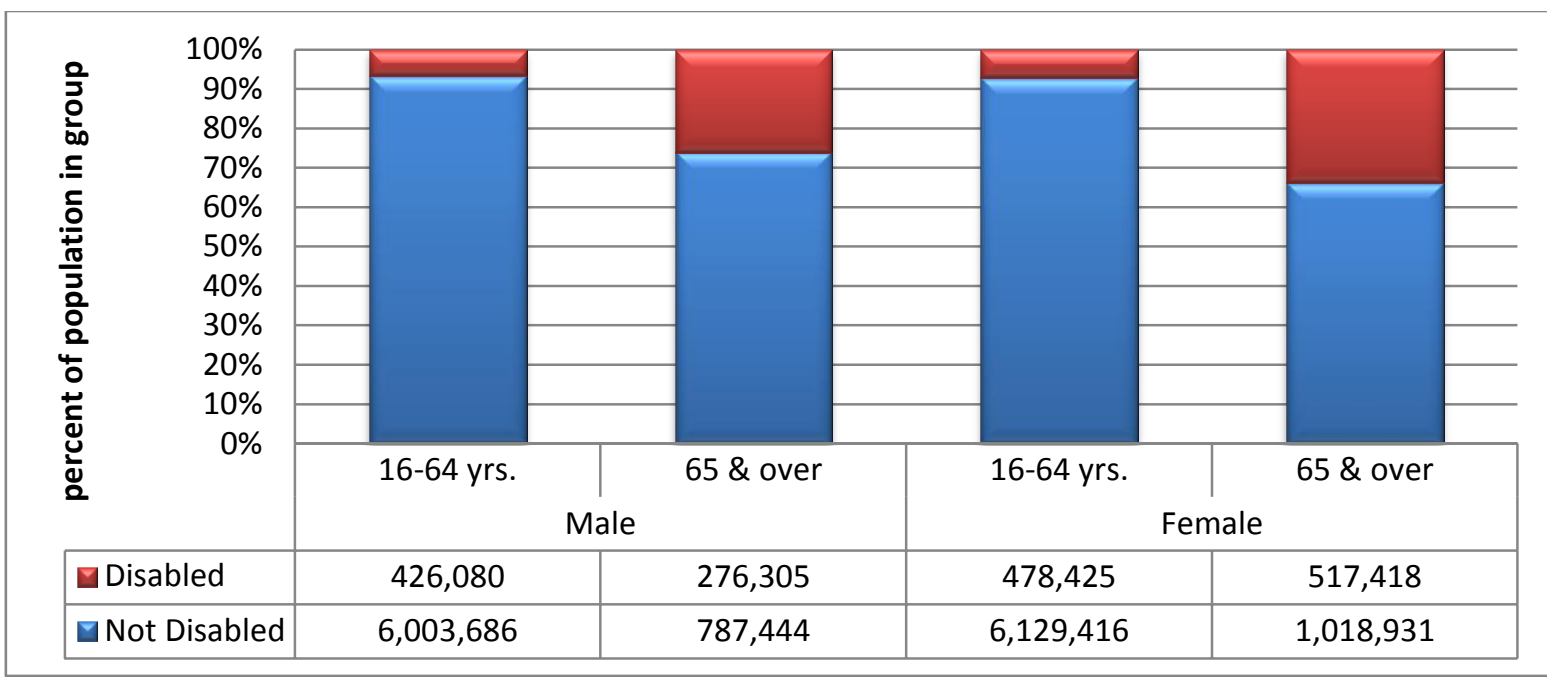

Figure 4-4. Distribution of population by disabled status, gender, and age group (2009 NHTS).

Figure 4-5 reconfirms that according to the 2009 NHTS data, shares of the disabled population increase significantly as people age for both gender groups. Furthermore, there is a significant gender gap in disability rates for those age 75 years old and over. It was expected that there would be a higher disability rate for elderly females due to an association with the longer lifespan in females than for males.

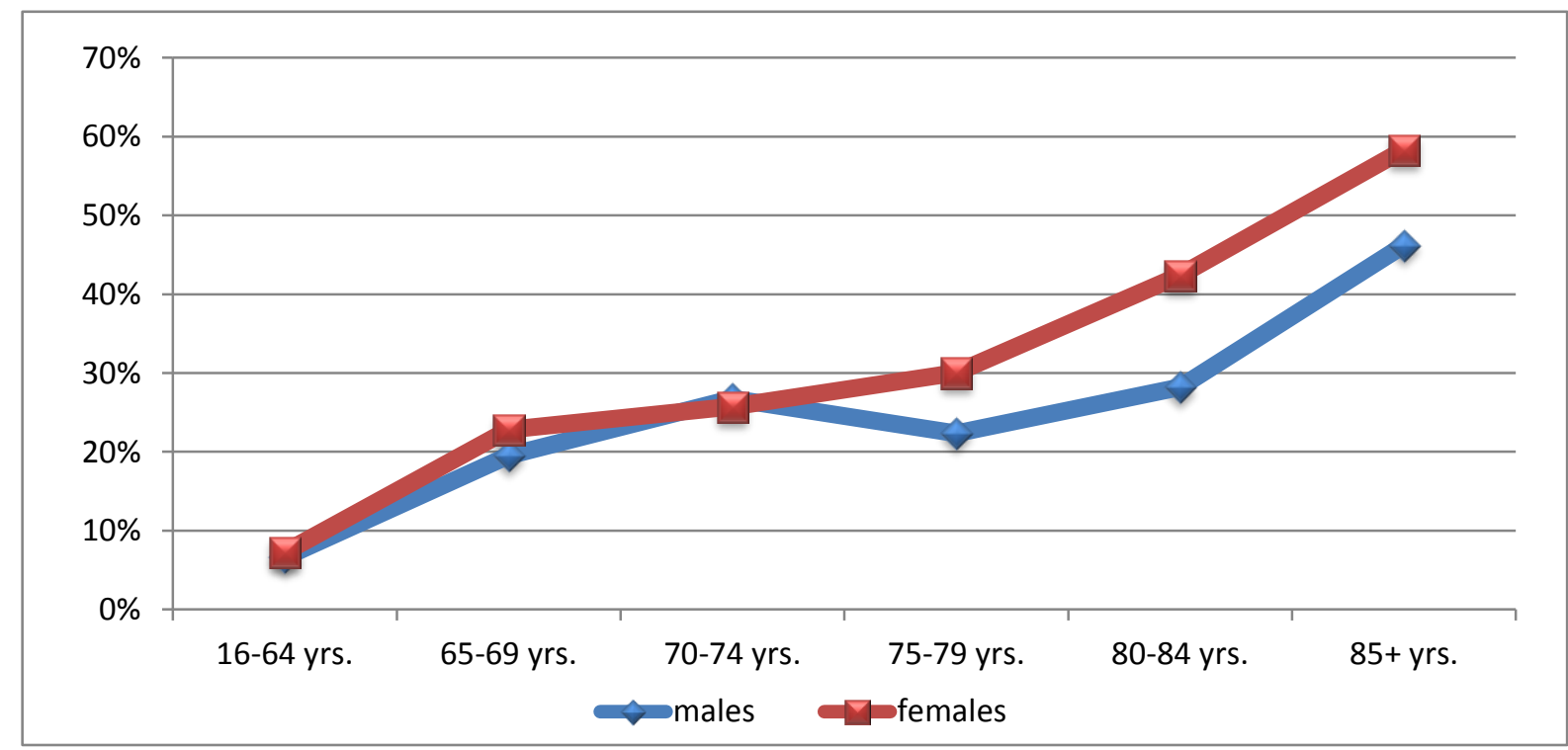

Figure 4-5. Percent of disabled population by age group, 2009 NHTS.

Further inspection of the profile of the disabled population in NYS found that elderly males (65+) accounted for $39 \%$ of all disabled males in 2009 , while $52 \%$ of disabled females in NYS were age 65 years and older during the same year. Certainly, there were more disabled elderly females in NYS than disabled elderly males, which could support the pattern seen in Figure 4-5. 


\subsubsection{Difference in Vehicle Ownership}

In terms of vehicles owned in disabled households verses non-disabled households, Figure 4-6 clearly shows a significant higher share of disabled households were zero-vehicles when compared to their non-disabled neighbors in the 2009 NHTS data. It is a well-known fact that a higher percent of households in the NYMTC owned zero vehicles by choice and not necessarily due to any financial constraints. Nevertheless, the percent of zero-vehicle households within disabled households that lived in NYMTC was significantly higher than that of their nondisabled counterparts, $54 \%$ versus $37 \%$ respectively, in 2009 NHTS.

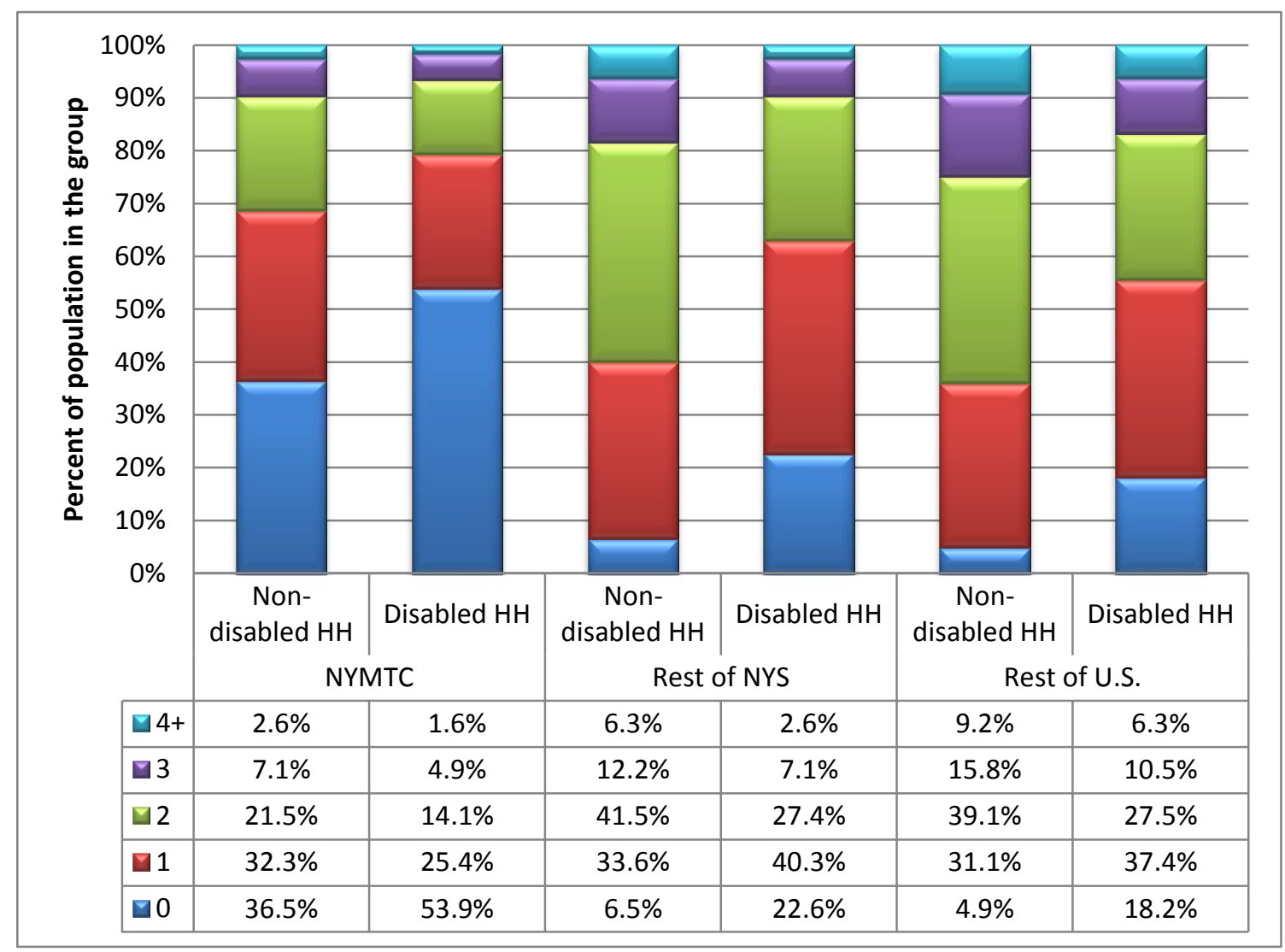

Figure 4-6. Distribution of vehicle ownership by disability status and region (2009 NHTS).

Outside the NYMTC, the share of zero-vehicle households among disabled households was visibly higher than that of non-disabled households. As presented in Figure 4-6, 23\% of disabled households that lived in the Rest of NYS were zero-vehicle households, while less than 7\% of their non-disabled-household neighbors from the same region were the same. Outside NYS, shares of zero-vehicle households were $18 \%$ versus $5 \%$ for disabled-household and non-disabled households, respectively.

Moreover, the majority (60\% or more) of non-disabled households that lived outside the NYMTC (in the "Rest of NYS" or "Rest of the U.S.") region owned two or more vehicles, while 
roughly about $40 \%$ of the disabled households in the same regions owned the two or more vehicles.

\subsubsection{Household Income Gap}

Based on household income distributions displayed in Figure 4-7, it is clearly visible that a higher percent of disabled households fell in the lowest income group (less than $\$ 25,000$, shown in blue bars) when compared to those of the non-disabled households. While slightly more than one in five non-disabled households earned less than $\$ 25,000$ in 2009 , it was more than twice as likely (43\%-53\%) for a disabled household from the same community to be in the lowest household income bracket during the same year. Again, cost of living in the NYMTC area is expected to be higher than other regions, so naturally NYMTC would have a higher share of households with over $\$ 75,000$ annual household income.

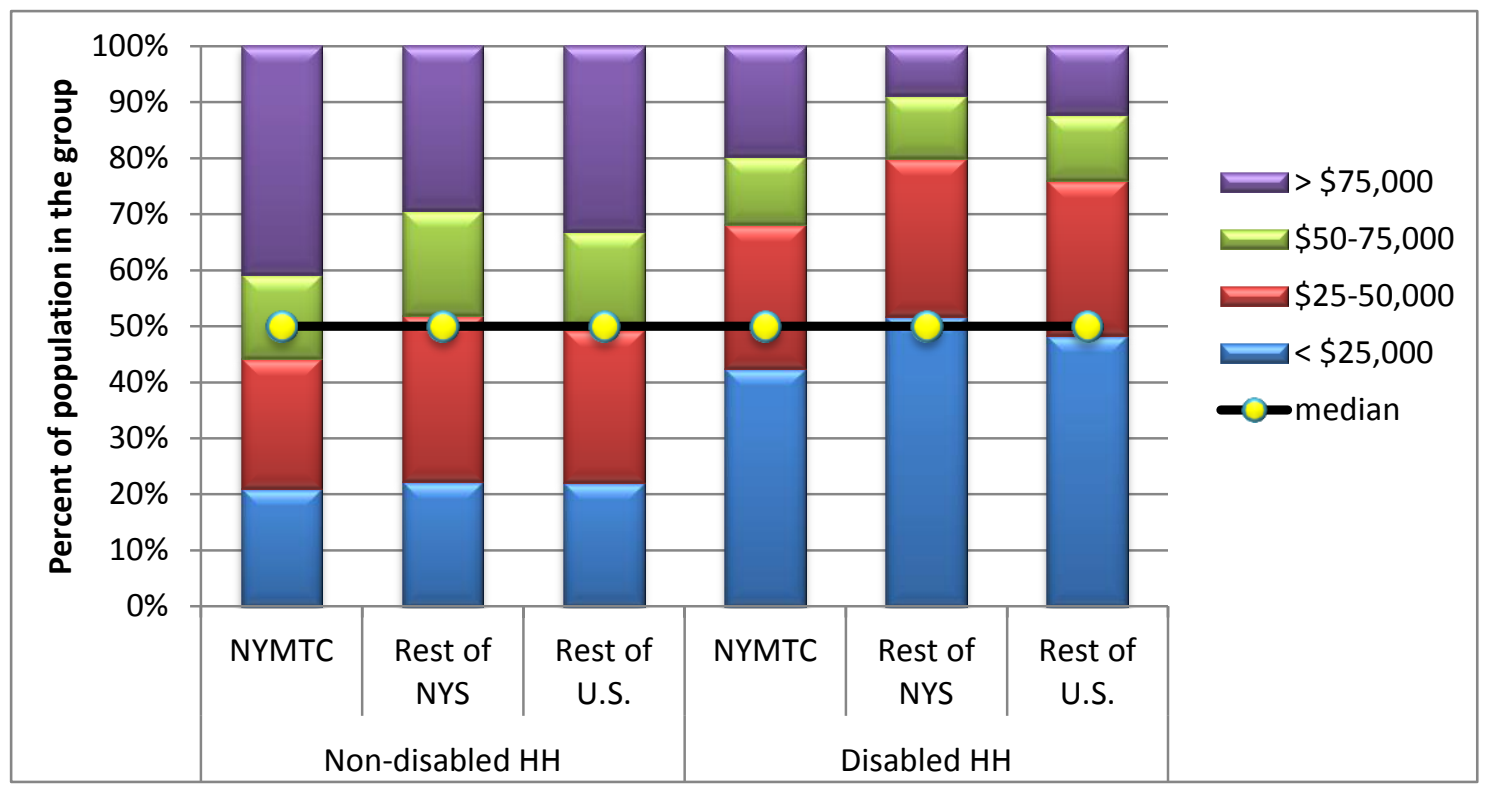

Figure 4-7. Distribution of household income by disability status and region (2009 NHTS).

Because household income data was provided by the 2009 NHTS in income categories instead of individual values, specific averages or median measures of income by group of population could not be calculated from the 2009 NHTS data directly. The median household income, however, could be roughly estimated based on where the 50\%-points of distribution are located (see in Figure 4-7). For example, the 2009 median household income for a non-disabled household from NYMTC was in the \$50-\$75,000 range, while a disabled household from the NYMTC region had a median household income in the $\$ 25-\$ 50,000$ range.

Note that the distributions shown in Figure 4-6 are household-count based (i.e., the size of each "color box" is dependent on the number of households that fell in that specific income group), therefore the specific placement of a mid-point within a given category (color box) could not be 
translated into a dollar value directly. With the use of a smaller income range for grouping (e.g., $\$ 10,000$ interval), a more refined estimate of the median could be made.

\subsubsection{Driving Status}

As expected, significant differences in driving status exists between non-disabled and disabled households. While over $80 \%$ of NYMTC non-disabled residents age 16 years and over reported themselves as drivers in 2009, only about half of NYMTC disabled persons in the same age group stated that they were drivers (Figure 4-8). Shares of drivers by region are similar for residents that lived outside NYMTC, with $92 \%$ of non-disabled residents age 16 years and over reported as drivers. The shares of drivers reported as disabled for age 16 years and over accounted for $65 \%$ of those who lived in the Rest of NYS and about $61 \%$ from those that lived in the Rest of the U.S.

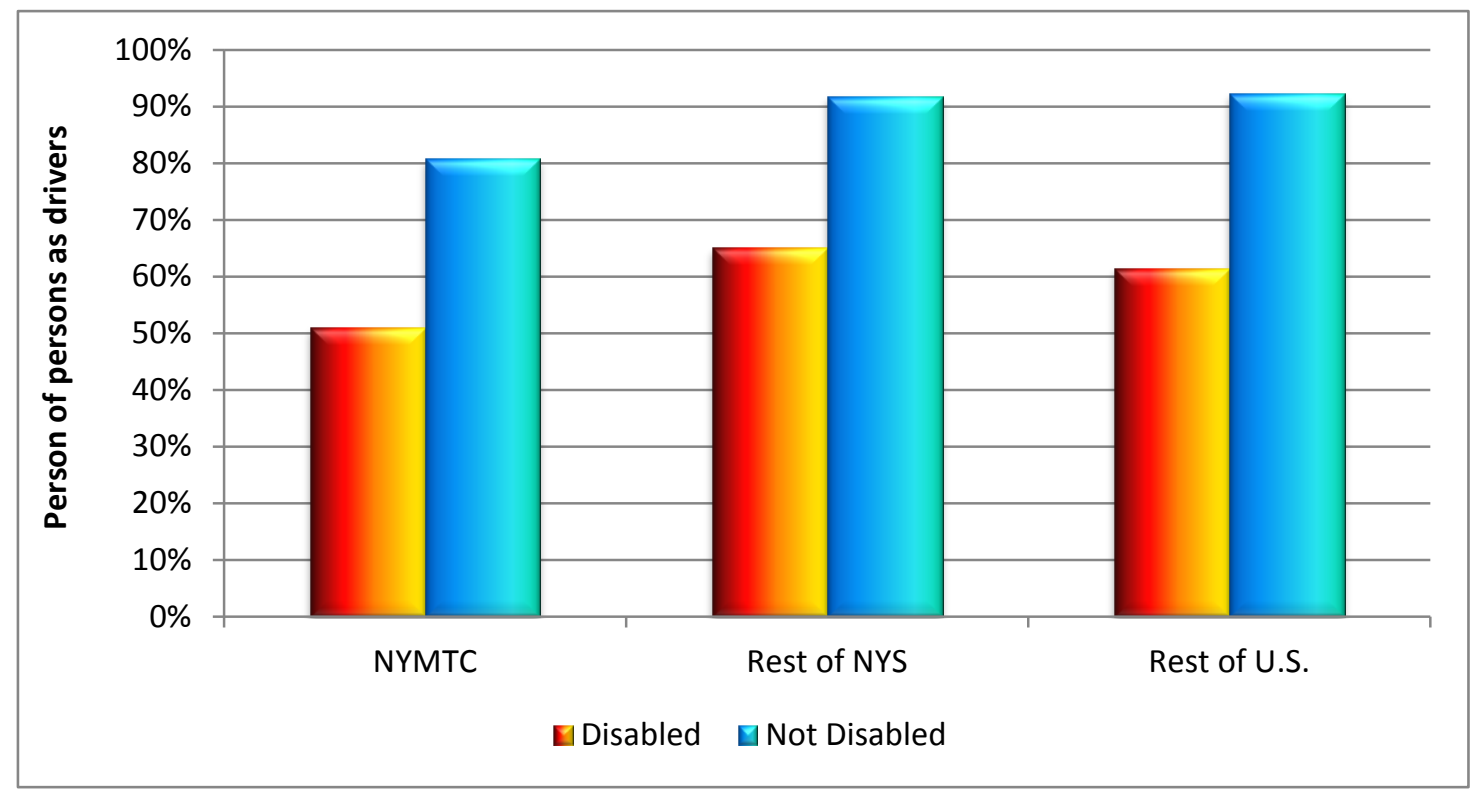

Figure 4-8. Percent of persons age 16 years and over reported as a driver and by disability status (2009 NHTS).

\subsubsection{Worker Status}

Based on 2009 NHTS data, worker status of the survey respondents age 16 years and older was examined by disability status and presented in Figure 4-9. While regional differences in worker status was not significant, the gap in share of workers between disabled and non-disabled persons was extremely large. Nearly $70 \%$ of the non-disabled population age 16 years and over were workers in 2009 , while only $20 \%$ or less of the disabled working age population from each region worked during the same year. 


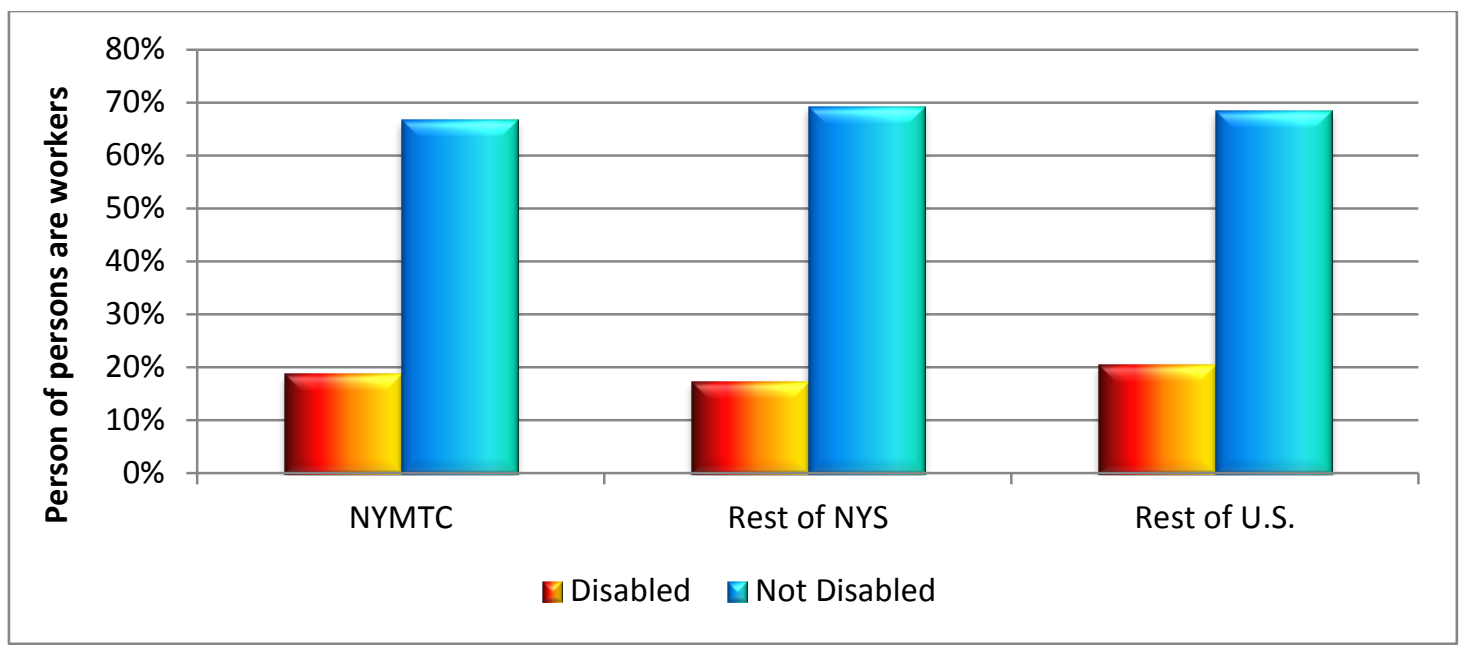

Figure 4-9. Percent of persons age 16 years and over who are workers (2009 NHTS).

\subsection{LENGTH OF TIME DISABLED}

For the 2009 NHTS, those who answered "yes" to the question of "having a condition or handicap that makes it difficult to travel outside of the home" were asked a follow-up question to gather information on the length of such a condition. The NHTS respondents were presented with a list of length categories to pick from, including 0-5 months, 6-11 months, 1-4 years, 5-9 years, 10 years or more, and all his/her life. Of the nearly 1.7 million New Yorkers that answered "yes" to the "having a condition" question (i.e., disabled population), about 99\% provided a response to the follow-up length-of-time disabled question.

\subsubsection{Population Distribution by Length of Time Disabled}

Table 4-2 presents the total number of the disabled population in each region by the specified length-of-time having a disability as captured in the 2009 NHTS. Along with distributions shown in Figure 4-10, more than half of the disabled population had a medical condition that lasted for a period from five to over ten years (purple and blue colored boxes), in all regions. Approximately $6 \%$ of the disabled NYMTC residents had a disability condition that lasted all his/her life (orange color boxes in Figure 4-10), while about $10 \%$ of their disabled counterparts that lived outside NYMTC had a life-long disability condition. Furthermore, the Rest of NYS seems to have a slightly higher share of disabled persons that lasted 10 or more years. No significant regional differences in the share patterns were identified.

Table 4-2. Population by Length of Time Having a Disability Condition by Region (2009 NHTS)

\begin{tabular}{|l|r|r|r|r|r|r|r|}
\hline \multicolumn{1}{|c|}{ Region } & $\mathbf{0 - 5}$ months & $\begin{array}{c}\text { 6-11 } \\
\text { months }\end{array}$ & \multicolumn{1}{|c|}{$\mathbf{1 - 4}$ years } & 5-9 years & $\begin{array}{c}\text { 10 years or } \\
\text { more }\end{array}$ & $\begin{array}{c}\text { All his/her } \\
\text { Life }\end{array}$ & \multicolumn{1}{c|}{ Total } \\
\hline NYMTC & 81,202 & 69,337 & 299,535 & 248,531 & 333,573 & 70,844 & $1,103,022$ \\
\hline Rest of NYS & 35,898 & 30,514 & 146,788 & 112,436 & 194,688 & 58,529 & 578,853 \\
\hline Rest of U.S. & $1,738,199$ & 790,639 & $6,456,306$ & $4,666,520$ & $6,738,152$ & $2,065,755$ & $22,455,570$ \\
\hline
\end{tabular}




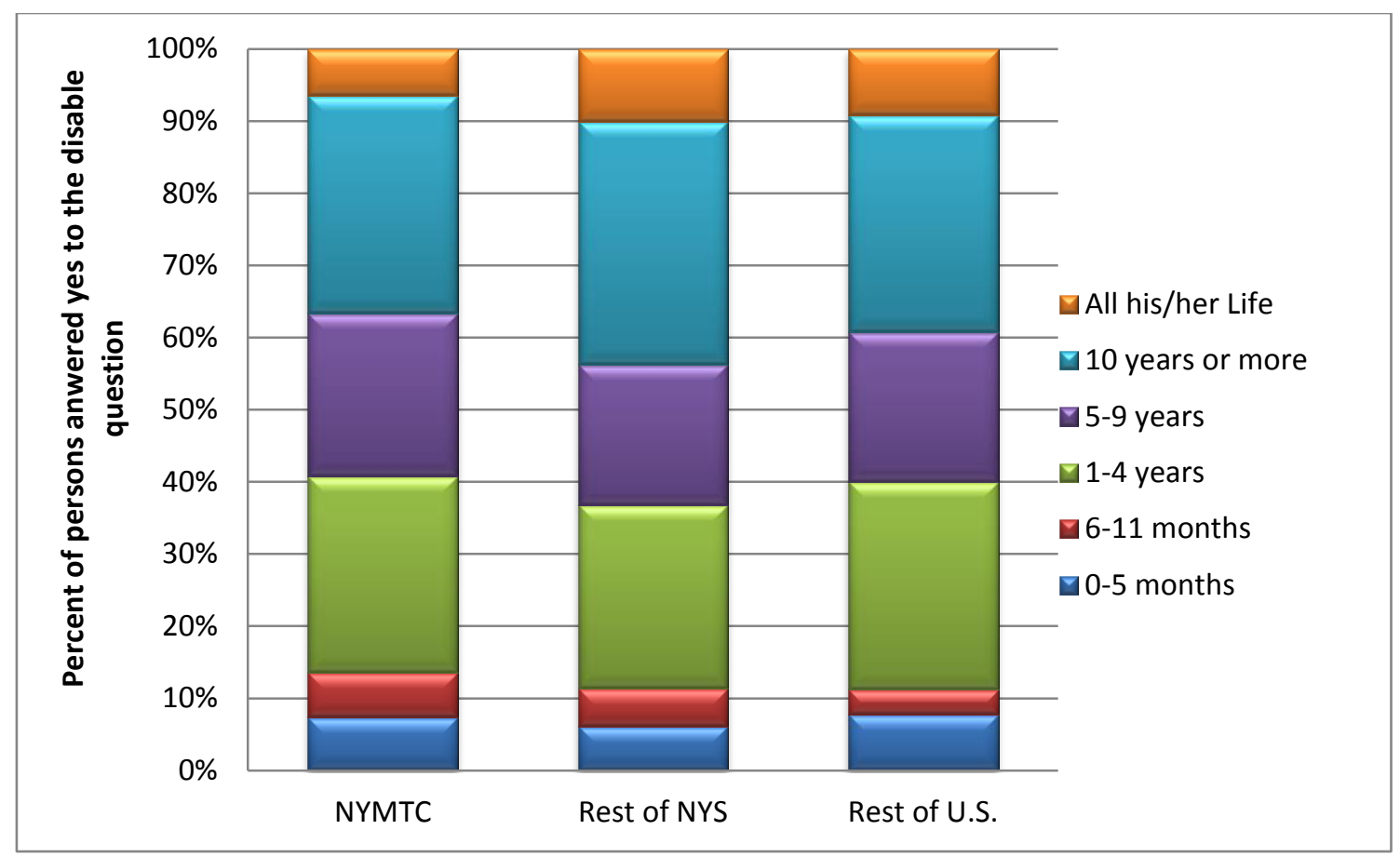

Figure 4-10. Distribution of disabled person by length of time disabled.

\subsubsection{Age Impacts on Length of Time Disabled}

Recall that NHTS disability-related questions were not asked for persons under 16 years old during the survey. Overall, according to 2009 NHTS data, about $51 \%$ of the disabled NYMTC population belonged to the younger age group (16 to 64 years old), and the younger age group accounted for $58 \%$ of the disabled population that lived outside NYMTC. This share varies significantly, when considering the length of time an individual had a disability, as presented in Figure 4-11. This is most visible within the younger age group of people that had a lifelong disability-82\% reported for the NYMTC population and over $91 \%$ of populations lived elsewhere (in Rest of NYS or Rest of U.S.). Younger disabled persons also accounted for a higher share within those having shorter than one-year disabilities, particularly for NYMTC residents. Nearly three in four disabled persons less than 65 years old from NYMTC responded as having a disability that lasted 0-5 months.

On the other hand, Figure 4-11 shows that the elderly disabled population that lived in NYS (NYMTC or Rest of NYS) accounted for the majority of disabled people having 1-4 or 5-9 years of disability. This observation is further confirmed in Figure 4-12, where the disabledpopulation shares by length of disability within each age group were plotted. In all regions, approximately one-third of elderly disabled population had a disability that lasted 10 years or more, including a small share of those with a lifelong disability. 


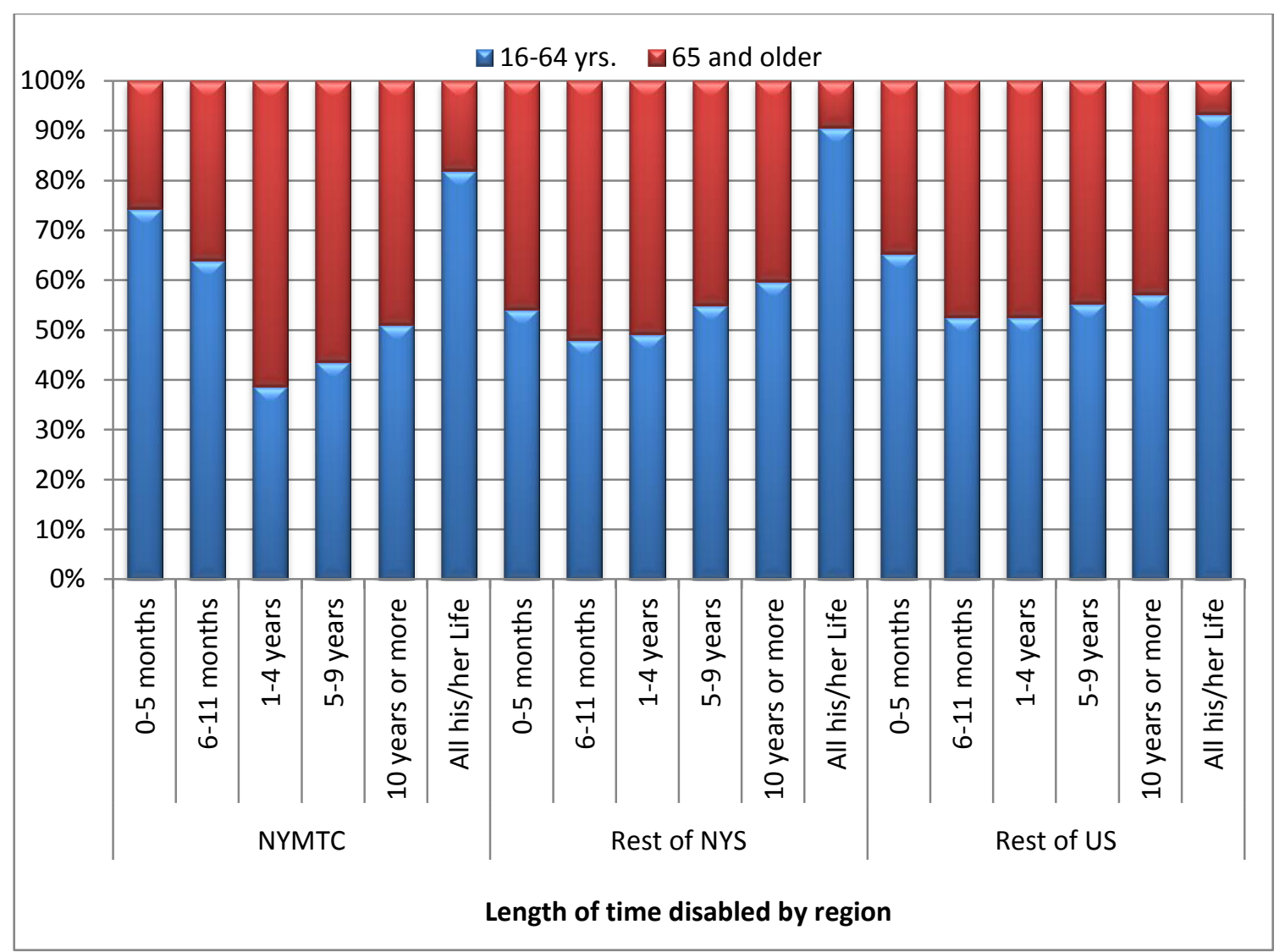

Figure 4-11. Share of elderly population within a given length of time disabled.

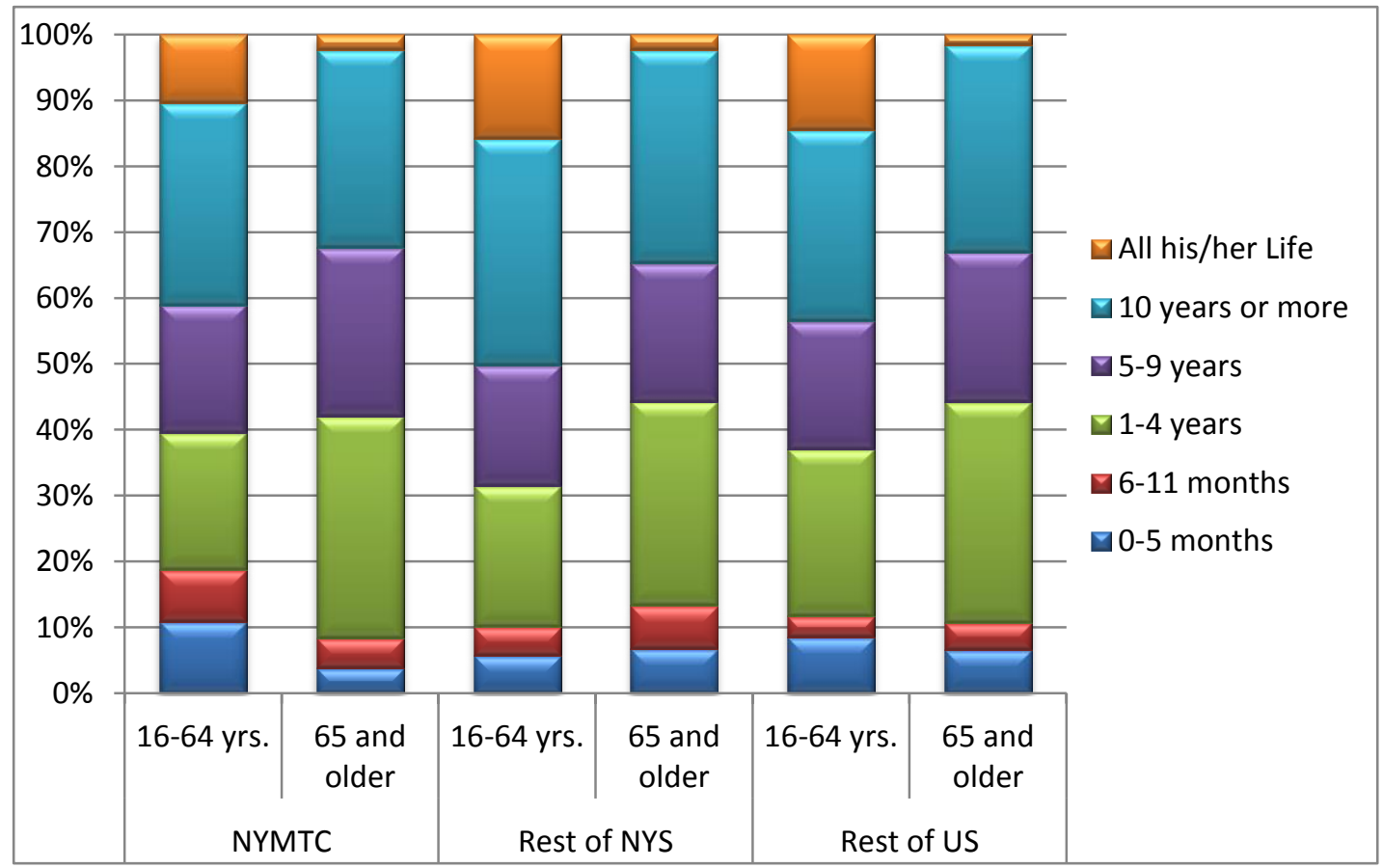

Figure 4-12. Distribution of length of disability within elderly and non-elder group. 
Table 4-3 summarizes the distributions of disabled populations by age and region for each given length-of-time-disabled category. The elderly population (age 65+ years old) was divided into more detailed age groups, while the non-elderly disabled populations age 16 to 64 years old were aggregated into one group. Statistics from Table 4-3 confirm that the majority of people with a lifelong disability belong to the younger age group (82-93\% depending on region).

Table 4-3. Age Distributions of Disabled Persons by Region within Each Length-Of-Time Disabled Category

\begin{tabular}{|c|c|c|c|c|c|c|c|}
\hline Age group & $\begin{array}{c}0-5 \\
\text { months }\end{array}$ & $\begin{array}{c}\text { 6-11 } \\
\text { months }\end{array}$ & $1-4$ years & $5-9$ years & $\begin{array}{l}10 \text { years } \\
\text { or more }\end{array}$ & $\begin{array}{c}\text { All } \\
\text { his/her } \\
\text { Life }\end{array}$ & Total \\
\hline \multicolumn{8}{|c|}{ New York MTC } \\
\hline 16-64 yrs. & $74 \%$ & $64 \%$ & $39 \%$ & $44 \%$ & $51 \%$ & $82 \%$ & $51 \%$ \\
\hline 65-69 yrs. & $11 \%$ & $13 \%$ & $5 \%$ & $9 \%$ & $13 \%$ & $4 \%$ & $9 \%$ \\
\hline 70-74 yrs. & $0 \%$ & $3 \%$ & $16 \%$ & $11 \%$ & $6 \%$ & $11 \%$ & $10 \%$ \\
\hline 75-79 yrs. & $2 \%$ & $2 \%$ & $12 \%$ & $6 \%$ & $12 \%$ & $2 \%$ & $9 \%$ \\
\hline $80-84$ yrs. & $5 \%$ & $8 \%$ & $12 \%$ & $15 \%$ & $10 \%$ & $1 \%$ & $11 \%$ \\
\hline $85+$ yrs. & $7 \%$ & $10 \%$ & $16 \%$ & $15 \%$ & $7 \%$ & $1 \%$ & $11 \%$ \\
\hline TOTAL & $100 \%$ & $100 \%$ & $100 \%$ & $100 \%$ & $100 \%$ & $100 \%$ & $100 \%$ \\
\hline \multicolumn{8}{|l|}{ Rest of NYS } \\
\hline 16-64 yrs. & $54 \%$ & $48 \%$ & $49 \%$ & $55 \%$ & $60 \%$ & $91 \%$ & $58 \%$ \\
\hline 65-69 yrs. & $16 \%$ & $10 \%$ & $5 \%$ & $10 \%$ & $10 \%$ & $2 \%$ & $8 \%$ \\
\hline 70-74 yrs. & $7 \%$ & $7 \%$ & $11 \%$ & $6 \%$ & $9 \%$ & $1 \%$ & $8 \%$ \\
\hline 75-79 yrs. & $7 \%$ & $7 \%$ & $8 \%$ & $9 \%$ & $7 \%$ & $1 \%$ & $7 \%$ \\
\hline $80-84$ yrs. & $3 \%$ & $25 \%$ & $10 \%$ & $8 \%$ & $8 \%$ & $4 \%$ & $9 \%$ \\
\hline $85+$ yrs. & $13 \%$ & $3 \%$ & $16 \%$ & $13 \%$ & $6 \%$ & $2 \%$ & $10 \%$ \\
\hline TOTAL & $100 \%$ & $100 \%$ & $100 \%$ & $100 \%$ & $100 \%$ & $100 \%$ & $100 \%$ \\
\hline \multicolumn{8}{|l|}{ Rest of US } \\
\hline $16-64$ yrs. & $65 \%$ & $53 \%$ & $53 \%$ & $55 \%$ & $57 \%$ & $93 \%$ & $59 \%$ \\
\hline 65-69 yrs. & $5 \%$ & $10 \%$ & $7 \%$ & $8 \%$ & $11 \%$ & $3 \%$ & $8 \%$ \\
\hline 70-74 yrs. & $11 \%$ & $6 \%$ & $8 \%$ & $9 \%$ & $9 \%$ & $2 \%$ & $8 \%$ \\
\hline 75-79 yrs. & $7 \%$ & $9 \%$ & $9 \%$ & $8 \%$ & $7 \%$ & $1 \%$ & $7 \%$ \\
\hline $80-84$ yrs. & $5 \%$ & $11 \%$ & $11 \%$ & $9 \%$ & $7 \%$ & $1 \%$ & $8 \%$ \\
\hline $85+$ yrs. & $8 \%$ & $11 \%$ & $13 \%$ & $11 \%$ & $7 \%$ & $1 \%$ & $9 \%$ \\
\hline TOTAL & $100 \%$ & $100 \%$ & $100 \%$ & $100 \%$ & $100 \%$ & $100 \%$ & $100 \%$ \\
\hline \multicolumn{8}{|l|}{ Entire US } \\
\hline $16-64$ yrs. & $66 \%$ & $53 \%$ & $52 \%$ & $55 \%$ & $57 \%$ & $93 \%$ & $59 \%$ \\
\hline 65-69 yrs. & $5 \%$ & $10 \%$ & $7 \%$ & $8 \%$ & $11 \%$ & $3 \%$ & $8 \%$ \\
\hline 70-74 yrs. & $10 \%$ & $6 \%$ & $8 \%$ & $9 \%$ & $9 \%$ & $2 \%$ & $8 \%$ \\
\hline 75-79 yrs. & $7 \%$ & $8 \%$ & $9 \%$ & $8 \%$ & $8 \%$ & $1 \%$ & $7 \%$ \\
\hline $80-84$ yrs. & $5 \%$ & $11 \%$ & $11 \%$ & $10 \%$ & $8 \%$ & $1 \%$ & $8 \%$ \\
\hline $85+$ yrs. & $8 \%$ & $11 \%$ & $13 \%$ & $11 \%$ & $7 \%$ & $1 \%$ & $9 \%$ \\
\hline TOTAL & $100 \%$ & $100 \%$ & $100 \%$ & $100 \%$ & $100 \%$ & $100 \%$ & $100 \%$ \\
\hline
\end{tabular}


Similarly, Table 4-4 displays the disabled population distribution by length of time disabled within each age group. This allows one to examine whether patterns in length of time disabled differs from one age group to another. Except for a slightly higher share of lifelong disability in the non-elderly group, particularly in regions outside NYMTC, no age-specific influences are visible overall.

Table 4-4. Distribution of Disabled Population by Length-of-Time Disabled Within Given Age Group by Region

\begin{tabular}{|c|c|c|c|c|c|c|c|}
\hline Age group & 0-5 months & $\begin{array}{c}\text { 6-11 } \\
\text { months }\end{array}$ & $1-4$ years & $5-9$ years & $10+$ years & $\begin{array}{c}\text { All his/her } \\
\text { Life }\end{array}$ & Total \\
\hline \multicolumn{8}{|c|}{ New York MTC } \\
\hline $16-64$ yrs. & $11 \%$ & $8 \%$ & $21 \%$ & $19 \%$ & $31 \%$ & $10 \%$ & $100 \%$ \\
\hline 65-69 yrs. & $9 \%$ & $9 \%$ & $14 \%$ & $23 \%$ & $44 \%$ & $2 \%$ & $100 \%$ \\
\hline 70-74 yrs. & $0 \%$ & $2 \%$ & $45 \%$ & $26 \%$ & $19 \%$ & $7 \%$ & $100 \%$ \\
\hline 75-79 yrs. & $2 \%$ & $1 \%$ & $39 \%$ & $17 \%$ & $40 \%$ & $1 \%$ & $100 \%$ \\
\hline $80-84$ yrs. & $4 \%$ & $5 \%$ & $30 \%$ & $32 \%$ & $29 \%$ & $0 \%$ & $100 \%$ \\
\hline $85+$ yrs. & $5 \%$ & $6 \%$ & $40 \%$ & $29 \%$ & $20 \%$ & $1 \%$ & $100 \%$ \\
\hline TOTAL & $7 \%$ & $6 \%$ & $27 \%$ & $23 \%$ & $30 \%$ & $6 \%$ & $100 \%$ \\
\hline \multicolumn{8}{|l|}{ Rest of NYS } \\
\hline 16-64 yrs. & $6 \%$ & $4 \%$ & $21 \%$ & $18 \%$ & $34 \%$ & $16 \%$ & $100 \%$ \\
\hline 65-69 yrs. & $12 \%$ & $6 \%$ & $16 \%$ & $23 \%$ & $40 \%$ & $3 \%$ & $100 \%$ \\
\hline 70-74 yrs. & $5 \%$ & $5 \%$ & $35 \%$ & $15 \%$ & $39 \%$ & $1 \%$ & $100 \%$ \\
\hline 75-79 yrs. & $6 \%$ & $5 \%$ & $29 \%$ & $25 \%$ & $33 \%$ & $1 \%$ & $100 \%$ \\
\hline $80-84$ yrs. & $2 \%$ & $15 \%$ & $30 \%$ & $17 \%$ & $30 \%$ & $5 \%$ & $100 \%$ \\
\hline $85+$ yrs. & $8 \%$ & $2 \%$ & $42 \%$ & $25 \%$ & $22 \%$ & $2 \%$ & $100 \%$ \\
\hline TOTAL & $6 \%$ & $5 \%$ & $25 \%$ & $19 \%$ & $34 \%$ & $10 \%$ & $100 \%$ \\
\hline \multicolumn{8}{|l|}{ Rest of US } \\
\hline 16-64 yrs. & $9 \%$ & $3 \%$ & $25 \%$ & $19 \%$ & $29 \%$ & $14 \%$ & $100 \%$ \\
\hline 65-69 yrs. & $5 \%$ & $4 \%$ & $26 \%$ & $21 \%$ & $42 \%$ & $3 \%$ & $100 \%$ \\
\hline 70-74 yrs. & $10 \%$ & $3 \%$ & $28 \%$ & $22 \%$ & $35 \%$ & $2 \%$ & $100 \%$ \\
\hline 75-79 yrs. & $7 \%$ & $4 \%$ & $35 \%$ & $23 \%$ & $30 \%$ & $1 \%$ & $100 \%$ \\
\hline $80-84$ yrs. & $5 \%$ & $5 \%$ & $38 \%$ & $24 \%$ & $28 \%$ & $1 \%$ & $100 \%$ \\
\hline $85+$ yrs. & $6 \%$ & $4 \%$ & $40 \%$ & $24 \%$ & $24 \%$ & $1 \%$ & $100 \%$ \\
\hline TOTAL & $8 \%$ & $4 \%$ & $29 \%$ & $21 \%$ & $30 \%$ & $9 \%$ & $100 \%$ \\
\hline \multicolumn{8}{|l|}{ Entire US } \\
\hline $16-64$ yrs. & $9 \%$ & $3 \%$ & $25 \%$ & $19 \%$ & $29 \%$ & $14 \%$ & $100 \%$ \\
\hline 65-69 yrs. & $5 \%$ & $5 \%$ & $25 \%$ & $21 \%$ & $42 \%$ & $3 \%$ & $100 \%$ \\
\hline 70-74 yrs. & $9 \%$ & $3 \%$ & $29 \%$ & $22 \%$ & $34 \%$ & $2 \%$ & $100 \%$ \\
\hline 75-79 yrs. & $7 \%$ & $4 \%$ & $35 \%$ & $22 \%$ & $31 \%$ & $1 \%$ & $100 \%$ \\
\hline $80-84$ yrs. & $5 \%$ & $5 \%$ & $37 \%$ & $24 \%$ & $28 \%$ & $1 \%$ & $100 \%$ \\
\hline $85+$ yrs. & $6 \%$ & $4 \%$ & $40 \%$ & $25 \%$ & $24 \%$ & $1 \%$ & $100 \%$ \\
\hline TOTAL & $8 \%$ & $4 \%$ & $29 \%$ & $21 \%$ & $30 \%$ & $9 \%$ & $100 \%$ \\
\hline
\end{tabular}




\subsection{TRAVEL LIMITATIONS DUE TO DISABILITY}

In addition to the questions of "with condition that made it difficult to travel outside home" and the "length of time disabled" discussed above, the 2009 NHTS also gathered information associated with potential travel impacts due to such a medical condition. A series of seven travel limitations was asked of the NHTS survey respondents, include whether a medical condition has resulted in:

- Limiting driving to daytime

- Using bus/subway less frequently

- Asking others for rides

- Giving up driving

- Using special transit services

- Using a reduced fare taxi

- Reduced day-to-day travel

Note that a person could answer "yes" to one or more limitations listed above. Therefore, they are not mutually exclusive questions. In addition, a person might choose to answer some of these limitation questions but not all (i.e., coded as "unreported" for a given question in NHTS). For this study, the share of disabled persons having a given limitation was calculated based on those who provided "yes" or "no" responses only, unless otherwise specified.

Using 2009 NHTS data, Figure 4-13 displays the shares of disabled persons who reported having a given limitation by elderly status and where they lived (either NYS or Rest of the U.S.) ${ }^{16}$. Between elderly and non-elderly (16-64 years old) disabled populations the most visible difference is on "Given up driving." Significantly more disabled elderly reported having such a limitation than their younger counterparts, regardless where they lived (top and bottom half of the chart for NYS and Rest of U.S., respectively). Within NYS, the disabled elderly also had a higher rate of using reduced fare taxi than their disabled younger neighbors.

\footnotetext{
${ }^{16}$ NHTS sample size limitation prohibits the analysis be performed at a more disaggregated geographic regions.
} 


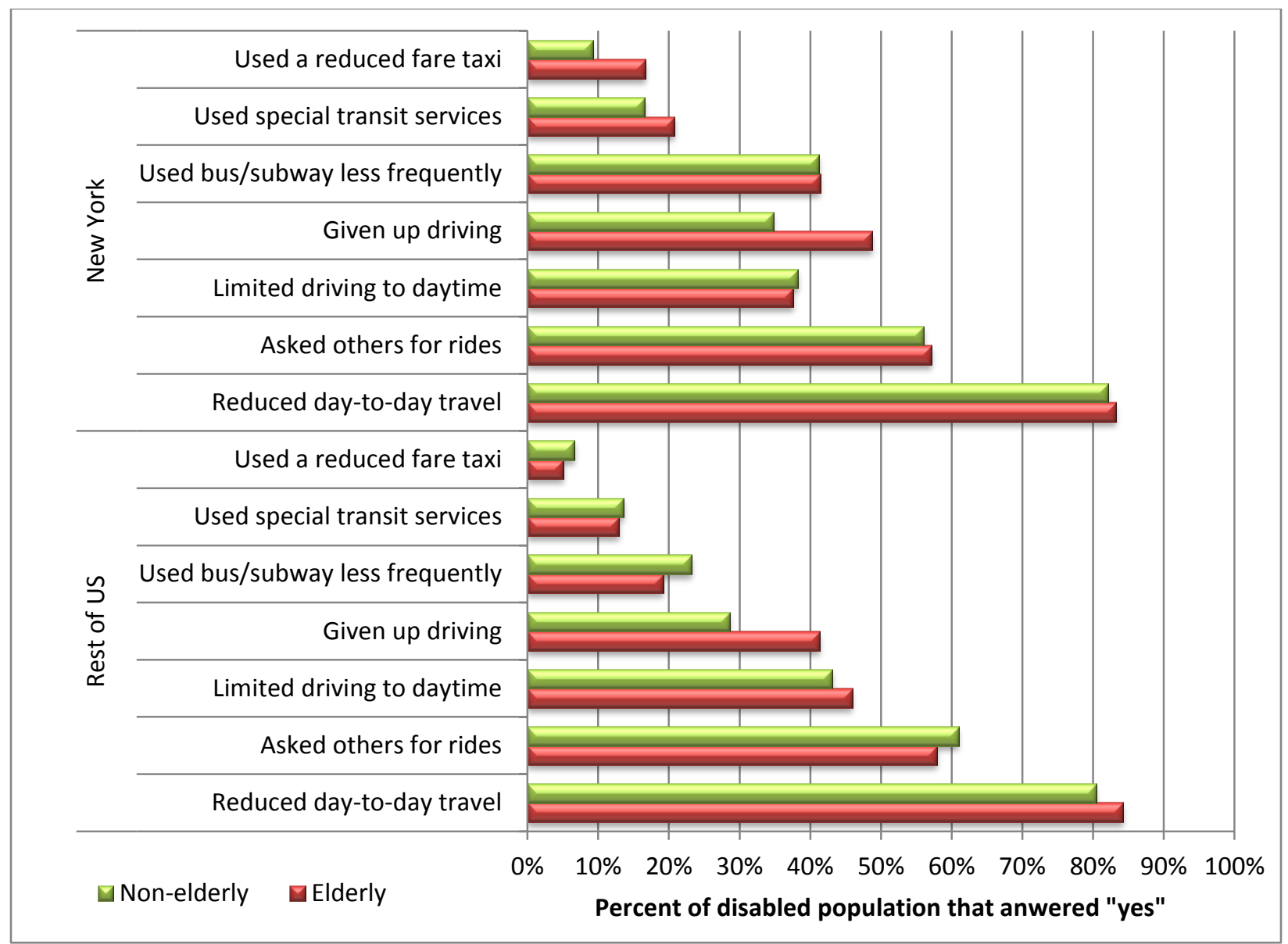

Figure 4-13. Shares of disabled population with given travel limitations by elderly status and region.

Furthermore, regional differences for limitation questions associated with use of transit or taxi are clearly noticeable in Figure 4-13. Disabled people that lived in NYS were more likely to report limitations in areas of "used a reduced fare taxi," "used special transit services "17," and "used bus/subway less frequently" than disabled persons that lived outside NYS. This would mostly relate to the fact that transit/taxi services are more readily available in NYS (particularly in NYMTC) than elsewhere in the U.S. Interestingly, outside NYS, the disabled elderly population was slightly less likely to report having the three transit/taxi related limitations than their younger counterparts were.

Table 4-5 summarizes the 2009 NHTS population (age 16 years and older only) by disability status and by urban/rural region. Due to the fact urban areas are where populations and business concentrate, it is expected that the majority of the population are located in urban regions, regardless of one's disability status.

\footnotetext{
${ }^{17}$ Special transit services such as dial-a-ride.
} 
Table 4-5. Population by Urban/Rural Type by Disability Status (2009 NHTS)

\begin{tabular}{|l|r|r|r|r|}
\hline \multicolumn{1}{|c|}{ Region } & NYMTC & Rest of NYS & Rest of US & Entire US \\
\hline \multicolumn{5}{|c|}{ Disabled } \\
\hline Rural & 52,185 & 169,889 & $4,864,028$ & $5,086,102$ \\
\hline Urban & $1,060,458$ & 415,695 & $17,722,606$ & $19,198,759$ \\
\hline TOTAL & $1,112,643$ & 585,585 & $22,586,633$ & $24,284,861$ \\
\hline \multicolumn{5}{|c|}{ Not Disabled } \\
\hline Rural & 468,270 & $1,801,164$ & $49,382,769$ & $51,652,203$ \\
\hline Urban & $8,451,187$ & $3,218,857$ & $150,323,075$ & $161,993,118$ \\
\hline TOTAL & $8,919,457$ & $5,020,020$ & $199,728,944$ & $213,668,421$ \\
\hline
\end{tabular}

To examine whether urban settings or city sizes might influence where the disabled population resides, shares of urban living were compared between disabled and non-disabled population groups and presented in Figure 4-14. Nearly all NYMTC populations lived in urban areas because of its regional characteristics, thus no influence on disability was expected. Outside NYMTC, Figure 4-14 indicates that slightly higher shares of the disabled population did live in urban areas. About $71 \%$ of the disabled population in NYS lived in urban areas outside the NYMTC, while only $64 \%$ of their non-disabled counterparts lived in an urban setting. The shares are closer for those that lived outside NYS, where $78 \%$ of the disabled population and $75 \%$ of the non-disabled population lived in urban areas.

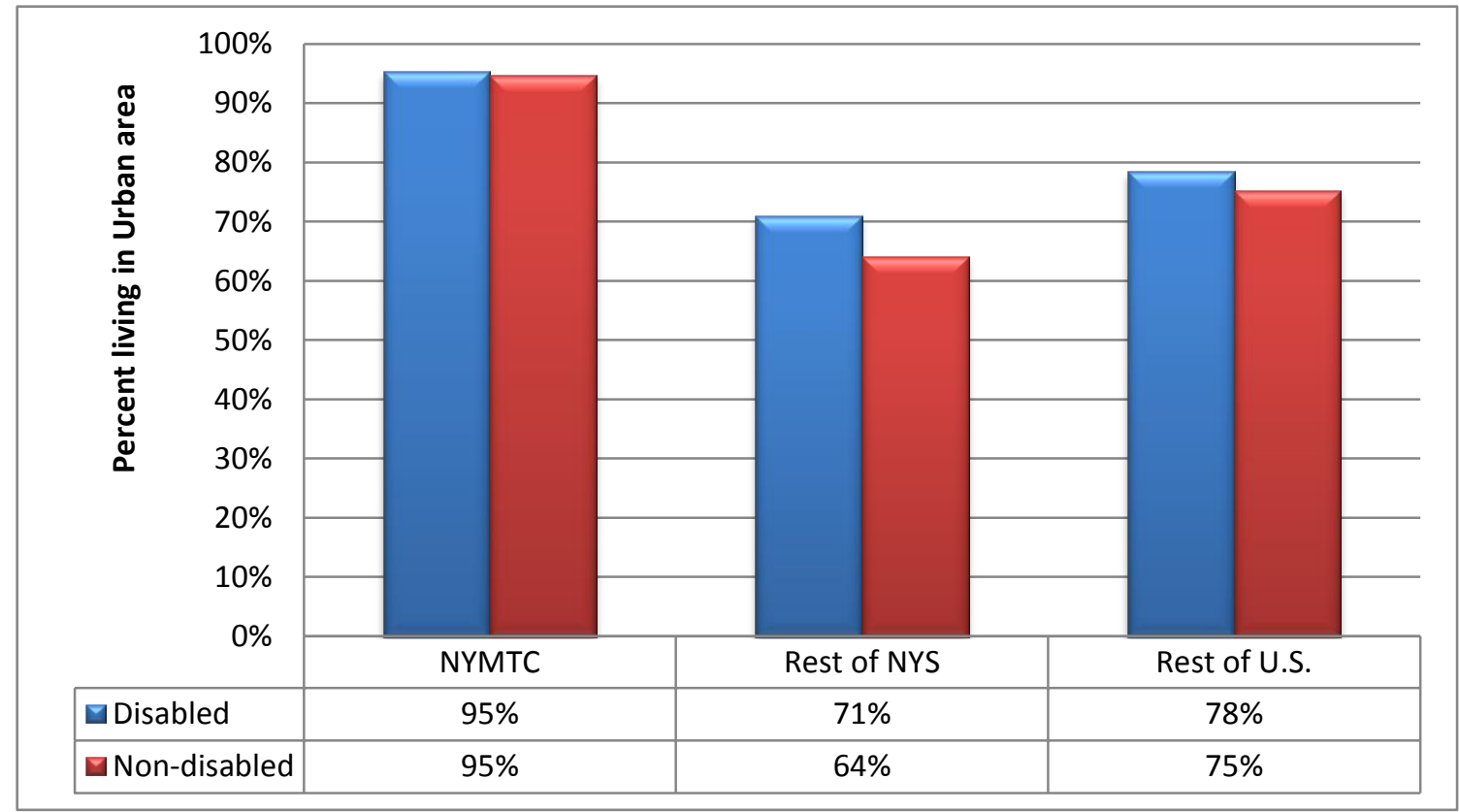

Figure 4-14. Percent of populations that lived in urban area, by disability status and region.

Further analysis of the population distributions by various metropolitan statistical area sizes (e.g., population of 3 million or more, 1-3 million, 500,000 to 1 million, etc.), between shares of disabled and non-disabled population groups, did not yield any noticeable differences among regions. 


\section{MOBILITY OF NYS DISABLED PERSONS}

This section examines travel behaviors of NYS disabled residents in 2009, which includes analyzing the level of travel by disabled persons, assessing any regional differences, determining their travel patterns, as well as identifying issues that might have associations with these travelers. Potential influences of not having a vehicle (zero-vehicles), as well as household size (e.g., one-person), on the travel behaviors of the disabled population were also examined.

\subsection{IMPACTS OF DISABILITY ON TRIP PURPOSES}

Figure 5-1 displays 2009 NHTS trip distributions by trip purpose, traveler disability status, and traveler's region of residence. Interestingly, the most visible difference between trip shares for disabled and non-disabled populations, among travelers from all regions, appears to be a shift of shares between trips made to "earn a living" and those conducted for "family and personal business" purposes.

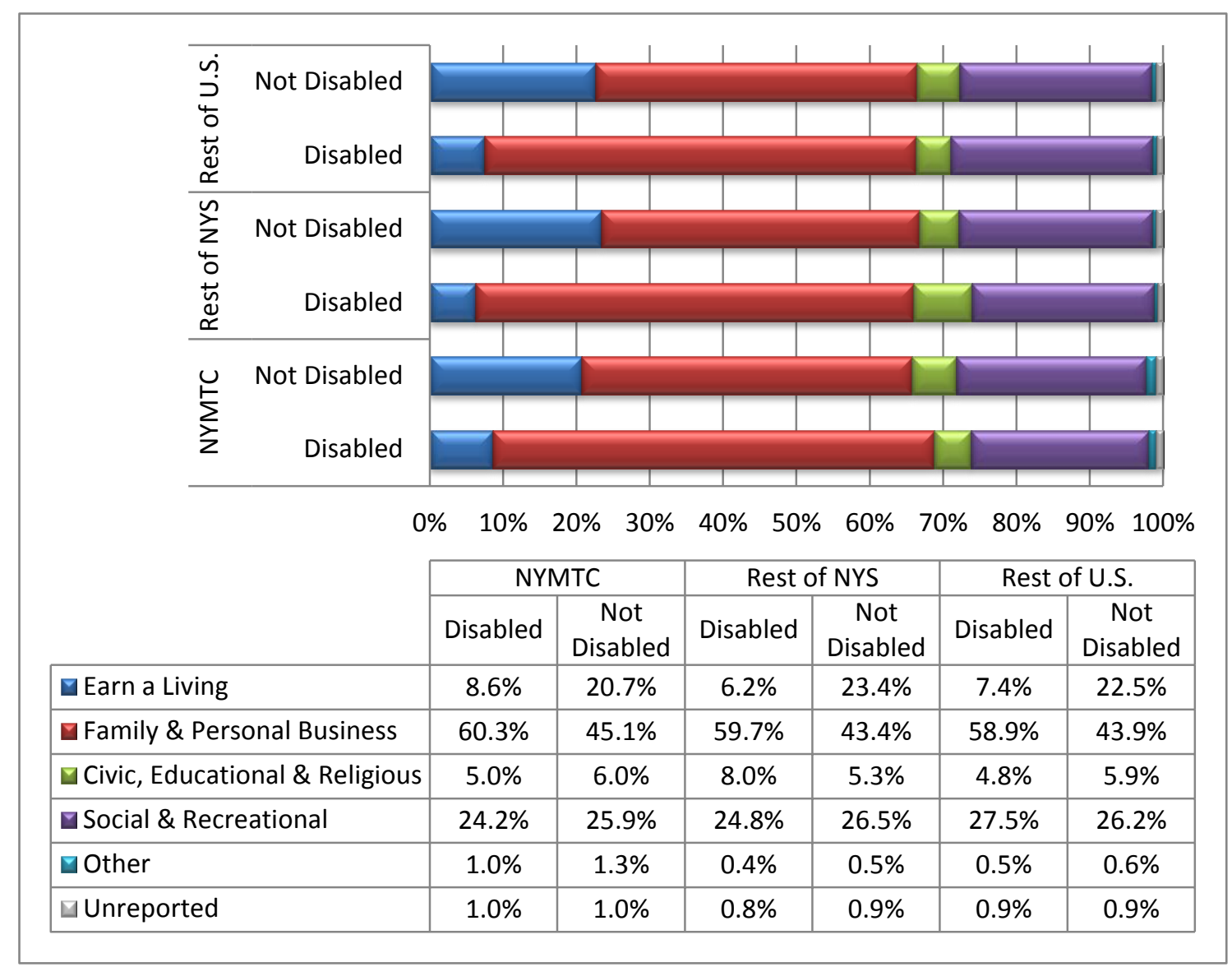

Figure 5-1. Distribution of trips by trip purpose, by disability status and region.

Specifically, Figure 5-1 shows that for trips made by NYMTC disabled travelers in 2009, $9 \%$ were work trips (i.e., earn a living) and $60 \%$ of their trips were for activities associated with 
family and personal business. On trips made by the non-disabled population from this same region, however, $21 \%$ of their trips were for work and the other $45 \%$ of were for "family and personal business" purposes. Consistent with an earlier finding (Section 4.1), disabled persons have a smaller likelihood of being in the work force when compared with their non-disabled counterparts.

Furthermore, patterns of trip purposes on trips made by NYS residents that lived outside NYMTC and on trips taken by persons that lived outside NYS are quite similar (see Figure 5-1). Both show about $60 \%$ of trips made by disabled populations in 2009 were for "family and personal business" purposes, and only about $6 \%-7 \%$ of their trips were made for work (earn a living) purposes. Both regions show $23 \%$ of trips taken by their non-disabled residents were for the purposes of "earn a living" and another $43 \%-44 \%$ of trips were to take care of family and personal business. Interestingly, the combined shares for the two trip purposes ("earn a living" and "family and personal business") taken by those that lived elsewhere outside the NYMTC summed up to around $67 \%$, of all trips made by residents from each respective region, regardless of disability status of the population. Note that patterns on shares of travel made for all other trip purposes (i.e., other than purposes of "earn a living" and "family \& personal business") were not significantly different between the disabled and non-disabled group. Moreover, no significant regional differences could be identified in the shares of all other trip purposes.

\subsection{INFLUENCE OF DISABILITY ON MODE CHOICES}

\subsubsection{Overview of Mode Share by Disability Status}

As mentioned in previous discussions, vehicle ownership in NYMTC is not as critical for one's mobility per se as in other areas of the country. This is mainly due to its extensive public transit network, widely available taxi system, and walkability within the NYMTC region. Therefore, combined public transit, taxi, and walking accounted for a significant mode share in of NYMTC residents to conduct their daily activities, regardless of disability status.

Specifically, Figure 5-2 shows that the combined mode share for public transportation (transit), taxi, and walking accounted for over half of all trips (53\%) made by the disabled NYMTC traveling population in 2009 , while $47 \%$ of trips made by the non-disabled NYMTC population utilized these same modes during 2009. Clearly, traveling as a driver by privately owned vehicle $(\mathrm{POV})$ is less likely among the disabled population than their non-disabled counterparts who lived in the same region, accounting for 24\% mode share for disabled NYMTC residents' travels and $41 \%$ for trips taken by the non-disabled NYMTC population. On the other hand, disabled persons are more likely to travel as passengers in POVs than their non-disabled counterparts are-mode shares of about $19 \%$ versus $11 \%$ for trips made by disabled and non-disabled NYMTC residents, respectively. 


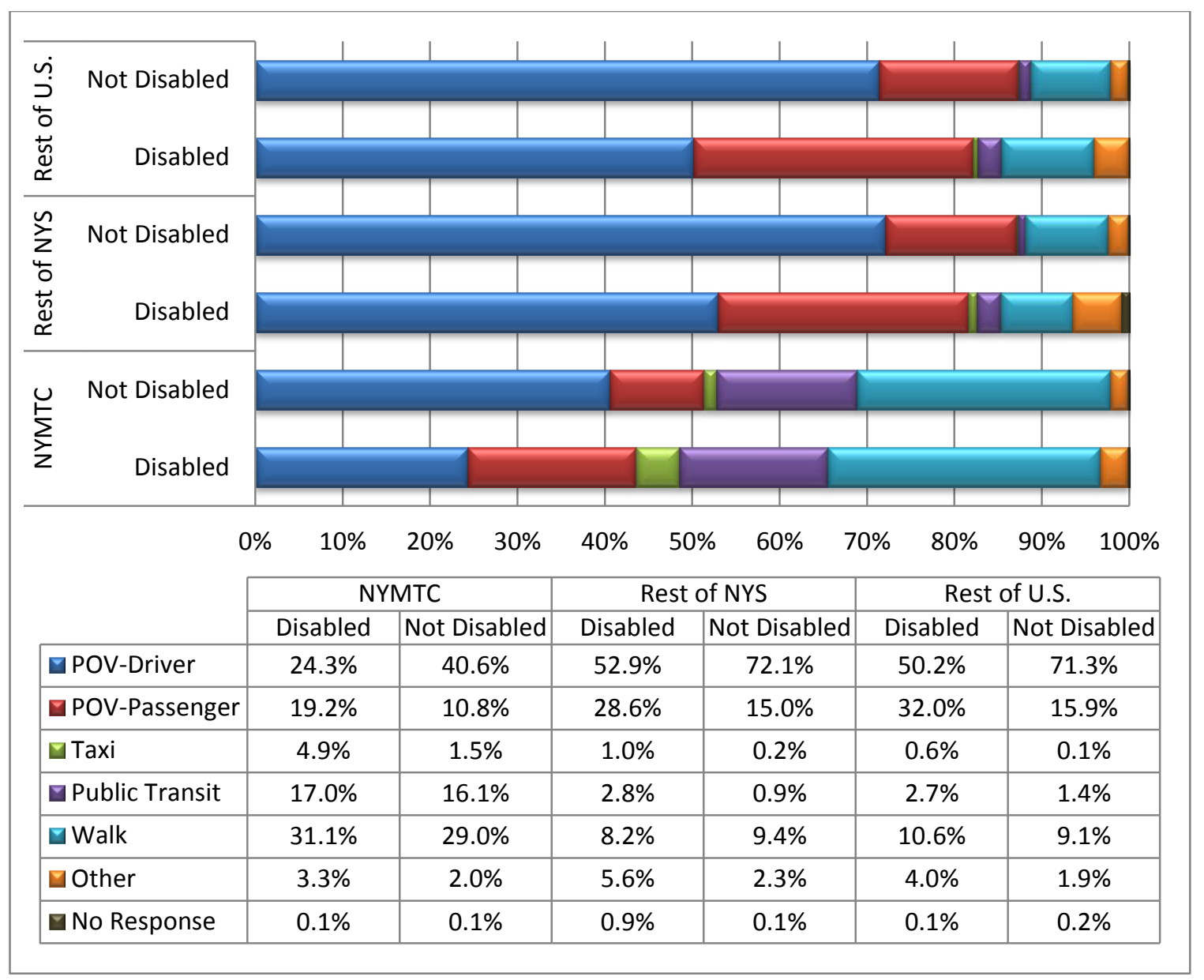

Figure 5-2. Mode shares by disability status and region (2009 NHTS).

Outside NYMTC, traveling as a POV driver is the most common means of transportation mode used by both the disabled and the non-disabled population. The mode shares of traveling by POV (either as a driver or as a passenger), for residents of the Rest of NYS and those that lived in the Rest of U.S. were very similar - about $82 \%$ on trips made by the disabled population and $87 \%$ by the non-disabled population in both regions. In terms of driving status, however, a disabled person is more likely to travel as a POV passenger, while a non-disabled person is more likely to drive. As seen in Figure 5-2, for people that lived in the Rest of NYS, mode share POV-driver accounted for $53 \%$ of trips taken by the disabled population, and $72 \%$ of those made by non-disabled travelers. On the contrary, mode share for traveling by the disabled as a POVpassenger for the Rest of NYS population is $29 \%$, and $15 \%$ of trips made by non-disabled population from the same region. As pointed out above, the patterns in mode shares for trips made by disabled and non-disabled populations from outside the NYS region are similar to those of the Rest of NYS. 


\subsubsection{Mode Choices among Zero-Vehicle Households by Disability Status}

As discussed in Section 4.1 above, the percent of zero-vehicle households is significantly higher in disabled population than that of non-disabled populations (see Figure 4-6). Data from NHTS was further examined to investigate how mode choices were impacted in disabled households that did not own any vehicles. Due to the concern of small sample size, geographic regions used for this comparison were limited to zero-vehicle households within areas of NYC (5-county), NYS, and the Rest of U.S., while specific statistics for Manhattan are presented only when sample size permits.

The differences in mode choice by disabled and non-disabled households are clearly evidenced in Figure 5-3. Within NYS areas (including NYS, NYC, and Manhattan), the most visible modechoice differences are in the use of public transit and taxi modes, as well as walking. Specifically, disabled zero-vehicle households from NYS used public transportation (public transit or taxi) for nearly $42 \%$ of their total person-trips taken during 2009 ; while only $30 \%$ of total person-trips made by their counterpart non-disabled neighbors were taken on public transportation. As expected, the share of using public transportation on daily travels made by disabled households within NYC was higher, which has a $45 \%$ share versus the $34 \%$ share among non-disabled households from the same region in 2009. Note that, in Figure 5-3, modeshare statistics on "POV-driver" and "Other" for the Manhattan area were not reliable due to small sample size.

Walking is a common mode of transportation in NYS (particularly in NYC, see Figure 5-2), this is especially true among zero-vehicle households. As seen in Figure 5-3, walking is the primary mode of transportation for trips made by zero-vehicle households that lived in NYS regardless of their disability status. Specifically, over half of person-trips made by non-disabled zero-vehicle NYS households in 2009 were walk trips; where walking accounted for nearly $63 \%$ of trips taken by non-disabled zero-vehicle households in Manhattan. Not surprisingly, mode shares of walking were lower among zero-vehicle disabled households than the shares for their non-disabled counterparts, since walking might be limited for persons with certain disabilities. Nevertheless, walking still held a significant share among zero-vehicle disabled households in NYS; accounting for over $45 \%$ of their total person-trips made in 2009 . Within NYC, $48 \%$ of trips made by zero-vehicle disabled households were by walking; this share jumped to $54 \%$ for those households in Manhattan.

Outside NYS, persons from disabled zero-vehicle households are more likely to ride with others (as a POV passenger) than their non-disabled counterparts did. Specifically, "POV-passenger" accounted for about $33 \%$ of total persons-trips made by disabled zero-vehicle households outside of NYS, while only $23 \%$ of person-trips among those non-disabled zero-vehicle households utilized the same mode. Again, walking was a major means of transportation for zero-vehicle households, regardless of their disability status. As Figure 5-3 presents, walking accounted for 
$38 \%$ of total person trips taken by non-disabled zero-vehicle households in 2009 , while this share was reduced to $29 \%$ among their disabled counterpart neighbors.

\begin{tabular}{|c|c|c|c|c|c|c|c|c|c|}
\hline \multirow{12}{*}{ 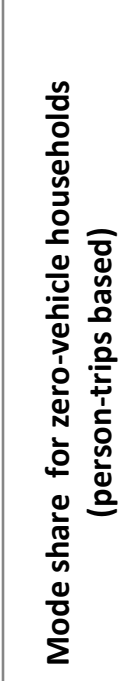 } & \multicolumn{9}{|l|}{$100 \%$} \\
\hline & \multicolumn{9}{|l|}{$90 \%$} \\
\hline & \multicolumn{9}{|l|}{$80 \%$} \\
\hline & \multicolumn{9}{|l|}{$70 \%$} \\
\hline & \multicolumn{9}{|l|}{$60 \%$} \\
\hline & \multicolumn{9}{|l|}{$50 \%$} \\
\hline & \multicolumn{9}{|l|}{$40 \%$} \\
\hline & \multicolumn{9}{|l|}{$30 \%$} \\
\hline & \multicolumn{9}{|l|}{$20 \%$} \\
\hline & \multicolumn{9}{|l|}{$10 \%$} \\
\hline & & $\begin{array}{c}\text { Non- } \\
\text { disabled }\end{array}$ & Disabled & $\begin{array}{c}\text { Non- } \\
\text { disabled }\end{array}$ & Disabled & $\begin{array}{c}\text { Non- } \\
\text { disabled }\end{array}$ & Disabled & $\begin{array}{c}\text { Non- } \\
\text { disabled }\end{array}$ & Disabled \\
\hline & & Res & U.S. & \multicolumn{2}{|c|}{ NYS } & \multicolumn{2}{|c|}{ NYC (5-county) } & \multicolumn{2}{|c|}{ Manhattan } \\
\hline \multicolumn{2}{|c|}{ 甲Other } & $10.1 \%$ & $13.7 \%$ & $4.4 \%$ & $3.6 \%$ & $3.9 \%$ & $1.9 \%$ & $2.8 \%$ & 0 \\
\hline \multicolumn{2}{|c|}{ 口Walk } & $38.1 \%$ & $28.8 \%$ & $53.2 \%$ & $45.1 \%$ & $54.1 \%$ & $47.5 \%$ & $62.6 \%$ & $53.7 \%$ \\
\hline \multicolumn{2}{|c|}{ Q Public Transit } & $18.8 \%$ & $16.2 \%$ & $29.4 \%$ & $36.1 \%$ & $30.5 \%$ & $40.4 \%$ & $22.1 \%$ & $34.6 \%$ \\
\hline \multicolumn{2}{|c|}{ 口Taxi } & $1.1 \%$ & $3.0 \%$ & $3.6 \%$ & $5.3 \%$ & $3.7 \%$ & $4.5 \%$ & $5.3 \%$ & $8.1 \%$ \\
\hline \multicolumn{2}{|c|}{ POV-Passenger } & $23.2 \%$ & $32.6 \%$ & $7.1 \%$ & $7.9 \%$ & $6.3 \%$ & $4.9 \%$ & $3.6 \%$ & $1.6 \%$ \\
\hline \multicolumn{2}{|c|}{ QPOV-Driver } & $8.8 \%$ & $5.7 \%$ & $2.2 \%$ & $2.1 \%$ & $1.6 \%$ & $0.7 \%$ & $3.5 \%$ & 0 \\
\hline
\end{tabular}

Figure 5-3. Mode shares for zero-vehicle households by disability status and region.

\subsection{HOUSEHOLD SIZE IMPACTS ON MODE CHOICE BY DISABILITY STATUS}

This section analyzes the conceivable influence of household size on mode choice made by travelers from disabled households. Comparisons of mode shares, by disability status and by region (NYC, NYS, and the Rest of U.S.), were conducted for each of the household size types (one-person, two-person, three-or-more-person). Due to sample size limitations, statistics on household-size breakdowns of disabled households from Manhattan, in many cases, resulted in unreliable estimates. Thus, Manhattan statistics were not included in some of the discussions presented below.

\subsubsection{One-Person Households}

Statistics presented in Figure 5-4 show that, among trips made by one-person households in 2009 , there were significant differences in mode shares by disability status of the households, as well as by location of those households. When traveling by vehicle, trips made by the person from a one-person disabled household were about 3 times as likely to be as a passenger than their 
non-disabled counterparts, regardless of the locations of households. Certainly, POV is a necessary mode of transportation for one-person households outside NYS, even for disabled households (combined-POV share of 75\%) compared to one-person households in NYS (combined-POV share of $51 \%$ ).

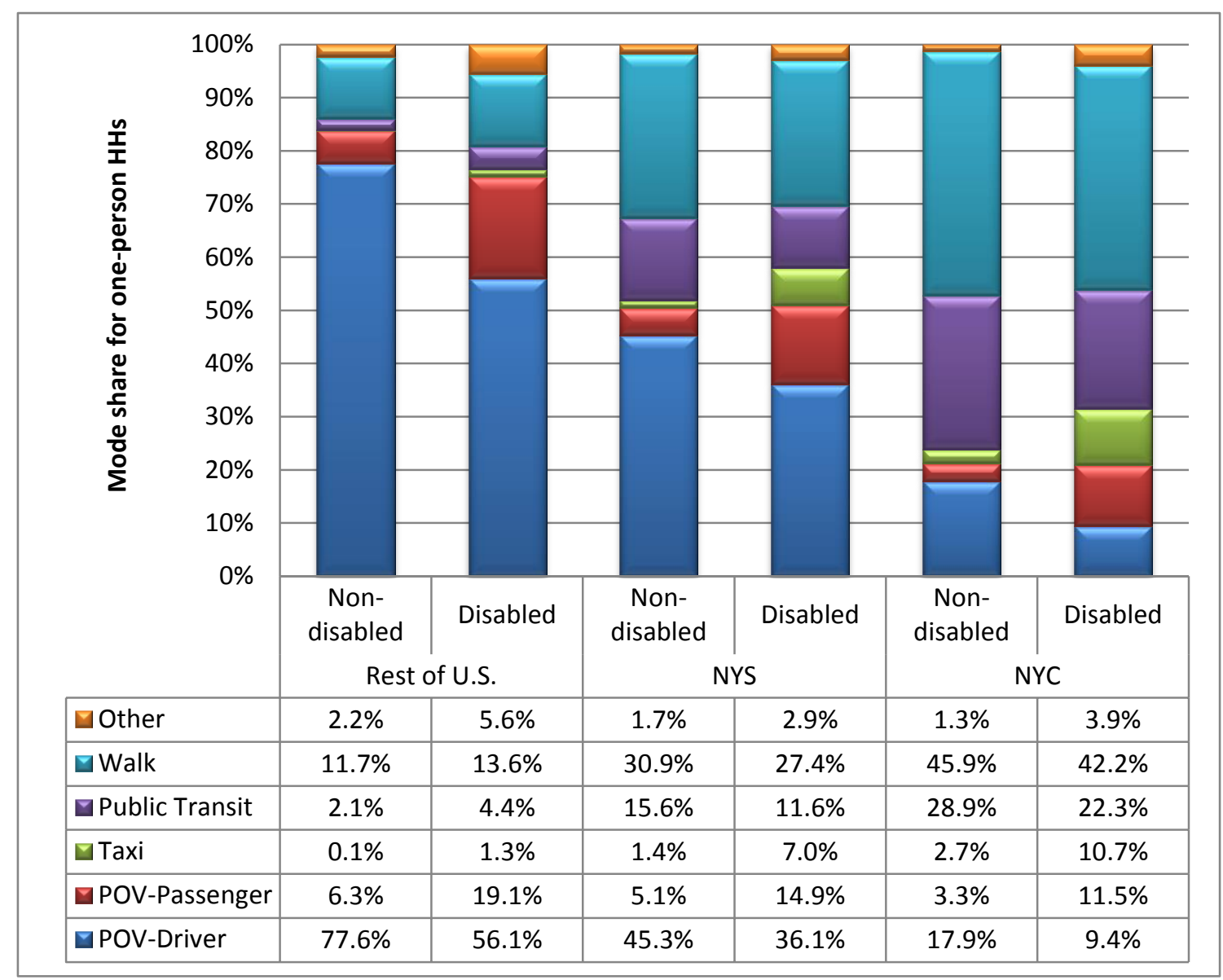

Figure 5-4. Mode share among one-person households by disability status and region.

As shown in Figure 5-4, using taxi as the mode of choice was significantly more common among the one-person disabled households than in their non-disabled counterparts. Particularly true for New Yorkers, taxi use accounted for $7 \%$ of total person-trips taken by the one-person disabled households from NYS; while taxis were only used in less than $1.5 \%$ of person-trips made by the non-disabled one-person households from the same region. Furthermore, taxis also accounted for nearly $11 \%$ of total trips made by the one-person disabled households from NYC, versus only $3 \%$ among their non-disabled counterparts.

Interestingly, the share of person trips taken on public transit was only about $12 \%$ among the one-person disabled households in NYS, versa $16 \%$ of trips taken by the non-disabled oneperson households from the same area during 2009. For NYC, public-transit mode shares were $29 \%$ and $22 \%$ for the one-person non-disabled and the one-person disabled households, respectively. This is different from mode share patterns examined so far (see Figure 5-2 and 
Figure 5-3). In those cases, the share of public transit use was higher among the disabled households than that in the non-disabled households.

Differences in shares of walking trips between the "one-person disabled" and the "one-person non-disabled" households were not as significant as discussed above. Figure 5-4 shows that walking was used in about $14 \%$ of person trips taken by the one-person disabled households in the Rest of U.S., versus $12 \%$ by their non-disabled counterparts in the same region. In NYS, walking accounted for $31 \%$ of trips made by the one-person non-disabled households and $27 \%$ of trips taken by the one-person disabled households in 2009. A similar $4 \%$ decrease in mode shares of walking, from $46 \%$ among the one-person non-disabled households to $42 \%$ for the oneperson disabled households, was also observed in NYC.

\subsubsection{Two-Person Households}

For households with two persons, Figure 5-5 shows a dramatic increase in the mode shares of "POV-passenger" from those seen above for one-person households (Figure 5-4). With an added person in the household, POV mode as a whole (including both POV-driver and POV-passenger) appeared to have become a more favorable mode for trips taken by both disabled and nondisabled households. This POV mode (counting both POV-driver and POV-passenger) was used in $87 \%$ of trips made during 2009 by the two-person disabled, as well as the two-person nondisabled, households from the Rest of U.S. This combined-POV mode share was $64 \%$ for the two-person non-disabled households from NYS, up from the $50 \%$ for the one-person nondisabled households from the same region. This mode also accounted for about $60 \%$ of trips made by the two-person disabled households in NYS, increased from the 51\% seen in Figure 5-4 for the one-person disabled households in that region. For two-person households in NYC, their POV mode shares were $27 \%$ and $25 \%$ for non-disabled and disabled households in 2009, respectively.

Note that the increase of POV mode shares had a noticeable effect on mode shares of public transportation (including transit and taxi) and walking. Specifically, the share of taxi for disabled households in NYS decreased significantly from $7 \%$ for the one-person disabled households (Figure 5-4) to 2\% for the two-person disabled households (Figure 5-5). Similarly, the share of the taxi serving disabled households in the NYC area dropped from $11 \%$ for the oneperson disabled households to about $3 \%$ in the two-person disabled households. The shares of public transportation for both disabled and non-disabled households in NYS, as well as those within NYC, also saw a decrease as their household size increased by one person. The only exception was for the share of walking trips in $\mathrm{NYC}$; it actually increased $7 \%$ in shares with the addition of one person in each household.

For non-disabled households in NYS, the shares of both walking and public transportation dropped significantly, from $31 \%$ (walking) and 17\% (public transportation) for one-person households to $23 \%$ and $11 \%$, respectively, among two-person households. Outside NYS, these 
mode-share shifts were not as substantial between the two size-categories for the non-disabled households.

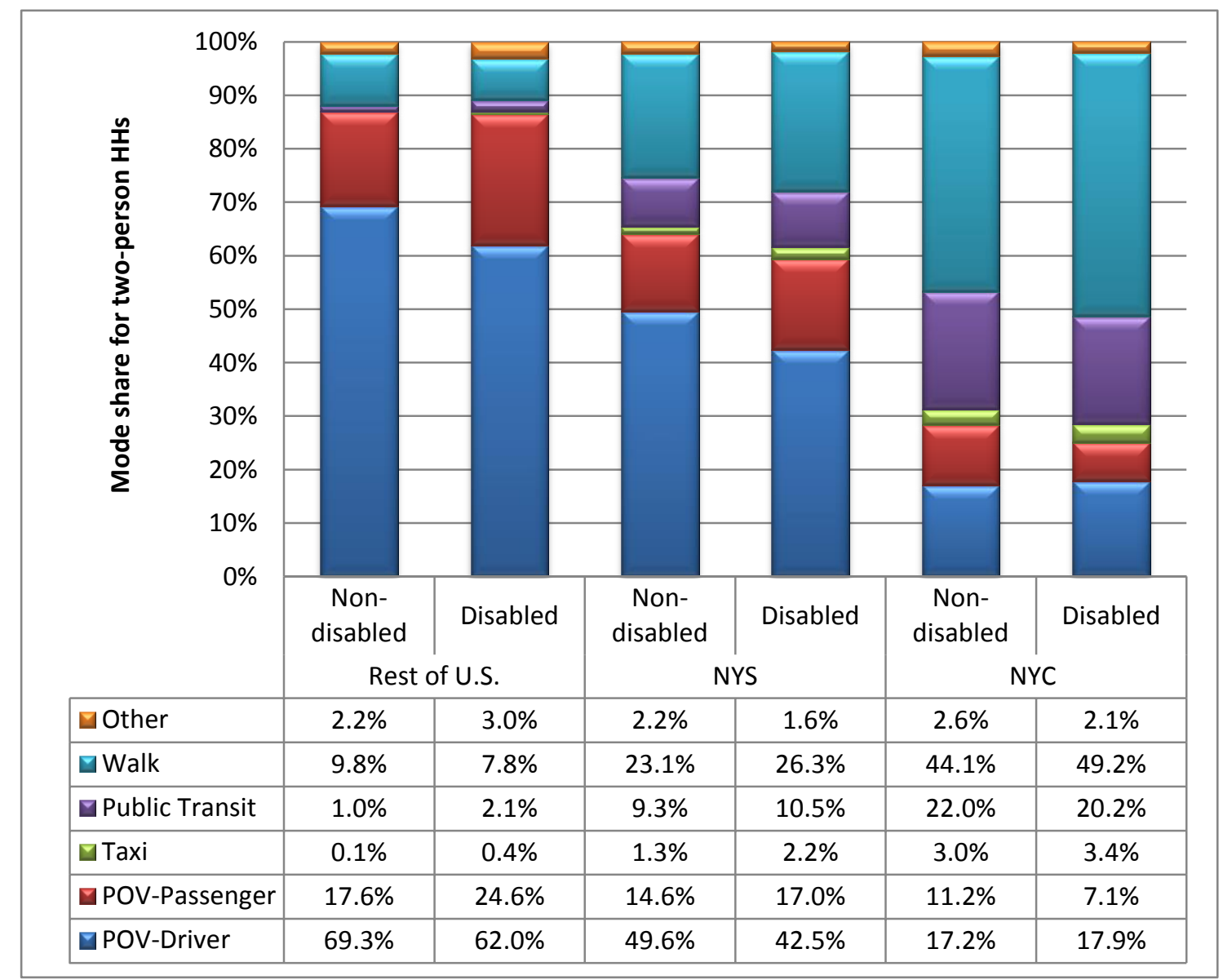

Figure 5-5. Mode shares among two-person households by disability status and region.

For disabled households outside NYS the share of walking as a mode decreased from $14 \%$ for one-person disabled households to $8 \%$ for two-person disabled households. Similarly, comparing statistics between these household size categories, the mode shares of public transportation (transit and taxi) dropped from 6\% in Figure 5-4 to less than 3\% (in Figure 5-5) in households from the Rest of U.S.

\subsubsection{Households with Three or More Persons}

The shares of "POV-passenger" mode continued to grow as the household size increased regardless of disability status or geographic location (see Figure 5-6 compared with Figure 5-4 and Figure 5-5). At the same time, the shares of "POV-driver" mode on trips made by households with three-or-more persons dropped at least $10 \%$ from their respective shares shown in Figure 5-5 (i.e., two-person households) for households in the Rest of U.S., and a 5\% decrease for both disabled and non-disabled households in NYS. 


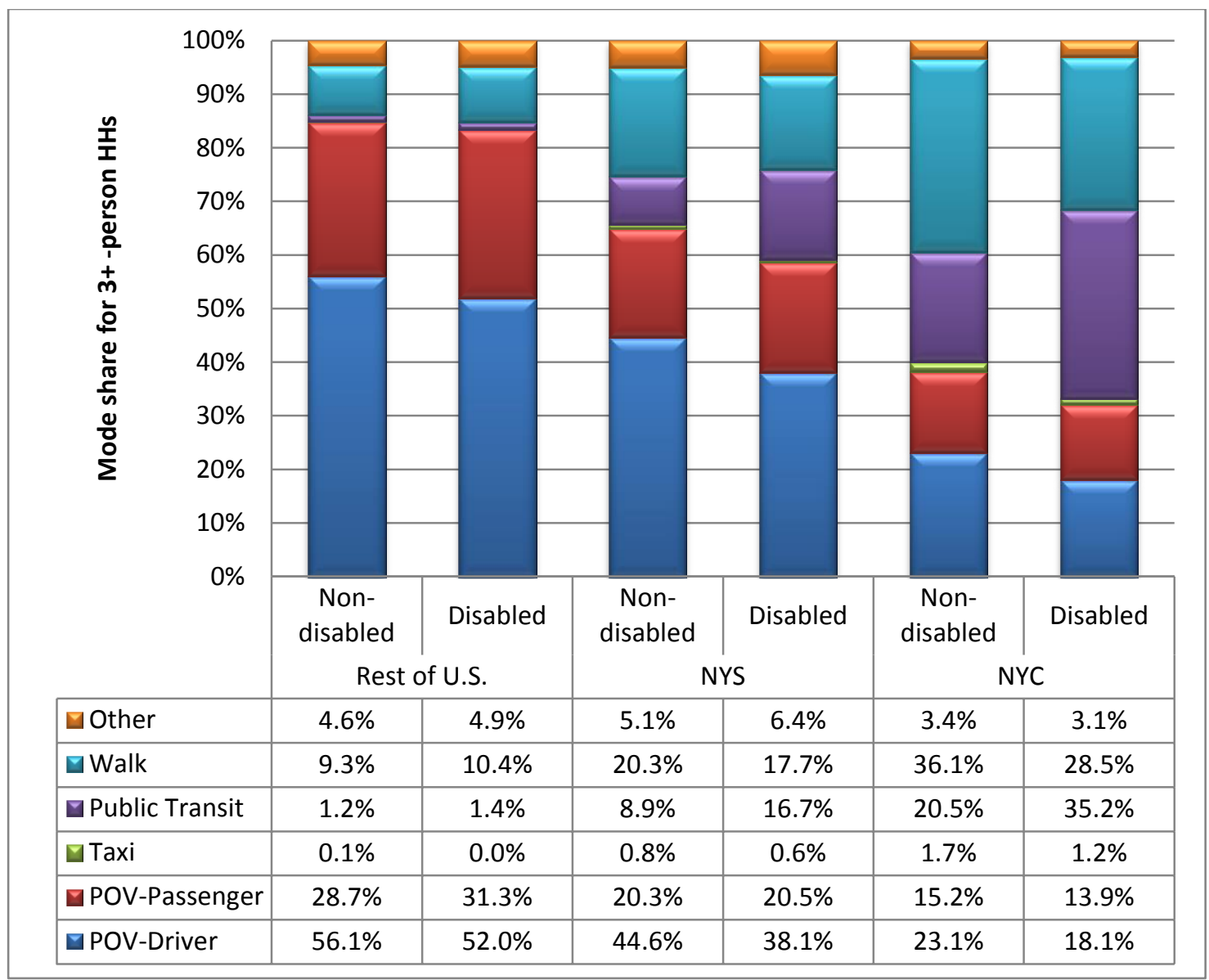

Figure 5-6. Mode shares among three-or-more person households by disability status and region.

The only exception is in trips made by larger households from NYC, where the shares of "POVdriver" in both disabled and non-disabled households increased from their respective two-person household neighbors. Public transit share for large-size disabled households in NYC also show a significant increase from those of their smaller-sized household neighbors. Over one in three trips made by NYC disabled large households (with 3+ persons) were by public transit, while less than one in four trips taken by their smaller-sized household counterparts utilized public transit.

To allow easier comparisons of mode share changes over increased household size as discussed above (see Figure 5-4 through Figure 5-6), statistics from all three household size categories were summarized by major mode: POV-driver, POV-passenger, public transportation (transit and taxi), and walking in Figure 5-7. 


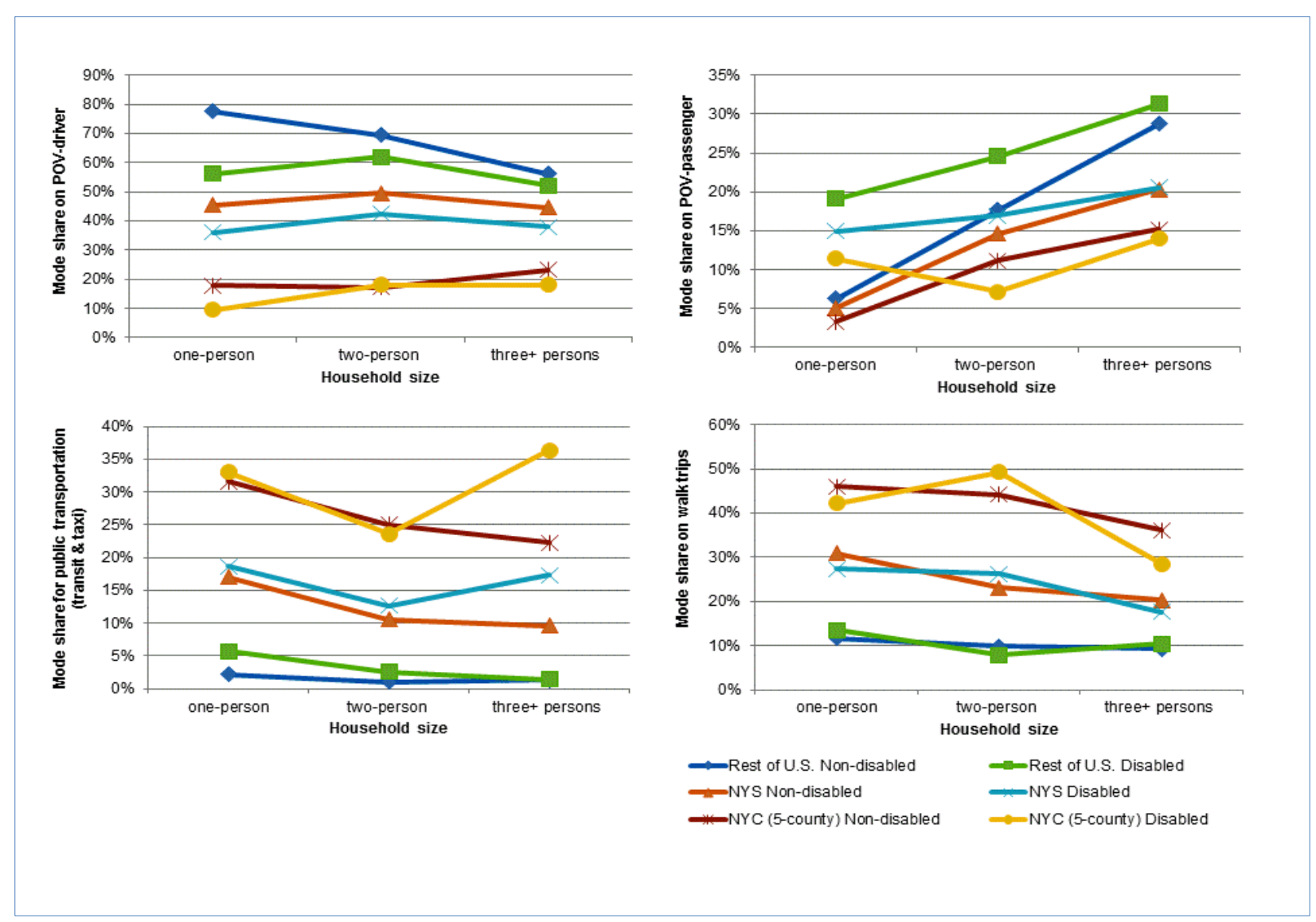

Figure 5-7. Mode shares by major mode of transportation over household size, region, and disability status.

\subsection{OVERVIEW ON IMPACTS OF DISABILITY ON TRIP RATES}

\subsubsection{Average Daily Person-Trip Rate}

Results from analyzing the 2009 NHTS data reflect that disabled persons traveled less frequently than their non-disabled neighbors did in 2009 regardless of where they lived. As shown in Figure 5-8, a typical disabled person from NYMTC made 2.3 trips per day while a typical nondisabled person from the same community took nearly four trips each day. Outside NYMTC, on average, a disabled traveler took fewer trips than his /her non-disabled counterpart did. Overall, according to 2009 NHTS data, a disabled person traveled roughly $60 \%$ of the volume made by a non-disabled person daily in 2009 , no matter where the person lived. That is, disability status has a significant impact on the person-trip frequency, but geographic region did not influence trip frequencies in any significant way. 


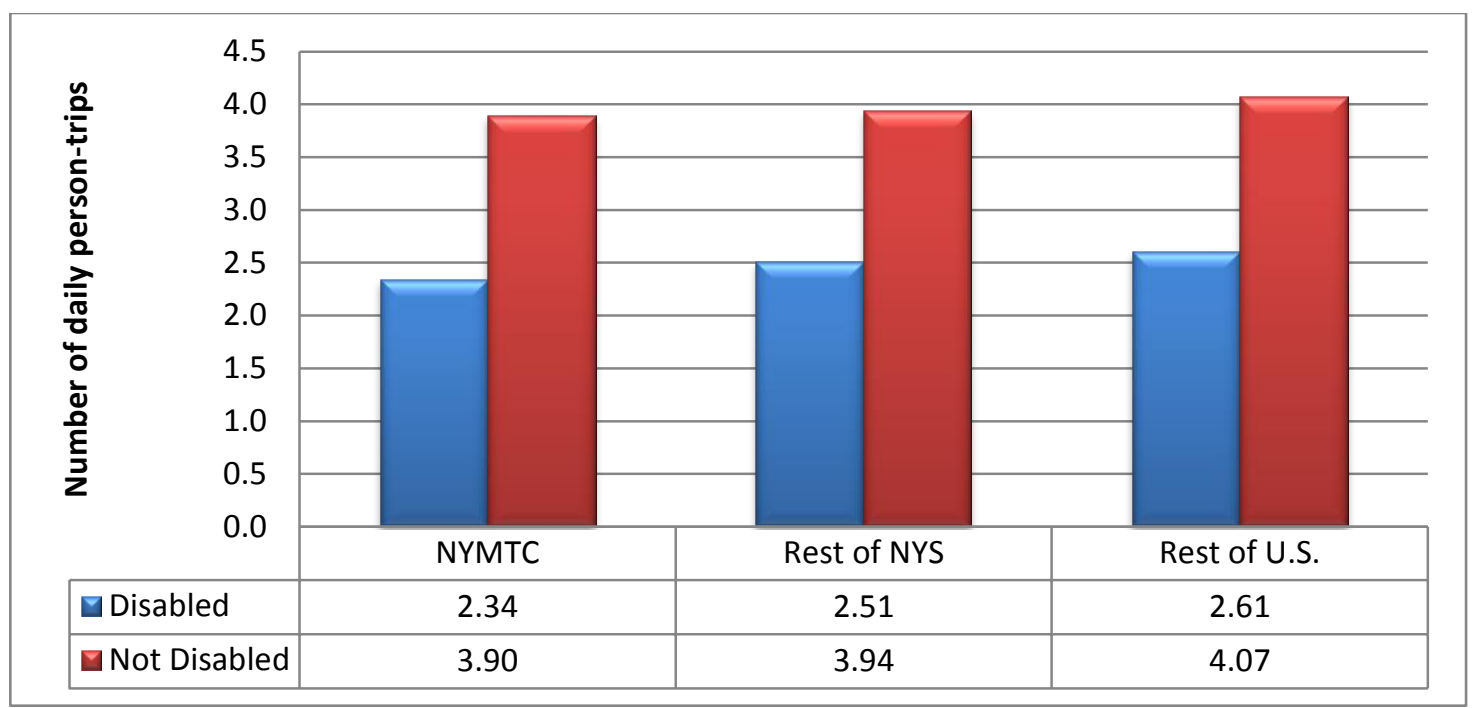

Figure 5-8. Average daily person-trip rates by disability status and region (2009 NHTS).

\subsubsection{Average Person Trip Length}

In addition to making fewer trips, a disabled person also traveled shorter distances than a nondisabled person from the same region. As presented in Figure 5-9, a disabled NYMTC resident traveled 4.1 miles on average for every person trip made in 2009, while the non-disabled traveler from the same region made an average 6.6-mile person trip.

Outside NYMTC, a typical disabled New Yorker traveled an average of 7.7-miles per trip, while non-disabled New Yorkers made an average of 9.9-mile long person trips. The average triplength difference between the disabled and non-disabled population outside NYS was not as significant as for NYS residents. Figure 5-9 shows that disabled persons from other parts of the country traveled about one-mile shorter than their non-disabled neighbors did on an average pertrip basis.

Also visible from Figure 5-9 is a significant difference in the average person-trip length between NYMTC and regions outside NYMTC. This is consistent with findings from examinations of the general population ${ }^{18}$ (as well as the study of elderly subpopulation ${ }^{19}$ ) where NYMTC residents on average traveled shorter distances than those living elsewhere.

\footnotetext{
${ }^{18}$ Southworth, F., T. Reuscher, and H.L. Hwang, New York State 2009 NHTS Comparison Report, Oak Ridge National Laboratory, ORNL/TM-2012/204, 2012, http://info.ornl.gov/sites/publications/Files/Pub36626.pdf ${ }^{19}$ Hwang, H.L., D. Wilson, T. Reuscher, J. Yang, R. Taylor, and S.M. Chin, Travel Patterns and Characteristics of Elderly Subpopulation in New York State, Oak Ridge National Laboratory, ORNL/TM-2015/83, February 2015, http://info.ornl.gov/sites/publications/Files/Pub54596.pdf.
} 


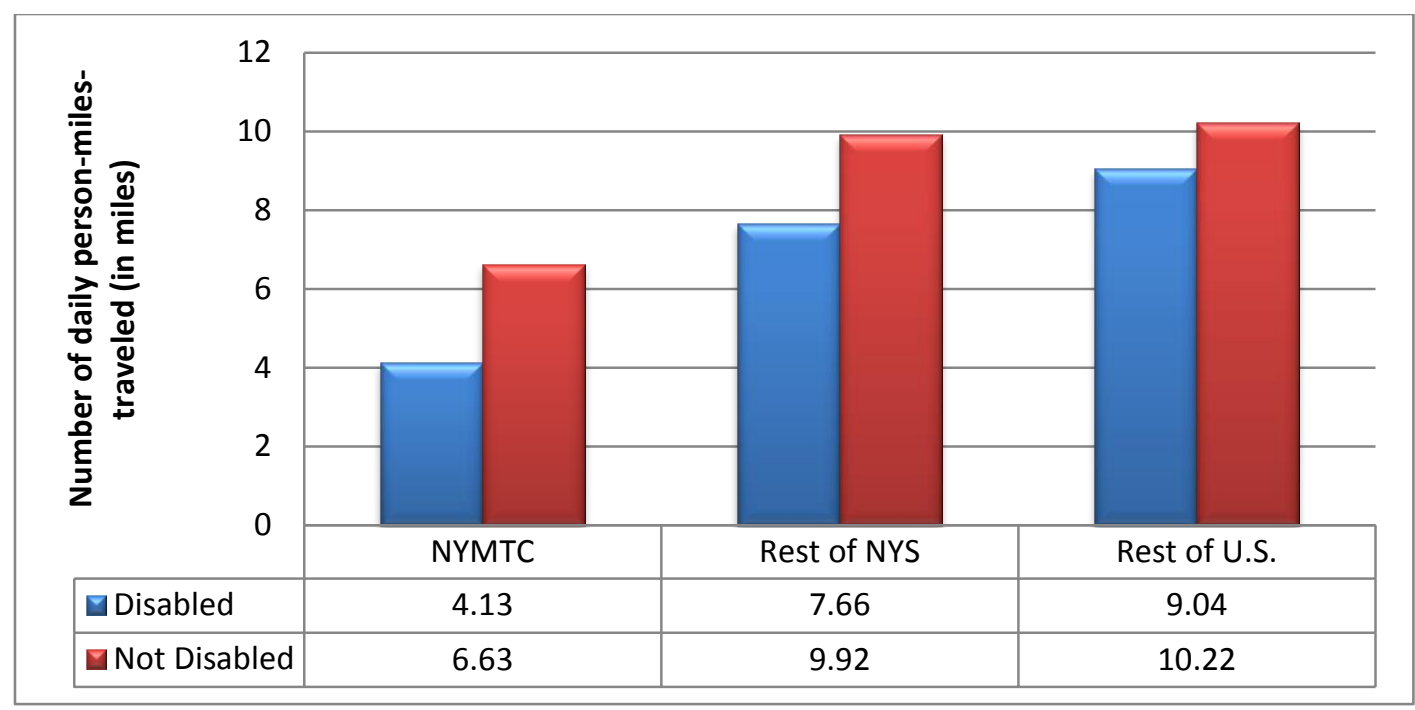

Figure 5-9. Average person trip length by disability status and region (2009 NHTS).

\subsubsection{Average Daily Vehicle-Trip Rate}

Unlike the daily person-trip rates, regional differences between NYMTC and other areas are evident when examining daily vehicle-trip rates. This is expected due to the high volume of zero-vehicle households within the NYMTC region, which is a unique characteristic of this region. As Figure 5-10 shows, regardless of disability status, a person that lived in NYMTC, on average, took significantly fewer daily vehicle trips than those living elsewhere in the country. Specifically, among disabled persons, NYMTC residents took an average of about one vehicle trip per day while disabled persons who lived elsewhere made over two vehicle trips a day on average. Similarly for non-disabled populations, while a NYMTC resident made an average of two vehicle trips per day, their counterparts living elsewhere took over three vehicle trips each day during the same year.

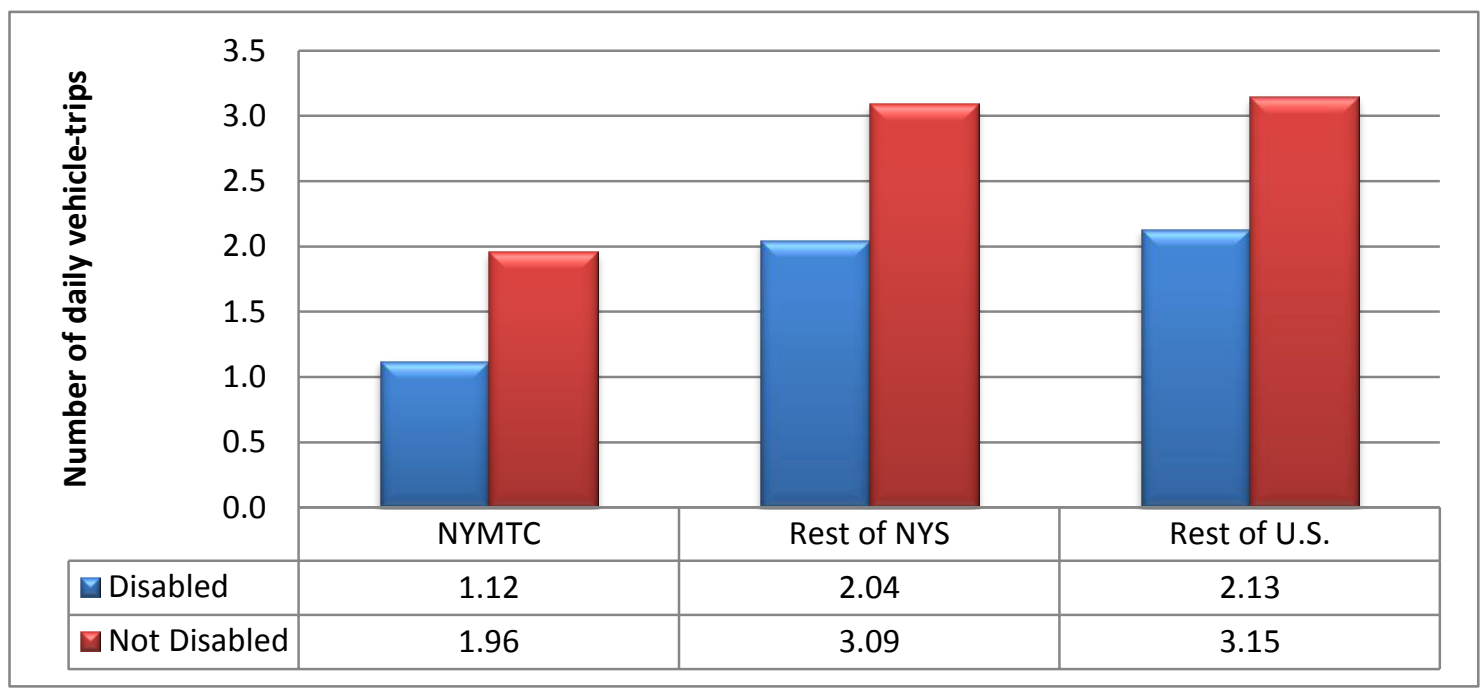

Figure 5-10. Average daily vehicle-trip rate by disability status and region (2009 NHTS). 
By disability status, Figure 5-10 also indicates that disabled populations clearly made fewer daily vehicle trips than their non-disabled counterparts did within the same region. For every two vehicle-trips made by a non-disabled NYMTC person per day, a disabled NYMTC resident would have traveled one vehicle-trip a day during 2009. Elsewhere in the country, a typical disabled person took about two vehicle-trips a day while a non-disabled person made an average of three vehicle-trips a day.

\subsubsection{Average Vehicle Trip Length}

In terms of average vehicle trip length by disability status, Figure 5-11 shows slightly longer vehicle-trips (measured in miles) made by people outside NYS than those in NYS. Non-disabled people on average also made longer vehicle trips than disabled persons from the same region, about 1-2 miles farther on average per-trip distances.

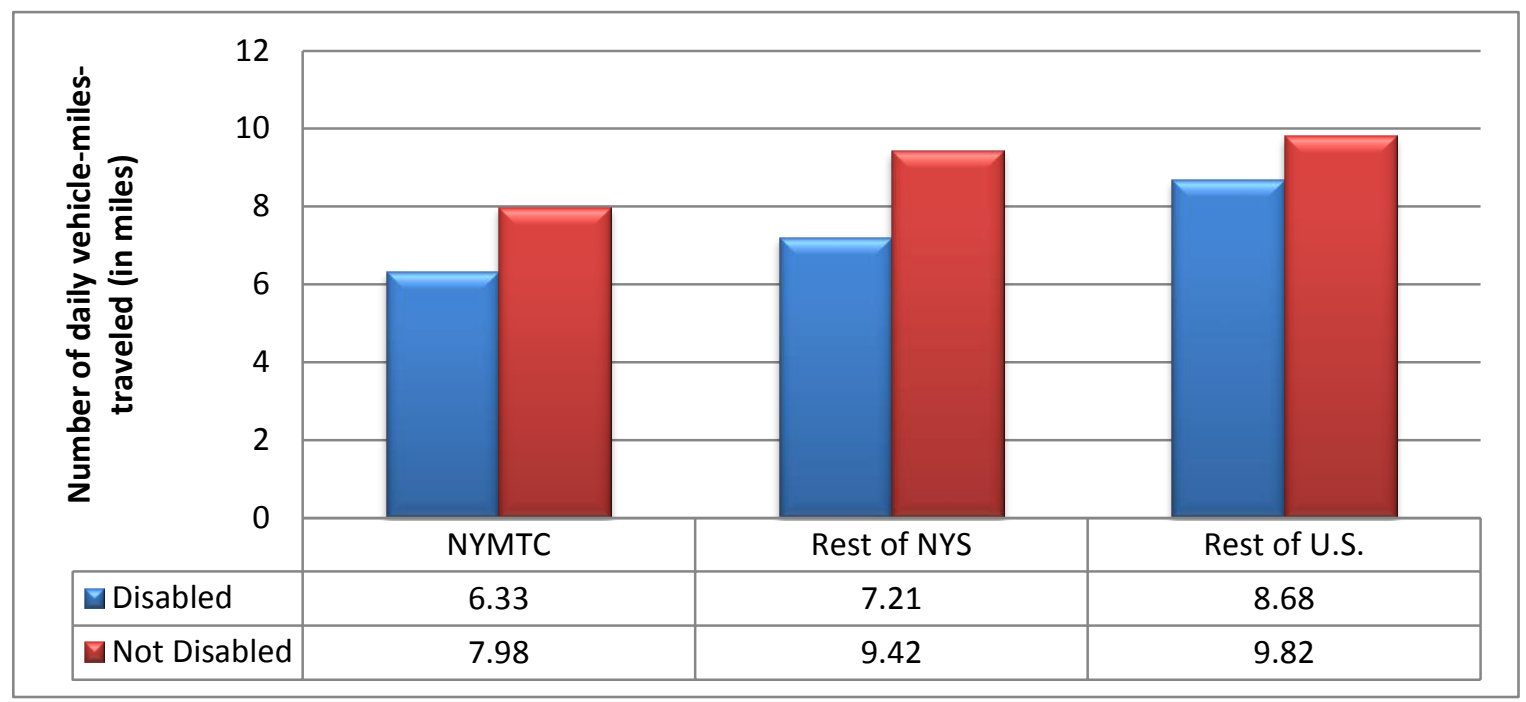

Figure 5-11. Average vehicle trip length by disability status and region (2009 NHTS).

Specifically, while a disabled NYMTC person traveled 6.3 vehicle-miles per trip, on average, a non-disabled NYMTC neighbor made a longer trip of 8.0 vehicle-miles during the same year. Elsewhere in NYS, disabled people traveled 7.2 vehicle-miles per trip versus a non-disabled person with 9.4 vehicle-miles in a trip. Outside NYS, the difference in average vehicle-trip length between disabled and non-disabled populations was slightly closer -8.7 miles vehicletrips for disabled travelers versus 9.8 miles for non-disabled persons. 


\subsection{TRAVEL STATISTICS FOR ZERO-VEHICLE HOUSEHOLDS BY DISABILITY STATUS}

The impacts of disability status on trip rate and travel distance for all travelers were addressed in Section 5.3. Based on 2009 NHTS data, it was found that a disabled person traveled less frequently and made shorter trips than his/her non-disabled neighbors in 2009. This subsection focuses on examining the travel behaviors of zero-vehicle households by their disability status. Travel statistics for these households were summarized by selected region, i.e., NYS, NYC (5county), Manhattan (where feasible), and the Rest of U.S, and are presented in Table 5-1. Note that vehicle-related statistics could not be reliably estimated using 2009 NHTS data due to small sample-size limitations.

Table 5-1. Trip Statistics for Zero-Vehicle Households by Disability Status (2009 NHTS)

\begin{tabular}{|c|c|c|c|c|c|c|c|c|}
\hline \multirow[b]{2}{*}{$\begin{array}{c}\text { Trip } \\
\text { statistics }\end{array}$} & \multicolumn{2}{|c|}{ Rest of U.S. } & \multicolumn{2}{|c|}{ NYS } & \multicolumn{2}{|c|}{ NYC (5-county) } & \multicolumn{2}{|c|}{ Manhattan } \\
\hline & $\begin{array}{c}\text { Non- } \\
\text { disabled }\end{array}$ & Disabled & $\begin{array}{c}\text { Non- } \\
\text { disabled }\end{array}$ & Disabled & $\begin{array}{c}\text { Non- } \\
\text { disabled }\end{array}$ & Disabled & $\begin{array}{c}\text { Non- } \\
\text { disabled }\end{array}$ & Disabled \\
\hline PT/person & 2.99 & 2.05 & 3.41 & 2.31 & 3.50 & 2.39 & 4.61 & 2.68 \\
\hline $\begin{array}{l}\text { PMT/Person } \\
\text { (Miles) }\end{array}$ & 13.86 & 6.90 & 10.14 & 5.36 & 10.27 & 5.10 & 13.49 & 6.11 \\
\hline $\begin{array}{l}\text { Average PT } \\
\text { Length } \\
\text { (Miles) }\end{array}$ & 5.06 & 3.83 & 3.39 & 2.76 & 3.36 & 2.60 & 3.07 & 2.61 \\
\hline VT/Driver & 0.57 & 0.45 & 0.14 & 0.13 & 0.10 & \multirow{3}{*}{$\begin{array}{c}\text { small } \\
\text { samples }\end{array}$} & 0.22 & \multirow{3}{*}{$\begin{array}{c}\text { small } \\
\text { samples }\end{array}$} \\
\hline $\begin{array}{l}\text { VMT/Driver } \\
\text { (Miles) }\end{array}$ & 6.35 & 2.87 & 1.50 & 0.74 & 1.30 & & 3.18 & \\
\hline $\begin{array}{l}\text { Average VT } \\
\text { Length } \\
\text { (Miles) }\end{array}$ & 11.63 & 6.65 & 12.83 & 6.25 & 14.28 & & 15.66 & \\
\hline
\end{tabular}

As seen in Table 5-1, persons from zero-vehicle disabled households in all regions consistently traveled less frequently than their non-disabled counterparts did. On average, a person from a zero-vehicle disabled household made at least one-person-trips fewer (per day) than the neighbor from a zero-vehicle non-disabled household. In terms of total daily miles-traveled per-person (i.e., PMT/person) in 2009, a person from a zero-vehicle disabled household traveled only about half of the distance as his/her non-disabled counterpart did. On average, the length of each person-trip (measured in miles) for persons from zero-vehicle disabled households was about $20 \%$ to $30 \%$ shorter than trips made by their non-disabled counterparts.

Note that travel statistics produced using 2009 NHTS to measure trip rates and distances associated with vehicle trips were driver-based. Because use of vehicles are generally limited among households within NYC (including Manhattan), sample sizes for calculating these vehicle-based statistics were rather small, especially within the frame of zero-vehicle disabled households. Therefore, no reliable estimates on VT, VMT, and average VT length could be 
obtained for disabled zero-vehicle households in NYC and Manhattan (i.e., estimates not shown in Table 5-1.

In Table 5-1, NYS as a whole, shows no significant difference in the vehicle-trip rates (per driver) between disabled and non-disabled zero-vehicle households. However, drivers from zero-vehicle disabled households, on the average, traveled about half of the daily VMT of their non-disabled counterparts in 2009, with 0.74 VMT verses 1.5 VMT, respectively. The average length of each vehicle-trip (in miles) for drivers from zero-vehicle disabled households was also about half of the average VT distance as traveled by their non-disabled counterparts.

Outside NYS, according to 2009 NHTS data, vehicle-trip rates (per driver) for disabled and nondisabled zero-vehicle households were at 0.57 and 0.45 , respectively. That is, drivers from the zero-vehicle disabled households in the Rest of U.S., on average, traveled about $27 \%$ less frequently by vehicle than their non-disabled counterparts. In terms of VMT per driver, however, a typical driver from a zero-vehicle disabled household in the Rest of U.S. traveled less than half (about $45 \%$ ) of the daily VMT as his/her non-disabled counterparts from the same region in 2009. As seen in Table 5-1, the average vehicle-trip length for drivers from zerovehicle disabled households in 2009 was 6.65 miles; while their non-disabled counterparts from the area averaged 11.63 miles.

\subsection{TRAVEL STATISTICS BY HOUSEHOLD SIZE AND DISABILITY STATUS}

As for zero-vehicle households discussed above, potential influences of household size on travel behaviors of disabled households were examined. Again, due to sample size limitations, travel statistics specifically targeted for disabled households from the Manhattan region could not be estimated with statistical assurance. Thus, statistics presented in this section are for the regions of NYS, NYC (5-county), and the Rest of U.S. Recall that the household size categories used in this study are one-person, two-person, and three-or-more persons for a given household. In addition, a "disabled household" is a household with one or more persons with a disability.

\subsubsection{Impacts of Household Size on Trip Frequencies by Disability Status}

Similar to travel statistics analyzed previously for zero-vehicle households, trip frequency is measured by person-trip per person and vehicle-trip per driver.

\section{Person-Trip per Person}

The differences in PT per person by household size, particularly by their disability status, are clearly visible in Figure 5-12. While average PTs for the non-disabled households show a declining pattern as household size increases in all regions, average PTs for their disabled counterparts are on the raise over the increase of household size. As a result, the gap in trip rates 
between the disabled and the non-disabled households become narrower as the household size increases.

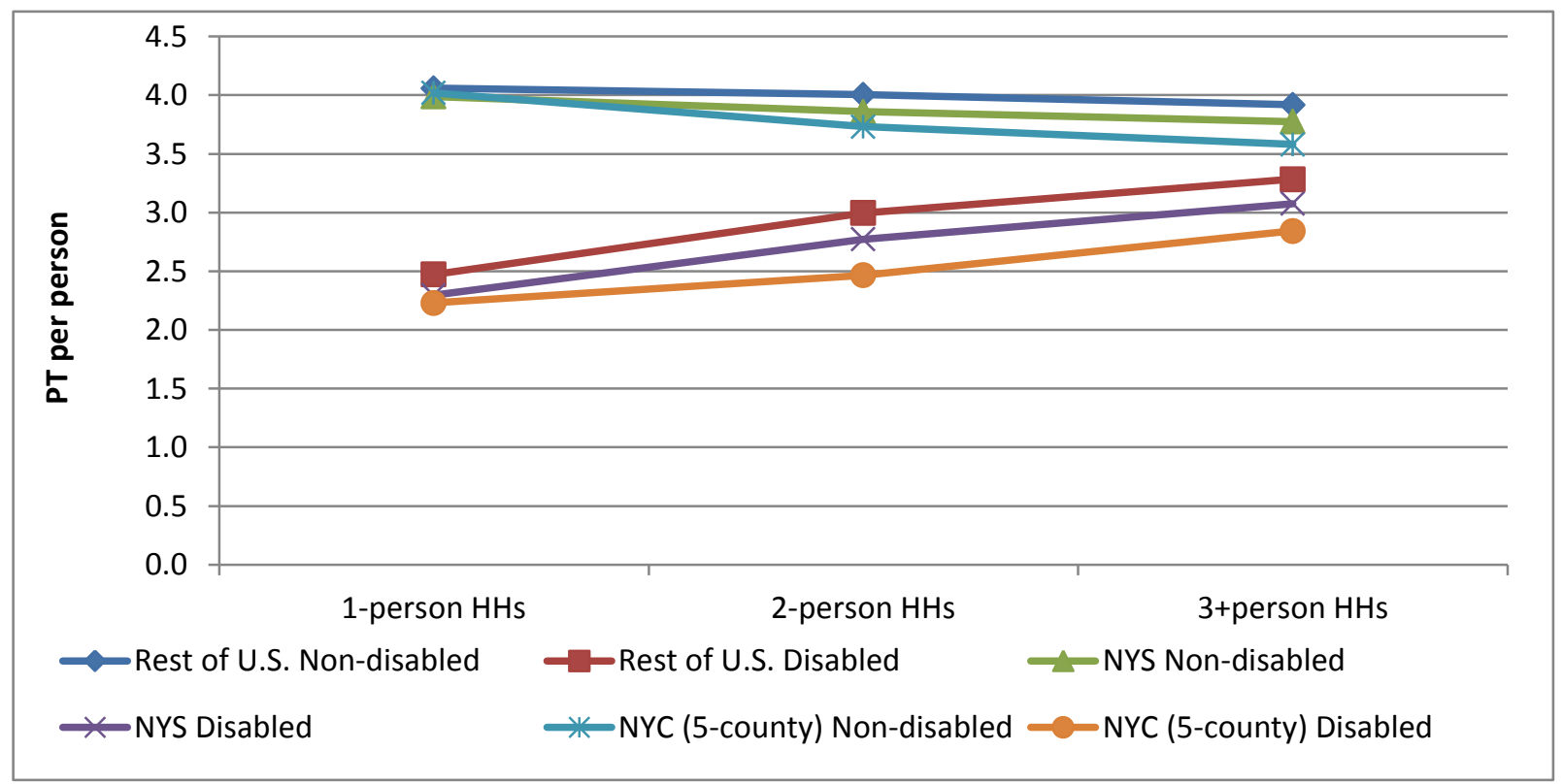

Figure 5-12. Person-trip per person by household size, disability status, and region (2009 NHTS).

According to 2009 NHTS data, a one-person disabled household, on average, took about 2.5 trips per person while their non-disabled counterparts made an average of around 4 trips per person during the same year. In households with three-or-more persons, the average PT rate for disabled households was approximately 0.7 lower than the rate for their non-disabled neighbors within the same region. This gap (between disabled and non-disabled) is about half of the PT rate difference seen in the one-person households. Within each disability-status, however, regional difference in PT rates for the one-person households was not that noticeable. As Figure 5-12 shows, regional gaps in trip rates widen as the household size increases in both disabled and non-disabled household groups.

\section{Vehicle-Trip per Driver}

The patterns of VT rates (driver-based) shown in Figure 5-13 are quite different from what was seen in Figure 5-12 for PT rates (person-based). Nearly all cases, by disability status and region as displayed in Figure 5-13, show an increasing trend in VT rate as the household size increases. Regional differences among VT rates are clearly shown in Figure 5-13. Expectedly, VT rates are higher for households outside NYS, since POV is the most common means of transportations for households from the Rest of U.S., regardless of their disability status.

The VT rates per driver presented in Figure 5-13 clearly show there are trip-frequency gaps between disabled and non-disabled households in all sizes of households, particularly for those in NYS (as a whole) or from the Rest of U.S. For instance, according to the 2009 NHTS data, 
drivers from the one-person disabled households in NYS took an average of 1.6 vehicle-trips on any typical day during 2009, while their counterparts from non-disabled households made an average of over two vehicle trips.

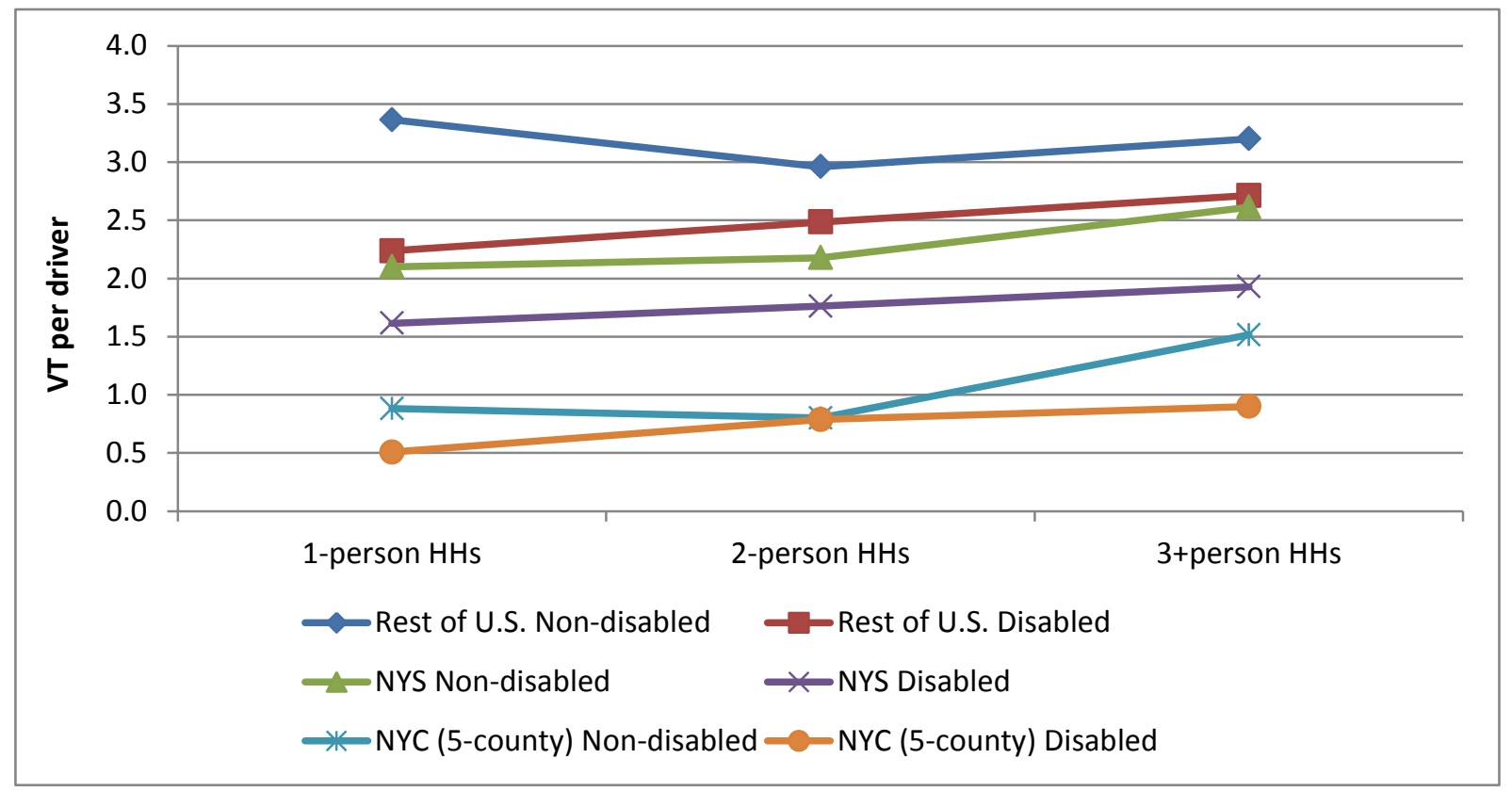

Figure 5-13. Vehicle-trip per driver by household size, disability status, and region (2009 NHTS).

Within NYC, differences in VT rates between disabled and non-disabled households are apparent in the cases of one-person and three-or-more-person households (Figure 5-13); where the VT rates for the disabled households were about one-half of a trip less than the non-disabled households had. In the NYC two-person households, however, there was no difference found in VT rates by disability status of households.

\subsubsection{Impacts of Household Size on Trip Length for Disabled Households}

In addition to trip-frequency discussed above, average distance of trips (i.e., trip length) by households for varying sizes and disability status were examined. Here the trip lengths were measured by person-mile-traveled per person and vehicle-mile-traveled per driver. Moreover, statistics on the average PT length (per person based) and the average VT length (per driver based) were also presented.

\section{Person-Mile-Traveled per Person}

As presented in Figure 5-14, both location and disability status of the households have certain impacts on PMT statistics. These PMT values also show a general increasing pattern as their household size increases. For NYS households, while PMTs for non-disabled households ranged from 23 miles to about 29 miles depending on household sizes, PMTs for their disabled counterparts were significantly shorter, ranging from 9 miles to about 19 miles during the same 
year. In NYC, Figure 5-14 shows that PMT values for both non-disabled and disabled households were significantly lower than for their counterparts that lived outside NYC. Specifically, smaller sized disabled households (one-person or two-person) from NYC traveled about $40 \%$ or less of the miles traveled by their counterparts from non-disabled households. Among the larger size households (i.e., three or more persons), a typical person from a disabled household in NYC, on average, traveled less than 12 miles in total daily distance, while their counterparts from non-disabled households traveled nearly 19 miles on a per-person average.

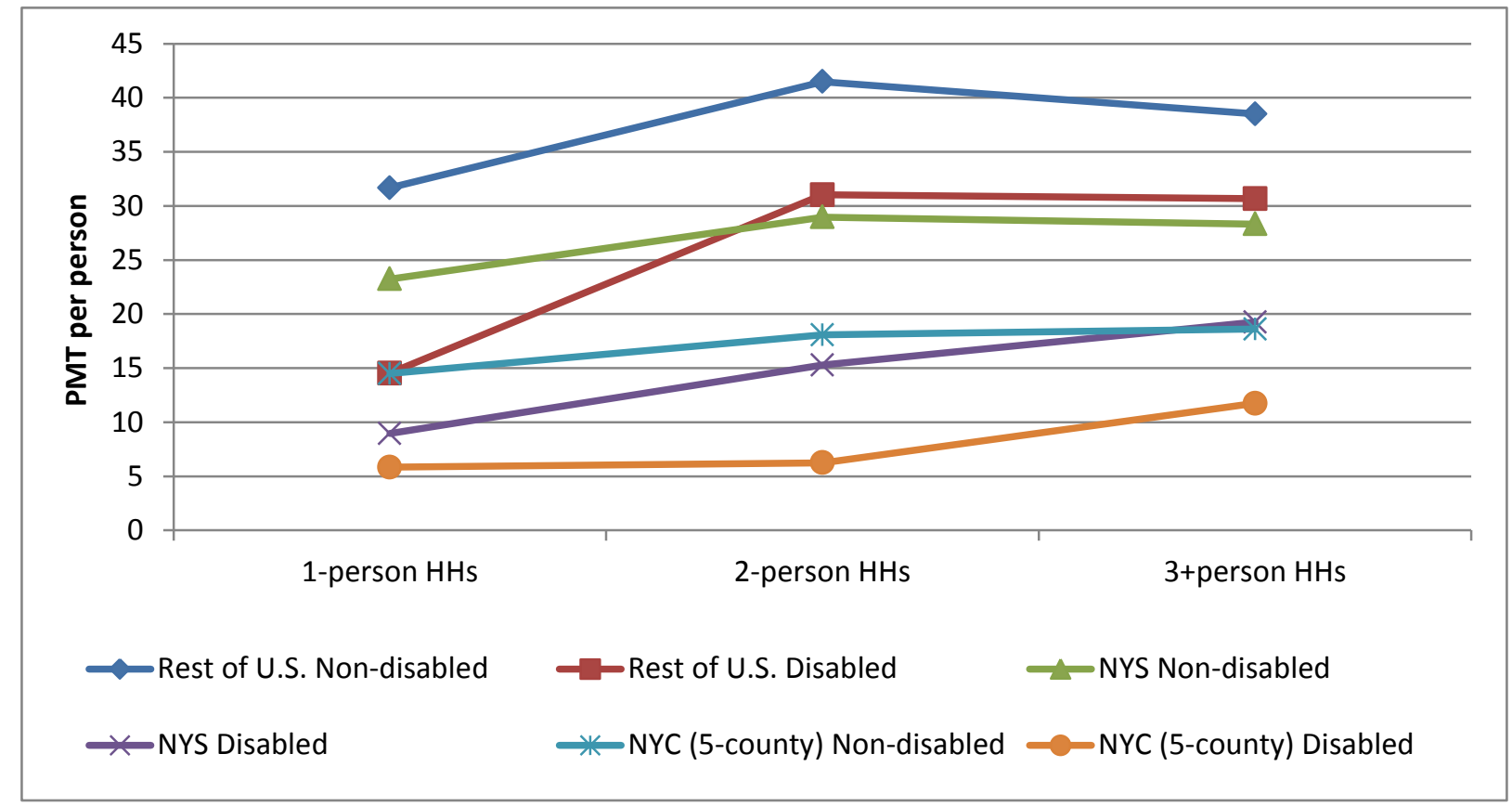

Figure 5-14. PMT per person (in miles) by household size, disability status, and region (2009 NHTS).

Outside NYS, PMT for persons from disabled households also traveled significantly fewer miles than distances traveled by their non-disabled counterparts. As shown in Figure 5-14, while persons from the one-person disabled households made a daily average of less than 15 miles on trips made in 2009, persons from one-person non-disabled households traveled more than twice the distance (32 miles). The difference between PMTs in larger size disabled and non-disabled households, in the Rest of U.S., was not as high, although still significant.

\section{Average Trip Length per Person-Trip}

While PMT provides the average daily total miles traveled per person, the "average person-trip length" statistics, which accounts for the number of trips made by a person, provides information on the distance traveled per trip by a person. As shown in Figure 5-15, persons from the disabled households in most cases made shorter trips than those taken by their non-disabled neighbors. Specifically, average PT length for persons from smaller-sized disabled households in NYS was about 2 miles shorter in distance than trips taken by their non-disabled neighbors in 2009. This 
difference reduced to about 1 mile for households with three or more persons from the same region, with average PT lengths of 8 miles and 7 miles for non-disabled and disabled households from the NYS, respectively. Note that, in NYS the average PT length gets longer as the households' size increases, regardless of the disability status of households.

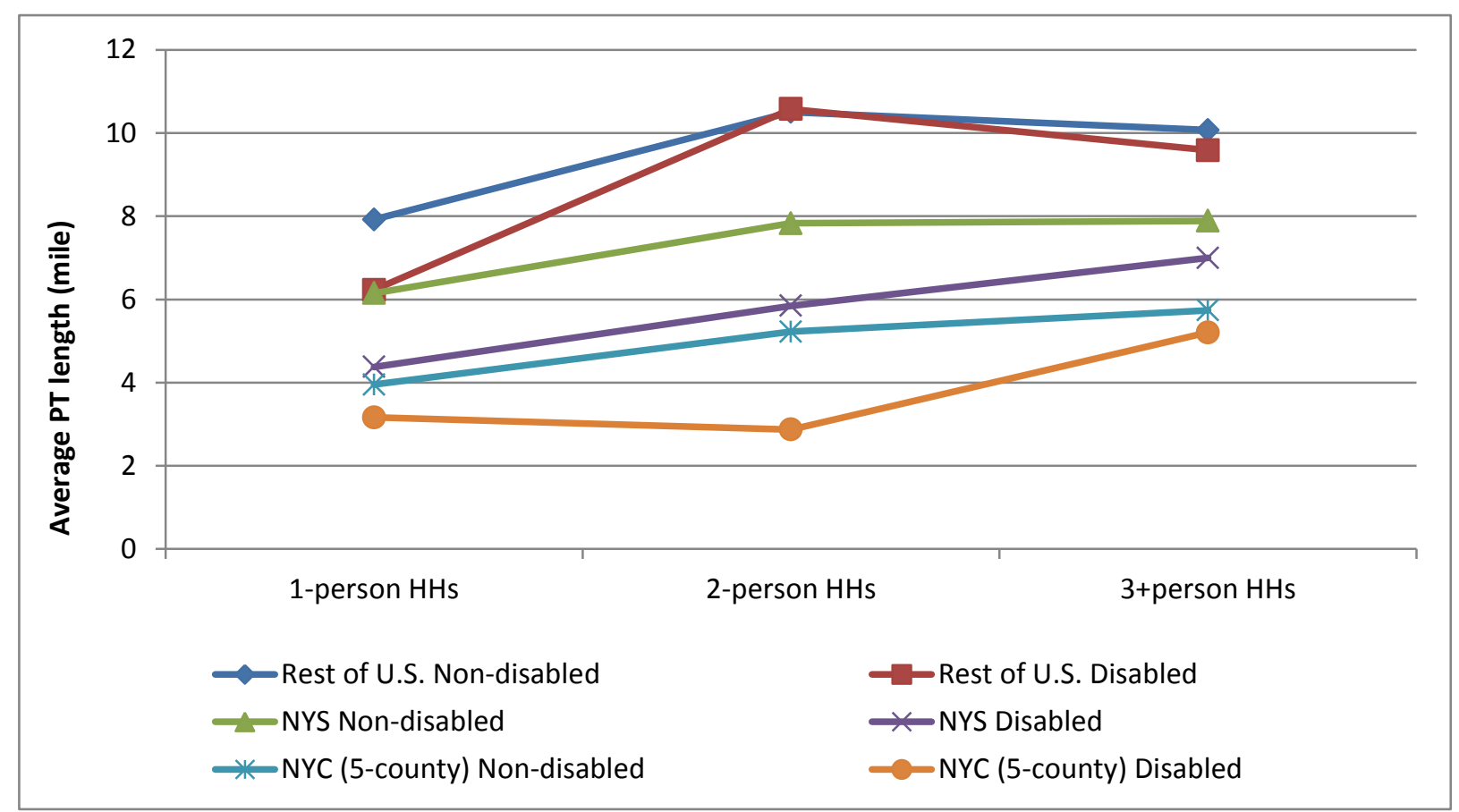

Figure 5-15. Average person-trip length in miles, by household size, disability status, and region (2009 NHTS).

Figure 5-15 also shows that for disabled households within NYC the average PT lengths stayed at around 3 miles for both one and two-person households, but jumped to over 5 miles for the largest household size group. Based on statistics estimated using the 2009 NHTS data, persons from NYC non-disabled households traveled a consistently longer distance than their neighbors from disabled households did, with the differences in distances ranging from about half a mile to more than two miles, depending on household size.

For households in the Rest of U.S., the average PT lengths for trips made by one-person disabled households was nearly 2 miles shorter than trips taken by the counterpart non-disabled households (see Figure 5-15). For larger-sized households in this region, however, the disability status of a household did not seem to have any significant impact on their average PT lengths.

\section{Vehicle-Miles-Traveled per Drive}

Regarding VT, as mentioned previously, all travel statistics associated with vehicles are perdriver based. Note that POV was not the primary mode of transportation for people in NYC where the major modes are walking and public transportation. Because of this the average 
volume of VMT for trips made by NYC households would be expected to be significantly lower than the VMT on trips made by households outside the region as shown in Figure 5-16.

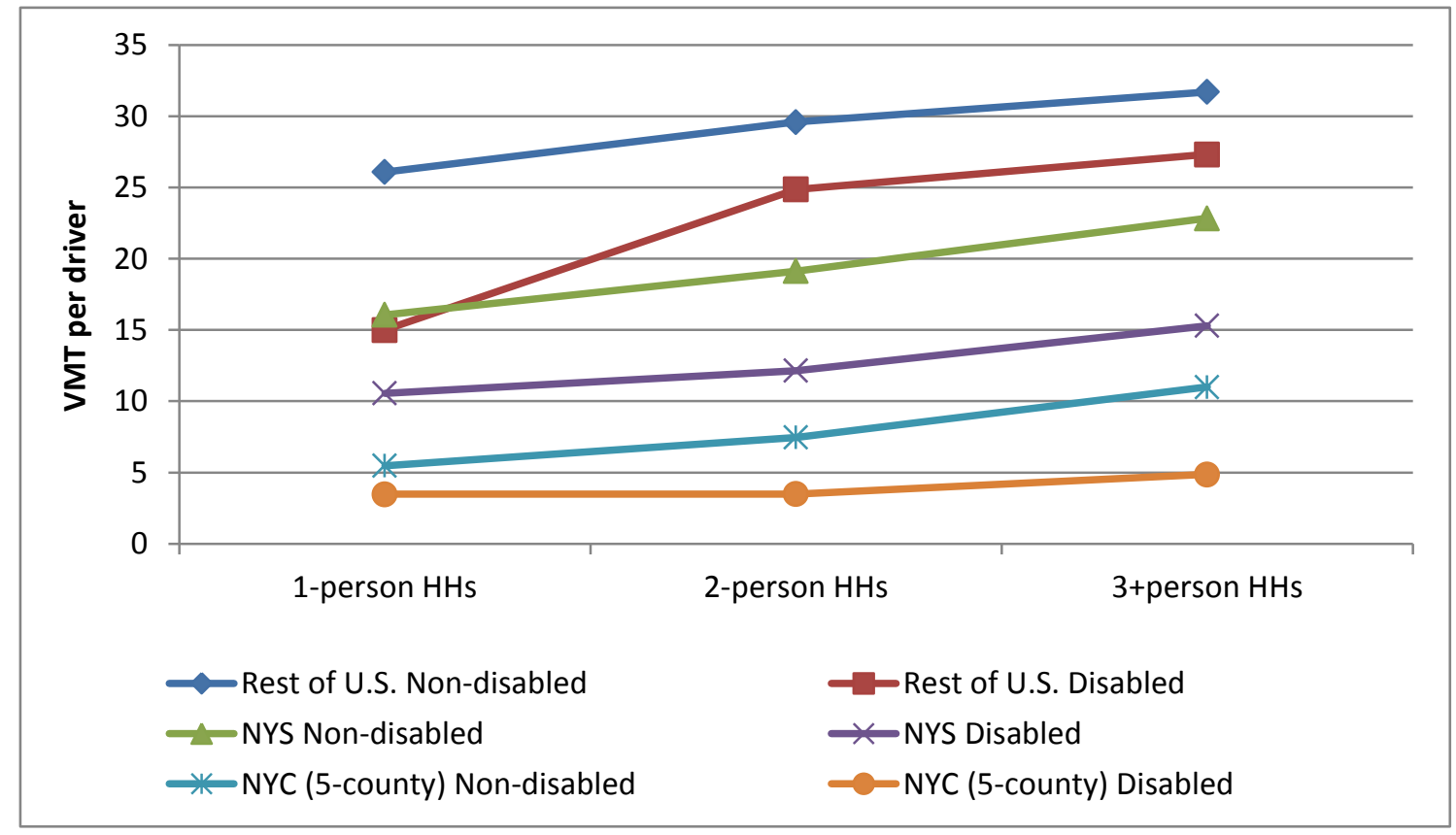

Figure 5-16. VMT per driver by household size, disability status, and region (2009 NHTS).

Figure 5-16 clearly shows an increasing trend in VMT (per driver) over the increase of household size in all regions and for both disability statuses. The VMT per driver for trips made by the disabled households in NYC were about 4 to 5 miles depending on household size, while VMT per driver for trips taken by their non-disabled neighbors were significantly longer in distance, ranging from 6 to 11 miles as the household size increases. Within the NYS region the per-driver VMT distances were about 35\% shorter for the disabled households when compared to non-disabled households.

Outside the NYS region, the values of VMT per driver also show increase as the household size increases_ranging from 26 miles to 32 miles for VT made by the non-disabled households and from 15 miles to 27 miles for VT taken by their disabled counterparts.

\section{Average Trip Length per Vehicle-Trip}

With the exception of NYC, the average VT lengths displayed in Figure 5-17 generally show an increasing trend as the household size increases. The gaps in trip lengths for NYS households, between the disabled and the non-disabled households, were about 1 to 2 miles. Specifically, VT trips made by smaller-sized disabled households in NYS, on average, were about 7 miles long. Average VT length for largest size disabled households (those with 3+ persons) from the same region was 8 miles in distance. Similarly, for non-disabled households in NYS, average VT 
length for one-person households was 8 miles while their larger-sized neighbors had an average VT length of 9 miles.

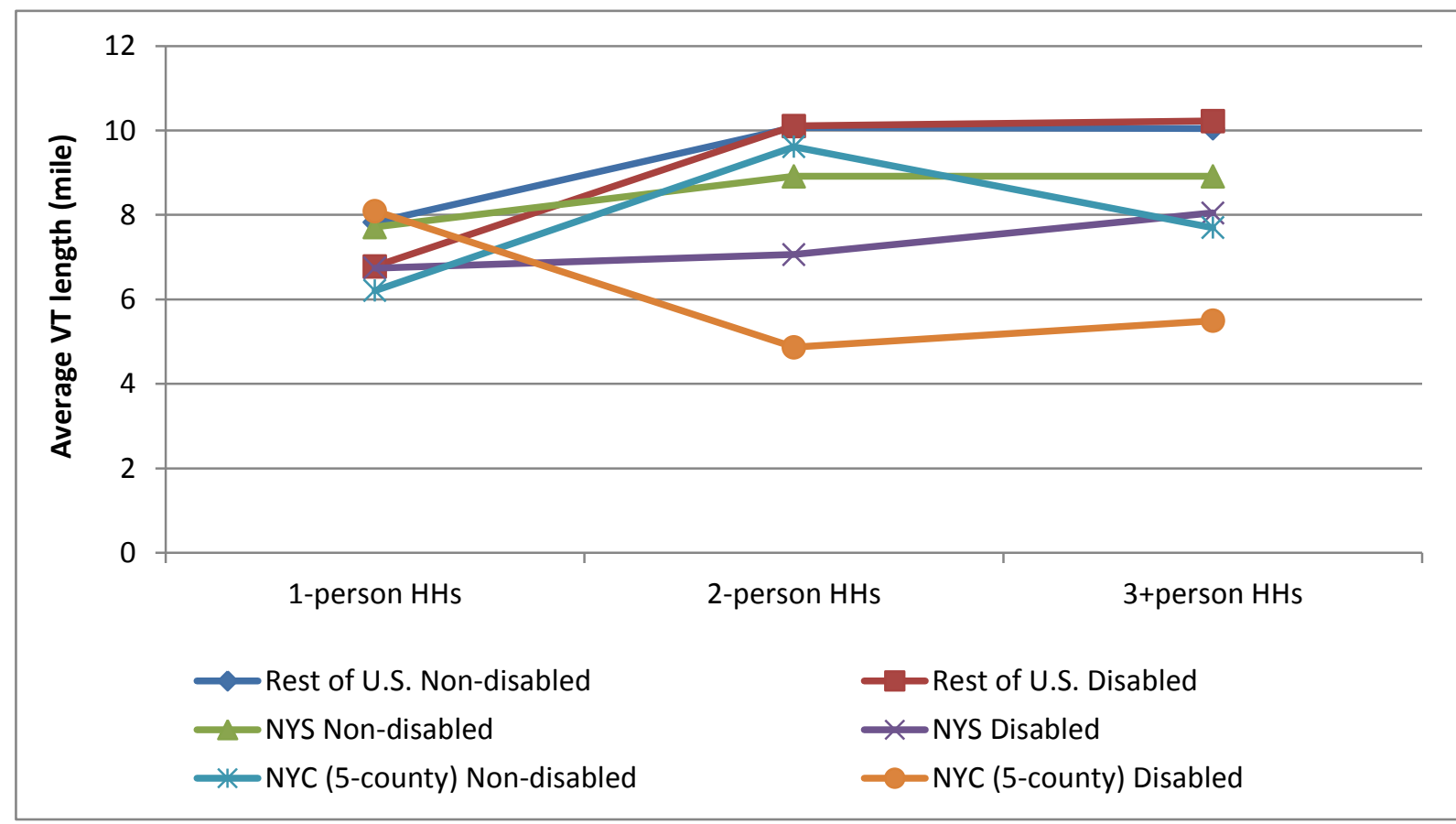

Figure 5-17. Average VT length by household size, disability status, and region (2009 NHTS).

For households from the Rest of U.S., the difference for the average VT lengths by disability status was only seen among the one-person households - an average of 7 miles in length for the disabled one-person households and 8 miles for their non-disabled counterparts. All larger size households from the Rest of U.S. had an average VT length of 10 miles, regardless of their disability status (see Figure 5-17).

Disabled one-person households from NYC appear to have a slightly higher average VT length than the average VT length of their counterpart non-disabled neighbors. This difference was not statistically significant, however, because of a high variation in the VT length measures for oneperson households in NYC. 


\section{SUMMARY}

\subsection{OVERVIEW}

The term "disability" could be used in various contexts by different entities on different applications. Because of this, disability does not always refer to a single definition. While medical and health professionals might view disability as a physiological condition, certain advocates could look at disability as the result of societal force on certain impairment. Specifically, the 2009ACS data provides disability details by six types: hearing difficulty, vision difficulty, cognitive difficulty, ambulatory difficulty, self-care difficulty, and independent-living difficulty. However, a "disabled person" was defined by the 2009 NHTS as one who answers "yes" to the question of: Do you have a temporary or permanent condition or handicap that makes it difficult to travel outside of the home? Thus, in the context of 2009 NHTS data, no specific disability type could be determined.

In this study, both the 2009 ACS data and the 2009 NHTS data were used to (1) examine demographic profiles and travel patterns of disabled individuals, (2) investigate how they compared with those of non-disabled individuals, and (3) identify regional differences for New York City, New York State, and the rest of the United States.

\subsection{KEY FINDINGS}

\subsubsection{Disability Prevalence}

According to the 2009 ACS data, of the 301 million people in the U.S., about 36 million people of all ages had at least one type of disability in that year. In the same year, over 2 million of the total 19 million New Yorkers reported disabilities. Overall, about 11\%-12\% of the 2009 U.S. population had a disability (Table 3-1).

Consistent with the 2009 ACS results, the 2009 NHTS data identified 1.7 million of the 16 million NYS residents age 16 years and older as having a disability in 2009. This is equivalent to a disability rate of about $11 \%$ of the NYS's 16 years and older population (Table 4-1).

\subsubsection{Age and Gender Characteristics}

A significant percentage of elderly persons had a disability in 2009 accounting for $37 \%$ of the total U.S. elderly populations, and 39\% of elderly in NYC (Table 3-1). Based on the 2009 ACS data, the most common disability types among the elderly population (65+ years old) were "ambulatory" and "independent living" difficulties. About a quarter of the elderly population had ambulatory difficulties; while only about 7\% of the non-elderly population (ages 5-64 years old) had the same type of disability. Furthermore, roughly one fifth of the elderly population had 
difficulties in independent living, while less than $4 \%$ of their younger adult counterparts (18-64 years old) reported having this difficulty (Figure 3-4).

The 2009 NHTS showed that the younger population (16 to 64 years old) had a disability rate of $7 \%$ in 2009 , while the disability rate for the elderly group was $31 \%$. This study found that the disability rate increases as the elderly age - from about $21 \%$ in the youngest elderly group (age 65-69 years old) to over half of the oldest elderly population (age 85+ years old) (Table 4-1). Considering gender, the 2009 NHTS data indicated that elderly males had an overall disability rate of $26 \%$ compared to $34 \%$ of elderly female with a disability (Figure 4-4).

\subsubsection{Economic Wellbeing}

According to the 2009 ACS, there is a significant difference in income distributions between people with and without a disability, regardless of where they lived. The shares of very-low income (under $\$ 15,000$ ) group in populations with a disability are 13\%-15\% higher than that in corresponding non-disabled populations (Figure C-2). Furthermore, the 2009 ACS data show that $30 \%$ of NYC disabled population has income below $100 \%$ of the poverty level, while only $15 \%$ of non-disabled individuals from the same area fell in this range of poverty level. Similar

poverty-level percentages for disabled and non-disabled populations that lived outside NYC were $18 \%$ and $8 \%$, respectively (Figure C-3).

People with disabilities earned much less when compared to their non-disabled colleagues. The 2009 ACS data show that, a typical NYC resident with a disability would only get 68 cents for every dollar a typical non-disabled working age person in the same region received. The situation was, in fact, worse for disabled workers that lived elsewhere, where for each dollar a typical non-disabled worker made, a typical disabled person only received about 66 cents (Table C-1).

The 2009 NHTS data also confirmed that a higher percent of disabled households fell in the lowincome group (under $\$ 25,000$ ) as compared to those of the non-disabled households.

Specifically, the 2009 NHTS data showed that a disabled household was more than twice as likely to be in the lowest household income bracket as its non-disabled neighbor was in 2009 (Figure 4-7).

\subsubsection{Employment Opportunity}

The 2009 ACS data showed that among the employed population in the U.S. only about 5\% were disabled, while about $4 \%$ of the NYS residents employed were disabled. At the national level, the 2009 ACS data revealed that $26 \%$ of those not in the labor force had a disability. Similarly, about 23\% of New Yorkers who were not in the labor force were disabled (Table 3-2). In 2009, half of the working age population with any type of disability was not in the labor force (Figure 3-7). This seems to reflect that a disability condition could have prevented a person from 
working. The most common work limitations reported were Self-Care and Independent Living difficulties.

Disabled persons have a smaller likelihood of being in the work force when compared with their non-disabled counterparts. The 2009 NHTS data reflected that the gap in the percentages of workers between disabled and non-disabled persons was extremely large. Nearly $70 \%$ of the non-disabled working age population (16+ years old) worked in 2009, while about $20 \%$ of their disabled working age neighbors worked in the same year (Figure 4-9).

\subsubsection{Mode Choices}

Per the 2009 ACS data, more than half of NYC workers utilized public transportation for commuting to work, even for workers with a disability. Outside NYC, commuting to work mostly relied on personal vehicles. Roughly, $70 \%$ of disabled workers drove to work, while about $77 \%-78 \%$ of their non-disabled co-workers used the same mode. About $13 \%$ of the disabled workers that lived outside NYC traveled to work by carpooling while $9 \%-10 \%$ of their non-disabled co-workers carpooled to work (Figure 3-26).

Per the 2009 NHTS data, over $80 \%$ of NYMTC non-disabled residents of the driving age group (age 16+ years old) reported themselves as drivers, while only about half of their disabled neighbors in the same age group stated that they were drivers. Outside NYMTC, $92 \%$ of nondisabled 16+ years old residents reported themselves as a driver. Among disabled driving-age persons, the share of drivers was $65 \%$ of New Yorkers that lived outside NYMTC and $61 \%$ for those that lived outside NYS (Figure 4-8).

About $9 \%$ of trips made by disabled travelers from NYMTC were for work purposes and $60 \%$ of their trips were for activities associated with family and personal business. On the other hand, $21 \%$ of travel made by non-disabled population from this same region was for work and $45 \%$ were for family and personal business purposes (Figure 5-1).

According to the 2009 NHTS, a disabled person is more likely to travel as a POV passenger when comparing to non-disabled person from the same neighborhood (Figure 5-2). This is especially true for people from zero-vehicle households (Figure 5-3).

\subsubsection{Travel Rates}

Results from the 2009 NHTS data reflected that disabled persons traveled less frequently than their non-disabled neighbors regardless of where they lived. A typical disabled person from NYMTC made 2.3 trips per day while a typical non-disabled person from the same community took nearly four trips each day. Outside NYMTC, a disabled person traveled roughly $60 \%$ of the number of daily trips made by a non-disabled person in 2009 , no matter where the person lived. 
Although disability status has a significant impact on the person-trip frequency, geographical region did not influence trip frequencies in any significant way (Figure 5-8).

The daily average trip-length difference between the disabled and non-disabled population that lived outside NYS was not as significant as for NYS residents. A disabled NYMTC resident traveled 4.1 miles on average for every daily-trip made in 2009, while the non-disabled traveler from the same region made an average 6.6-mile daily trip. Outside NYMTC, a typical disabled New Yorker traveled an average of 7.7-miles per trip on a daily average, while his/her nondisabled counterpart made an average of 10-mile long daily trips (Figure 5-9). The 2009 NHTS data also showed a significant difference in the average daily person-miles-traveled between NYMTC and regions outside. This is consistent with findings from examinations of the general population $^{20}$ (as well as the study of elderly subpopulation ${ }^{21}$ ) where NYMTC residents on average traveled shorter distances than residents that lived elsewhere.

\subsubsection{Zero-Vehicle Disabled Households}

Disabled zero-vehicle households from NYS used public transportation (public transit or taxi) for nearly $42 \%$ of their total person-trips taken during 2009; while only $30 \%$ of total person-trips made by their counterpart non-disabled neighbors were taken on public transportation (Figure 53). The share of using public transportation on daily travels made by disabled households within NYC was higher, which has a $45 \%$ share versus the $34 \%$ share among non-disabled households from the same region in 2009.

On average, a person from a zero-vehicle disabled household made at least one-person-trips fewer (per day) than the neighbor from a zero-vehicle non-disabled household (Table 5.1). In addition, a person from a zero-vehicle disabled household traveled only about half of the distance as his/her non-disabled counterpart did. On average, the length of each person-trip (measured in miles) for persons from zero-vehicle disabled households was about $20 \%$ to $30 \%$ shorter than trips made by their non-disabled counterparts (Table 5.1).

\subsubsection{Influence of Household Size}

The share of person trips taken on public transit was only about $12 \%$ among the one-person disabled households in NYS, versa $16 \%$ of trips taken by the non-disabled one-person households from the same area during 2009. For NYC, public-transit mode shares were $29 \%$ and $22 \%$ for the one-person non-disabled and the one-person disabled households, respectively

\footnotetext{
${ }^{21}$ Hwang, H.L., D. Wilson, T. Reuscher, J. Yang, R. Taylor, and S.M. Chin, Travel Patterns and characteristics of Elderly Subpopulation in New York State, Oak Ridge National Laboratory, ORNL/TM-2015/83, February 2015, http://info.ornl.gov/sites/publications/Files/Pub54596.pdf.
} 
(Figure 5-4). According to 2009 NHTS data, a one-person disabled household, on average, took about 2.5 trips per person while their non-disabled counterparts made an average of around 4 trips per person during the same year. In households with three-or-more persons, the average PT rate for disabled households was approximately 0.7 lower than the rate for their non-disabled neighbors within the same region (Figure 5-12).

Specifically, smaller sized disabled households (one-person or two-person) from NYC traveled about $40 \%$ or less of the miles traveled by their counterparts from non-disabled households. Among the larger size households (i.e., three or more persons), a typical person from a disabled household in NYC, on average, traveled less than 12 miles in total daily distance, while their counterparts from non-disabled households traveled nearly 19 miles on a per-person average (Figure 5-14).

\subsection{FUTURE RESEARCH}

This research extended the original 2009 NHTS-focused Task 14 scope to include an investigation on disability statistics collected by the Census Bureau, and to a lesser degree, a brief examination on what CDC data might offer, particularly information on health and disability related aspects. To work within the resources allocated to the original task, a decision was made to limit this study to use only the latest 2009 NHTS year; consequently, trend analysis was not included.

As a recommendation to this current study, a supplemental research to examine how disability statistics and related patterns change over time is suggested. In addition to investigating how travel behavior has changed over the last three NHTS cycles $(1995,2001$, and 2009) utilizing the rich set of annual ACS data for the corresponding NHTS survey years for a more in-depth review on trends for the disabled populations is recommended. This could allow policy makers and planners from NYS to measure their performance in programs and/or investments made to support disadvantaged and disabled residents of the state. 


\section{APPENDIX A GLOSSARY}

This glossary provides the most commonly used terms in the NHTS and definitions of those terms. These definitions are provided to assist the user in the interpretation of the NHTS data.

Term

Adult

Block Group

Census Tract

Driver

Employed

Education Level

\section{Definition}

For NHTS, this is defined as a person 18 years or older.

A subdivision of a Census tract that averages 1000 to 1100 people, and approximately 400-500 housing units. The source used for the 2009 NHTS was TeleAtlas MatchMaker (derived from Census 2000 definition).

A small subdivision of a county, containing approximately 4,000 persons. Tracts can range in population from 2,500 to 8,000. The geographic size of the tract may vary considerably, depending on population density. Tracts were designed to be homogeneous in regard to population characteristics, economic status and living conditions when they were first delineated. Since the first tracts were delineated for the 1890 Census, today's tracts may be far from homogeneous. The source used for the 2009 NHTS was TeleAtlas MatchMaker (derived from Census 2000 definition).

A driver is a person who operates a motorized vehicle. If more than one person drives on a single trip, the person who drives the most miles is classified as the principal driver.

A person is considered employed if (s)he worked for pay, either full time or part time, during the week before the interview. This includes persons who work at home or persons who have more than one job.

The number of years of regular schooling completed in graded public, private, or parochial schools, or in colleges, universities, or professional schools, whether day school or night school. Regular schooling advances a person toward an elementary or high school diploma, or a college, university, or professional school degree. 
Term

Household

Household Income

Household Members

Household Vehicle

\section{Definition}

A group of persons whose usual place of residence is a specific housing unit; these persons may or may not be related to each other. The total of all U.S. households represents the total civilian non-institutionalized population. A household does not include group quarters (i.e., 10 or more persons living together, none of whom are related).

Household income is the money earned by all family members in a household, including those temporarily absent. Annual income consisted of the income earned 12 months preceding the interview. Household income includes monies from all sources, such as wages and salary, commissions, tips, cash bonuses, income from a business or farm, pensions, dividends, interest, unemployment or workmen's compensation, social security, veterans' payments, rent received from owned property (minus the operating costs), public assistance payments, regular gifts of money from friends or relatives not living in the household, alimony, child support, and other kinds of periodic money income other than earnings. Household income excludes in-kind income such as room and board, insurance payments, lump-sum inheritances, occasional gifts of money from persons not living in the same household, withdrawal of savings from banks, tax refunds, and the proceeds of the sale of one's house, car, or other personal property.

Household members include all people, whether present or temporarily absent, whose usual place of residence is in the sample unit. Household members also include people staying in the sample unit who have no other usual place of residence elsewhere.

A household vehicle is a motorized vehicle that is owned, leased, rented or company-owned and available to be used regularly by household members during the two-week travel period. Household vehicles include vehicles used solely for business purposes or business-owned vehicles, so long as they are driven home and can be used for the home to work trip, (e.g., taxicabs, police cars, etc.). Household vehicles include all vehicles that were owned or available for use by members of the household during the travel period, even though a vehicle may have been sold before the interview. Vehicles excluded from household vehicles are those which were not working and were not expected to be working within 60 days, and vehicles that were purchased or received after the designated travel day. 
Term

Journey-to-Work

Trips (Commute trips)

Means of

Transportation

\section{Definition}

Includes travel to and from a place where one reports for work. Does not include any other work-related travel. Does not include any trips for persons who work at home.

A mode of travel used for going from one place (origin) to another (destination). A means of transportation includes private and public transit modes, as well as walking.

The following transportation modes, grouped by major mode, are included in the NHTS data.

Private Vehicle - a stipulation for being a private vehicle is that the vehicle is privately owned or operated.

1. Car. Includes cars and station wagons. Leased and rented cars are included if they are privately operated and not used for picking up passengers in return for fare.

2. Van. Includes vans or minivans designed to carry 5 to 13 passengers, or to haul cargo.

3. Sport Utility Vehicle. Includes vehicles that are a hybrid of design elements from a van, a pickup truck and a station wagon. Examples include a Ford Explorer, Jeep Cherokee, or Nissan Pathfinder.

4. Pickup Truck. Includes vehicles with an enclosed cab that usually accommodates 2-3 passengers, and has an open cargo area in the rear. Late model pickups often have a back seat that allows for total seating of 4 -6 passengers. Pickup trucks usually have the same size of wheel-base as a full-size station wagon. This category also includes pickups with campers.

5. Other Truck: This category consists of all trucks other than pickup trucks (i.e., dump trucks, trailer trucks, etc.). 
6. RV or Motor Home: An RV or motor home includes a self-powered recreational vehicle that is operated as a unit without being towed by another vehicle (e.g., a Winnebago motor home).

7. Motorcycle: This category includes large, medium, and small motorcycles and mopeds.

8. Golf Cart: This includes all electric or gas operated vehicles designed for use on a golf course, but whose use has recently extended to use within smaller, often gated, communities.

Public Transportation, as used in FHWA publications and analysis of NHTS data, typically includes the following that are indicated in bold below, mass transit bus, commuter bus, commuter train, subway/elevated rail, and streetcar/trolley.

Bus. This category includes:

9. mass transit systems, these are local public transit buses that are available to the general public,

10. commuter buses, these are buses used for short-distance public transport purposes (e.g., city bus or public bus), school buses, and

12. charter/tour buses, these are private buses operating on a fixed schedule between population centers, and

13. city to city buses, these are buses that run from one urban center to the other (e.g., Greyhound), and

14. shuttle buses, these are buses that shuttle passengers from one fixed place to another (e.g., airport shuttles).

Train: This category includes: 
15. Amtrak/Intercity Train that run from one urban center to another,

16. Commuter trains and passenger trains

17. Subway and elevated rail (also known as rail rapid transit) is a high capacity system operated on a fixed rail or guide way system on a private right of way, and

18. Trolley/streetcars are vehicles that run on a fixed rail system powered by electricity obtained from an overhead power distribution system.

\section{Other Modes}

11. School Buses.

19. Taxi. Taxis include the use of a taxicab by a passenger for fare, including limousines. The taxi category does not include rental cars if they are privately operated.

20. Ferry. This includes travel by passenger line ferries.

21. Airplane. . Airplanes include commercial airplanes and smaller planes that are available for use by the general public in exchange for a fare. Private and corporate planes and helicopters are also included.

22. Bicycle: This category includes bicycles of all speeds and sizes that do not have a motor.

23. Walk: This category includes walking and jogging.

24. Special Transit for People with Disabilities. This includes things like "Dial-A-Ride"

97. Other. Includes any type of transportation not previously listed, (e.g. 
skate boards, roller blades, sailboats, cruise ships, etc).

\section{Metropolitan Statistical Area (MSA)}

Motorized Vehicle

New York City

New York State Metro Area

Passenger

Person Miles of Travel (PMT)
Except in the New England States, a Metropolitan Statistical Area is a county or group of contiguous counties which contains at least one city of 50,000 inhabitants or more, or "twin cities" with a combined population of at least 50,000. In addition, contiguous counties are included in an MSA if, according to certain criteria, they are socially and economically integrated with the central city. In the New England States, MSA's consist of towns and cities instead of counties. The source used for the 2009 NHTS was 1999 Metropolitan Areas: Cartographic Boundary Files. File ma99_99.shp from http://www.census.gov/geo/www/cob/ma1999.html.

Motorized vehicles are all vehicles that are licensed for highway driving. Snow mobiles and minibikes are specifically excluded.

New York City is defined in this report as the five county area: Bronx, Kings, Queens, New York (Manhattan), and Richmond.

The New York State Metro area includes the following three areas: (1) Nassau, Suffolk; (2) New York City, (which includes the following counties: Bronx, Kings, Queens, New York, and Richmond); and (3) Putnam, Rockland, and Westchester.

For a specific trip, a passenger is any occupant of a motorized vehicle, other than the driver.

PMT is a primary measure of person travel. When one person travels one mile, one person mile of travel results. Where 2 or more persons travel together in the same vehicle, each person makes the same number of person miles as the vehicle miles. Therefore, four persons traveling 5 miles in the same vehicle results in 20 person miles $(4 \times 5=20)$.

A person trip is a trip by one or more persons in any mode of transportation. Each person is considered as making one person trip. For example, four persons traveling together in one auto are counted as four person trips. 
Term

POV

Travel Day

Travel Day Trip

Travel Day Trip Purpose

\section{Definition}

A privately-owned vehicle or privately-operated vehicle. Either way, the intent here is that this is not a vehicle available to the public for a fee, such as a bus, subway, taxi, etc.

A travel day is a 24-hour period from 4:00 a.m. to 3:59 a.m. designated as the reference period for studying trips and travel by members of a sampled household.

A travel day trip is defined as any time the respondent went from one address to another by private motor vehicle, public transportation, bicycle, walking, or other means. However, a separate trip is not counted in two instances:

1. When the sole purpose for the trip is to get to another vehicle or mode of transportation in order to continue to the destination.

2. Travel within a shopping center, mall or shopping areas of 4-5 blocks is to be considered as travel to one destination.

A trip purpose is the main reason that motivates a trip. There are 36 travel day trip purposes used in the 2009 NHTS.

Trip purposes were collected using a From-To approach. For each trip, the origin and destination are on the file in specific terms if reported by the respondent (e.g. from work to Bob's Beef Pit). The 36 trip reasons are defined below. The numbers in parentheses represent the value of WHYTO (trip purpose) in the dataset.

1. To Home (01). Represents a trip to the respondents' primary residence.

Go to Work (11). This is the first trip to the work location on travel day.

3. Return to Work (12). A trip to work that is not the first trip to the workplace on the travel day (e.g., returning to work after lunch).

4. Attend Business Meeting/Trip (13). Represents a work related trip whose purpose is to attend a business meeting. 


\section{Definition}

5. Other Work Related (14). A work related trip whose purpose is not specified.

6. Go to School as a Student (21). Represents a trip whose purpose is to go to school as a student.

7. Go to Religious Activity (22). Represents a trip whose purpose is to go to a place to attend a religious activity.

8. Go to Library, School Related (23). Represents a trip whose purpose is to go to the library as part of a school related activity.

Go to Daycare/Before or After School Care (24). Represents a trip

9. whose purpose is to attend day care or a supervised before or after school care program

10. Other School/Religious Activity (20). Represents school and religious activities that are not captured in WHYTO 21-24 above.

Medical/Dental Services (30). Represents a trip made to obtain medical,

11. dental, or mental health treatment, or other related professional services.

Buy Goods: groceries/clothing/hardware store (41). Represents a

12. shopping trip whose purpose is to purchase commodities for use or consumption elsewhere. This purpose also includes all shopping trips even if nothing is purchased.

Buy Services: video rentals/dry cleaning/post office/car service/bank

13. (42). This category includes the purchase of services other than medical/dental or other professional services.

14. Buy Gas (43). Represents a trip made specifically to get gas.

15. Shopping/Errands (40). Represents shopping and errand trips that are not captured in WHYTO 41-43 above.

16. Go to the Gym/Exercise/Play Sports (51). Represents a trip made for exercise, to engage in exercise or to participate in a sport.

Rest or Relaxation/Vacation (52). Represents a trip made for the

17. purpose of relaxing or taking a vacation, but does not include visiting family. 
18. Visit Friends/Relatives (53). Represents the social/recreational trip whose purpose is to visit with family and friends.

Go out/Hang out: entertainment/theater/sports event/go to bar (54).

19. Represents trips whose purpose is entertainment related or hanging out with friends. Typically this event takes place in a public venue.

20.

Visit Public Place: historical site/museum/park/library (55). Represents a trip purpose that is educational or enlightening.

21. Social/Recreational (50). This category includes social and recreational trips that are not captured in WHYTO 51-55 above.

Use Professional Services: attorney/accountant (61). Represents a trip

22. made for to engage professional services other than for medical/dental purposes.

23. Attend Funeral/Wedding (62). Represents a trip whose purpose is to attend a funeral or a wedding.

24. Use Personal Services: grooming/haircut/nails (63). Represents a trip for personal services such as to get a massage or get a haircut.

25. Pet Care: walk the dog/vet visits (64).

Attend Meeting: PTA/home owner's association/local government (65).

26. Represents a trip purpose to attend a non-work related meeting, such as a community meeting

27. Family Personal Business/Obligations (60). Represents a trip for 13 personal business but is not captured in WHYTO 61-65 above.

28. Pickup Someone (71). Represents a trip whose purpose was to pick up a passenger.

Take and Wait (72). Represents a trip made to take someone to a

29. destination and then wait with or for them at the destination and then depart together.

30. Drop Someone Off (73). Represents a trip whose purpose was to drop off a passenger (but not wait for them).

Transport Someone (70). Represents trips with a passenger that are

31. related to picking up or dropping off someone but is not captured in WHYTO 71-73 above. 
32. Social Event (81). Represents a trip whose purpose is to attend a social event but eating a meal is not a key component of the event.

33. Get/Eat Meal (82). Represents a trip whose primary purpose is to get and eat a meal.

34. Coffee/Ice Cream/Snacks (83). Represents a trip whose purpose is to get/eat a snack or drink, something less than a meal.

35. Meals (80). Represents a trip whose purpose is to eat or get a meal but is not captured in WHYTO 81-83 above.

36. Other (97). Represents a trip purpose not captured by any of the specific WHYTO categories described above.

Urbanized Area

An urbanized area consists of the built up area surrounding a central core (or central city), with a population density of at least 1,000 persons per square mile. Urbanized areas do not follow jurisdictional boundaries thus it is common for the urbanized area boundary to divide a county.

For the 2009 NHTS, Urban Areas were calculated two ways.

- Variable URBAN uses the 2000 Urbanized Areas: Cartographic

Boundary Files. File ua00_d00.shp from

http://www.census.gov/geo/www/cob/ua2000.html. Two codes are

used: $0=$ Not in Urban Area, $1=$ in Urban Area

- Variable URBAN1 uses the 2000 Urbanized Areas: Cartographic

Boundary Files. File ua00_d00.shp from

http://www.census.gov/geo/www/cob/ua2000.html. Three codes are

used: $0=$ Not in Urban Area, $1=$ in Urban Cluster, $2=$ in Urban Area,

$3=$ in area surrounded by urban areas.

\section{Vehicle}

In the 2009 NHTS, the term vehicle includes autos, passenger vans, sport utility vehicles, pickups and other light trucks, RV's, motorcycles and mopeds owned or available to the household. 
Term

Vehicle Miles of

Travel (VMT)

Vehicle Occupancy

Vehicle Trip

\section{Definition}

VMT is a unit to measure vehicle travel made by a private vehicle, such as an automobile, van, pickup truck, or motorcycle. Each mile traveled is counted as one vehicle mile regardless of the number of persons in the vehicle.

Vehicle occupancy is the number of persons, including driver and passenger(s) in a vehicle; also includes persons who did not complete a whole trip. NHTS occupancy rates are generally calculated as person miles divided by vehicle miles.

A trip by a single privately-operated vehicle (POV) regardless of the number of persons in the vehicle.

Worker See "Employed." 


\section{APPENDIX B CDC DISABILTY STATISTICS}

\section{INTRODUCTION}

The Center for Disease Control and Prevention (CDC) is one of the major operating components of the Department of Health and Human Services (DHHS). To assist in fulfilling its mission to protect Americans from health, safety and security threats, the CDC collects and maintains several health-related survey programs and produces many statistics regarding public health and wellbeing. The CDC also routinely conducts critical analyses and provides important health information to increase public awareness of potential dangerous health threats, as well as responds when needs arise. The CDC defines disability as "any condition of the body or mind that makes it more difficult for the person with the condition to do certain activities and interact with the world around them.

The Behavioral Risk Factor Surveillance System (BRFSS) ${ }^{22}$ is an annual state-based system of health surveys that collects information on health risk behaviors, preventive health practices, and health care access primarily related to chronic disease and injury. Established in 1984 with 15 states, BRFSS now collects data in all 50 states and Washington D.C., as well as U.S. territories. The BRFSS is a random-digit-dialed telephone survey of the U.S. noninstitutionalized civilian population aged 18 and older. BRFSS completes more than 400,000 adult interviews each year, making it the largest continuously conducted health survey system in the world ${ }^{23}$.

The 2013 BRFSS survey included, for the first time, questions on five functional disability types: vision, cognition, mobility, self-care, and independent living. Responses of "yes" to at least one of the five disability questions were identified as having a disability. As in the ACS data, under the BRFSS one respondent could report two or more disability types. Prior to 2013 survey, disability status of a person was not explicitly identified and information on disability type was not collected. The older (prior to 2013) BRFSS survey only asked respondents two disabilityrelated "yes/no" questions: "Activity limitation due to health problems" and "Health problems requiring special equipment."

\section{ACCESSING CDC DHDS ONLINE TOOL}

The Disability and Health Data System (DHDS) is an online, interactive data tool developed and maintained by the CDC on the health and wellness of adults with disabilities. It covers information on the five disability types covered under the BRFSS. Currently the DHDS tool uses the 2013 BRFSS collected data, since that was the first year CDC started to collect

\footnotetext{
${ }^{22}$ Behavioral Risk Factor Surveillance System, Centers for Disease Control and Prevention, http://www.cdc.gov/BRFSS/.

${ }^{23}$ About BRFSS, Centers for Disease Control and Prevention, http://www.cdc.gov/brfss/about/index.htm
} 
disability information by disability type. The DHDS provides the public with an easy tool to access disability statistics and related reports, which were generated using CDC-collected data, at state, regional, and national levels. The DHDS data tool can be accessed via http://dhds.cdc.gov/ website. A brief description of the major features in the DHDS and their operations are presented in the following.

\section{DHDS Homepage}

Figure B-1 displays a screenshot of the homepage of the DHDS online tool. In addition to all background and supporting information, three main features that allow users to view/access disability statistics are provided in the middle of the screen, including Maps \& Data Tables, State Profiles, and Dual Area Profiles. These options are also provided as the top three options in the selection-menu listed on the upper left corner of the homepage. Other menu options in this selection-menu provide documentations (e.g., methods, data) for interested users.

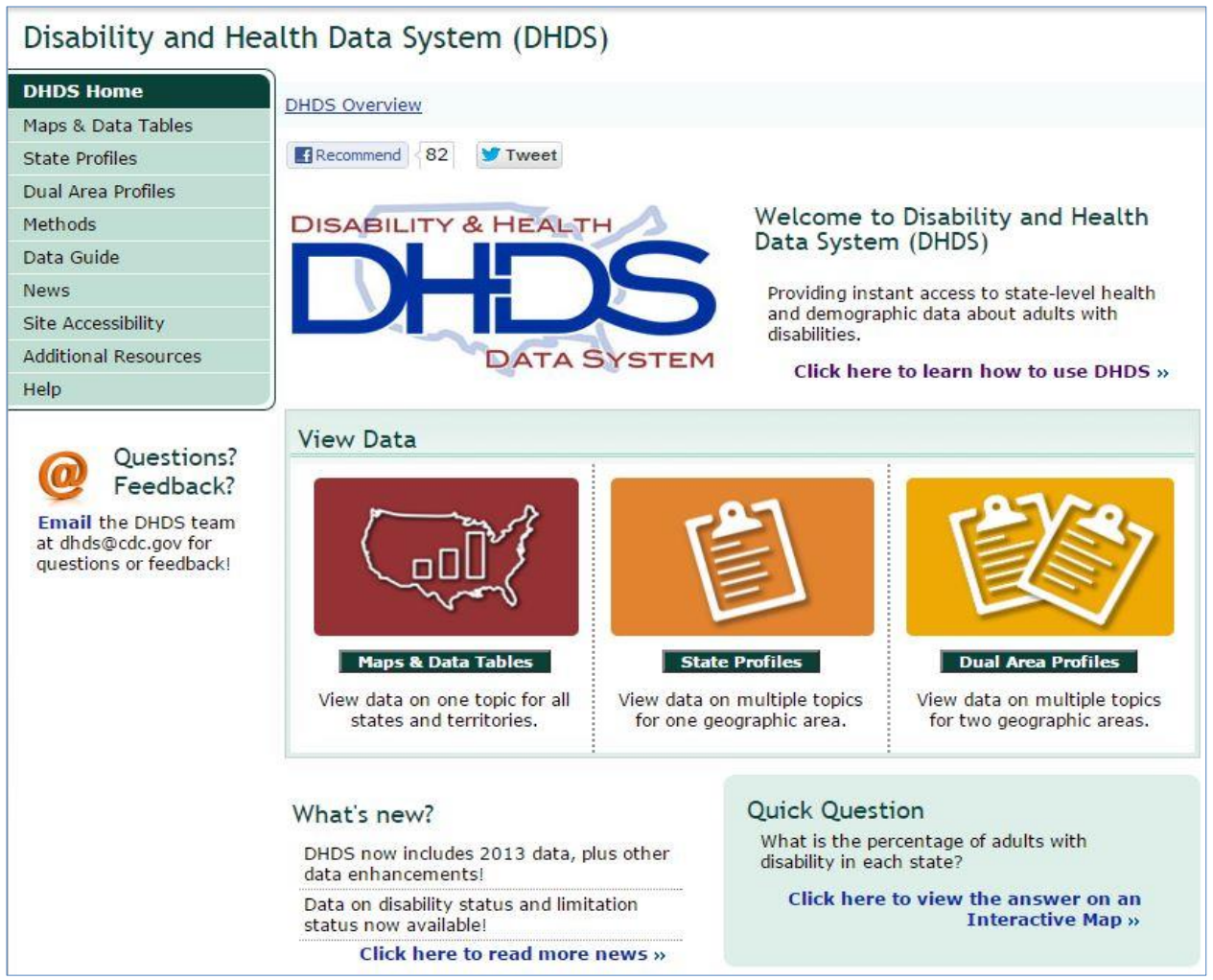

Figure B-1. Screenshot of the homepage for the CDC DHDS online tool.

When necessary, a user can click on the link provided (shown on top right of the "View Data" box) to learn how to operate the DHDS tool. This link takes the user to an online Getting Started Guide that provides a step-by-step procedure for operating the system. For the purpose of this report, discussions in this appendix focus on the disability statistics provided within the DHDS "View Data" box. In addition to the option of viewing data under the "Maps \& Data Tables" option, users of the DHDS could use the "State Profiles" option to obtain state-level profile for a 
selected state or utilize the "Dual Area Profiles" option to compare statistics from two selected areas (national, regional, or states).

\section{Maps \& Data Tables Option}

As shown in Figure B-2, data associated with many disability and health aspects of the U.S. population are available from the DHDS. Using "Disability Estimates" as an example, the expanded menu-tree shows that data (or indicator) available include disability status and types as a whole, as well as those broken down by age, sex, race/ethnicity, or veteran status. Recall that, current release of DHDS is based on 2013 data collected by the CDC.

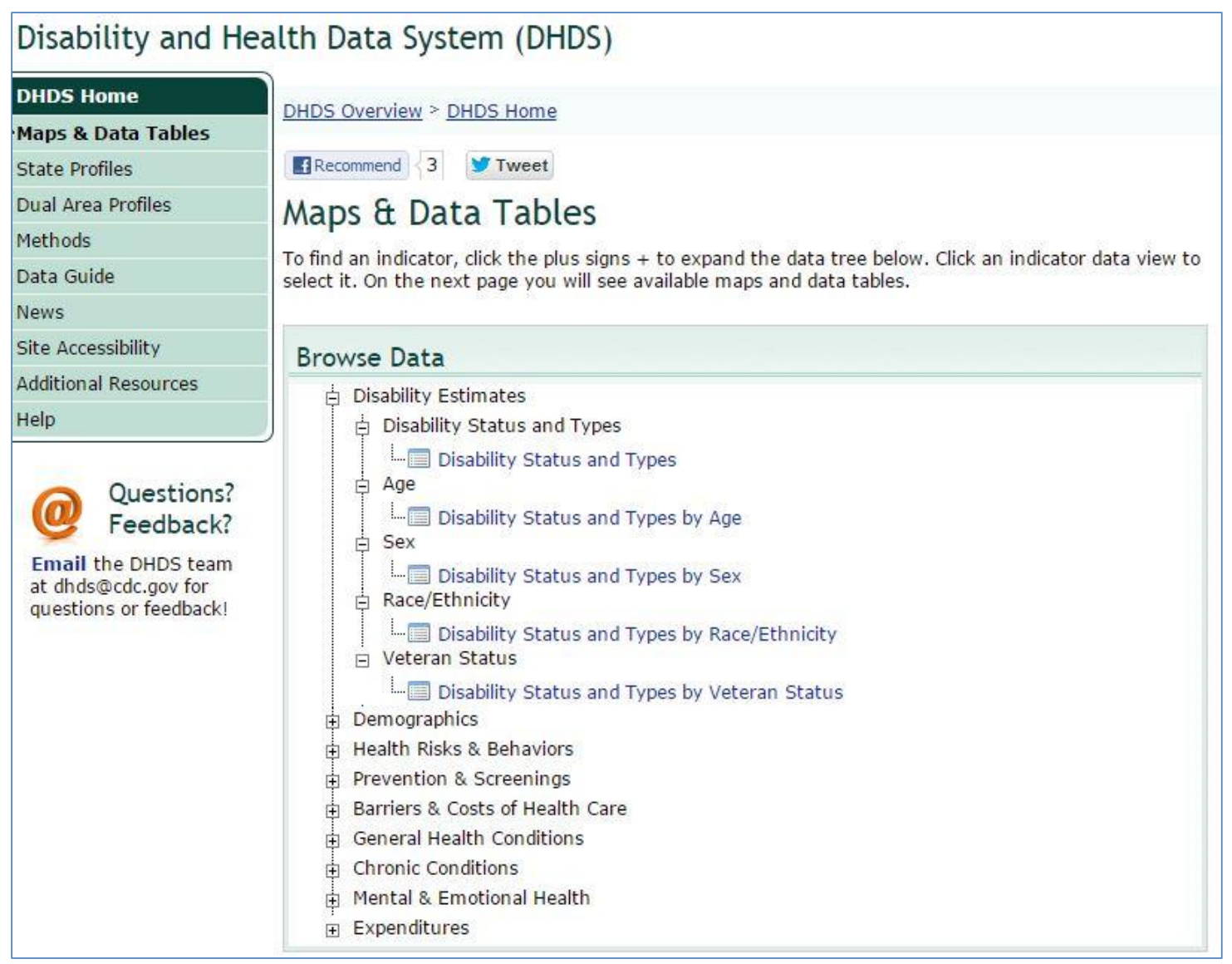

Figure B-2. Example of the "Maps \& Data Tables" feature provided by the DHDS.

Continuing with the above example, Figure B-3 presents a list of choices when the first data table, labeled "Disability Status and Types" (i.e., the option with no breakdowns), was selected. Two types of interactive maps are available; one provides information for a single indicator selected by the user and the other allows two different indicators to be shown for a side-by-side comparison. Furthermore, on each type of interactive maps, the users can select the display in two different color contrasts, one with a standard contrast and the other with a high contrast. Regardless of which contrast was selected, the DHDS has a built-in function that allows users to 
select from more than a dozen preset color themes for customized map/graphic displays of the data, as well as to change the number of categories used in displaying the selected indicator.

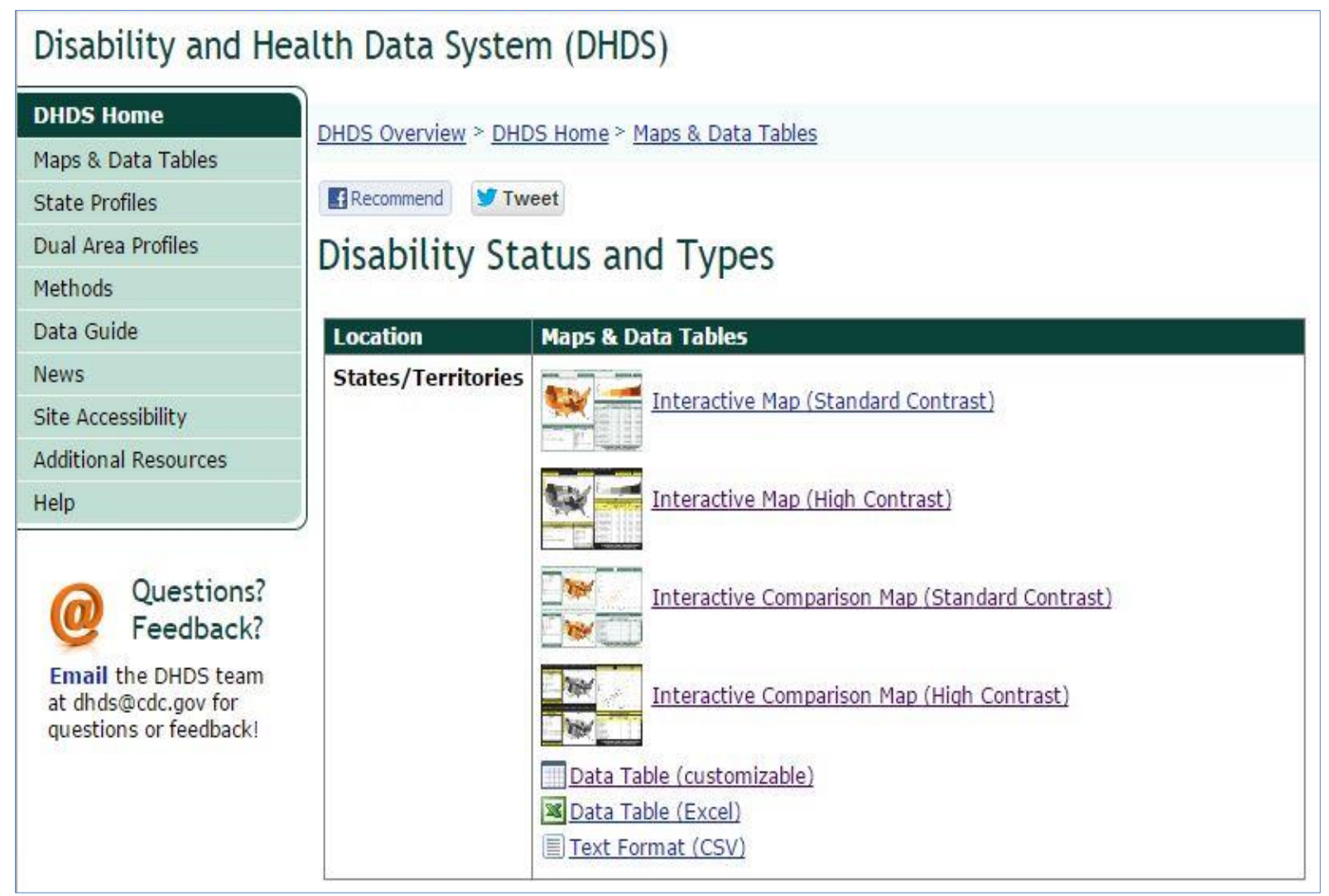

Figure B-3. Choices of maps and tables provided under the "Disability Status and Types" option.

\section{Interactive Map}

Figure B-4 presents a screenshot of the "Interactive Map (High Contrast) scenario in the "Disability Status and Types" options shown in Figure B-3. The indicator used in the Figure B-4 display is noted in the heading; where in this example is for disability estimates on people with "any types of disabilities in 2013." If a specific disability type is of interest, the user can click the "Choose Data" box on the left upper corner to bring up the menu for selecting different data from all available items. In addition to showing information on all states at the national level, options under the "Select Census Area" box (see Figure B-4) allows the user to narrow the display for states within a given Census Division or Census Region.

Furthermore, information displayed in the map, chart, and table windows of the DHDS are synchronized; meaning any changes made to data, region, or color settings will simultaneously be reflected in all displayed windows. When a specific state is selected, for example NYS (see Figure B-4 map with NYS highlighted in pink), the corresponding record in the table will also be highlighted. Recall DHDS uses sample-survey data collected under CDC's BRFSS program, thus estimates generated from the use of this data are subject to uncertainties. Here, as shown in 
Figure B-4, a state level indicator is provided in three parts, mean (average) and lower and upper limits (at the 95\% confidence level, or 95\% CI). For example Figure B-4 shows that, in 2013, $22.1 \%$ of the NYS adult population (age 18 years and older) had "any type of disability." The $95 \%$ CI for this NYS estimate is $(20.9 \%, 23.3 \%)$, where the total estimated number of disabledperson is nearly 3.4 million in 2013 for NYS.

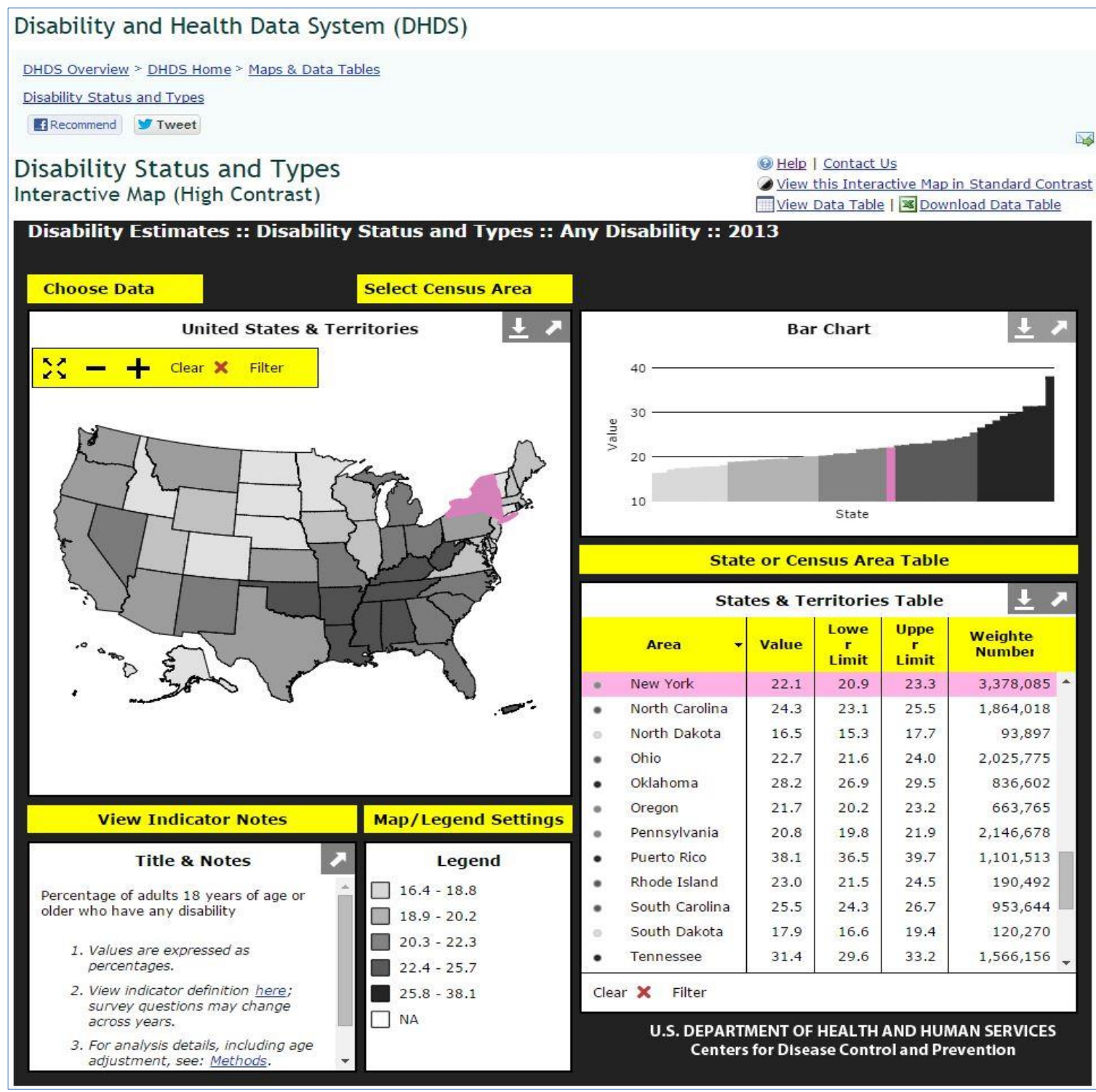

Figure B-4. Example of an interactive map for disability statistics shown with high contrast.

\section{Interactive Comparison Map}

This option is useful when a comparison between two different indicators (or data elements) is required. The example in Figure B-5 shows a comparison between two disability indicators, cognitive disability on the top part and self-care disability at the bottom portion of the screen. Instead of a bar chart like the one seen in Figure B-4, a scatter plot showing the association 
between the two selected indicators (at the state level) is presented. The data table displayed in the lower right window lists the state-level estimates for both indicators. For instance, Figure B5 example shows that $16.3 \%$ of Alabama's population had a cognitive disability in 2013 , while $5.3 \%$ of its population had a self-care disability in the same year.

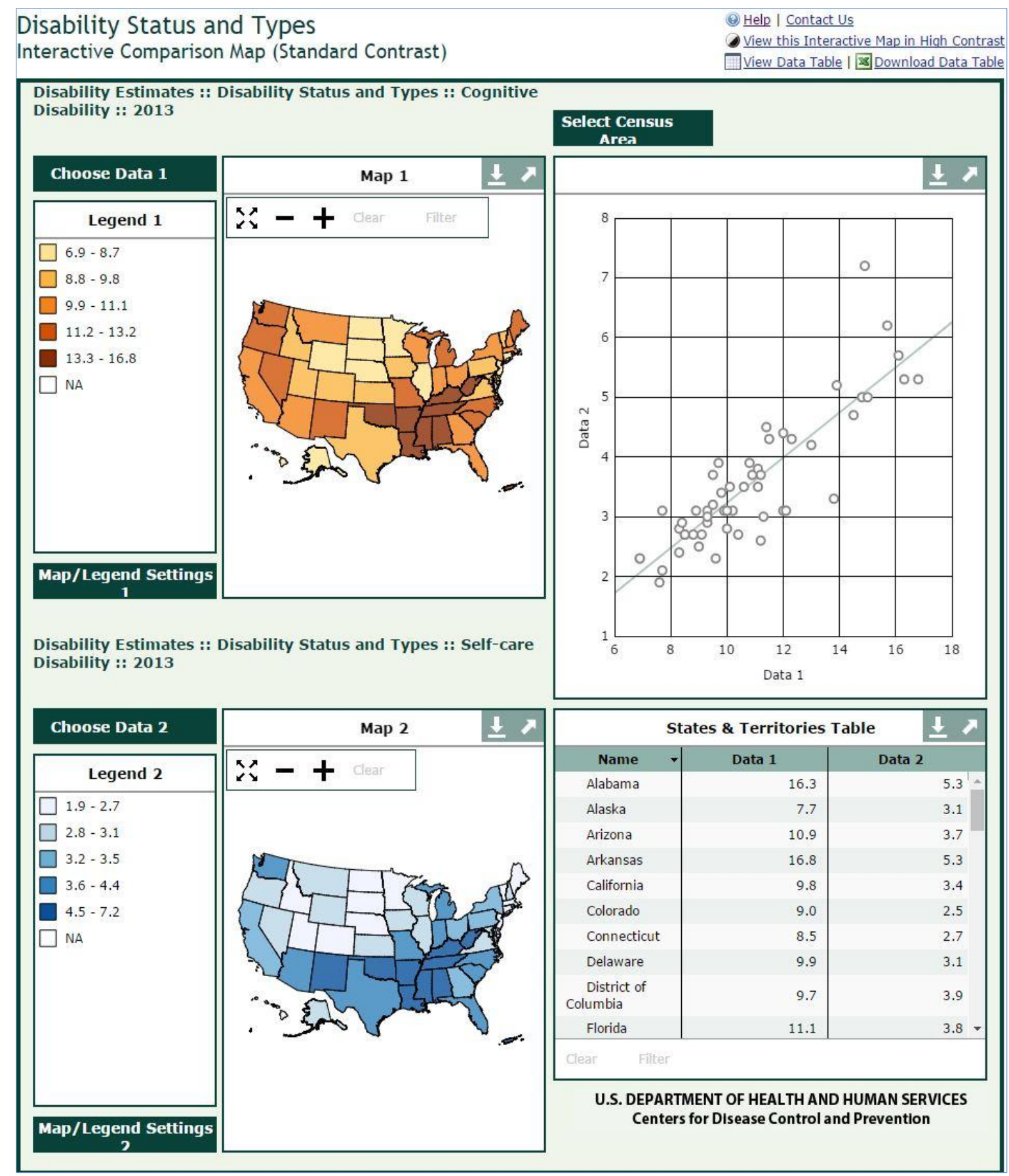

Figure B-5. Disability estimates displayed under the "Interactive Comparison Map" option. 
Figure B-6 shows another example for the comparison of two indicators, filtered at a selected Census Region (i.e., 9 states within the Northeast Region), rather than considering all states (and U.S. territories) as in the previous example.

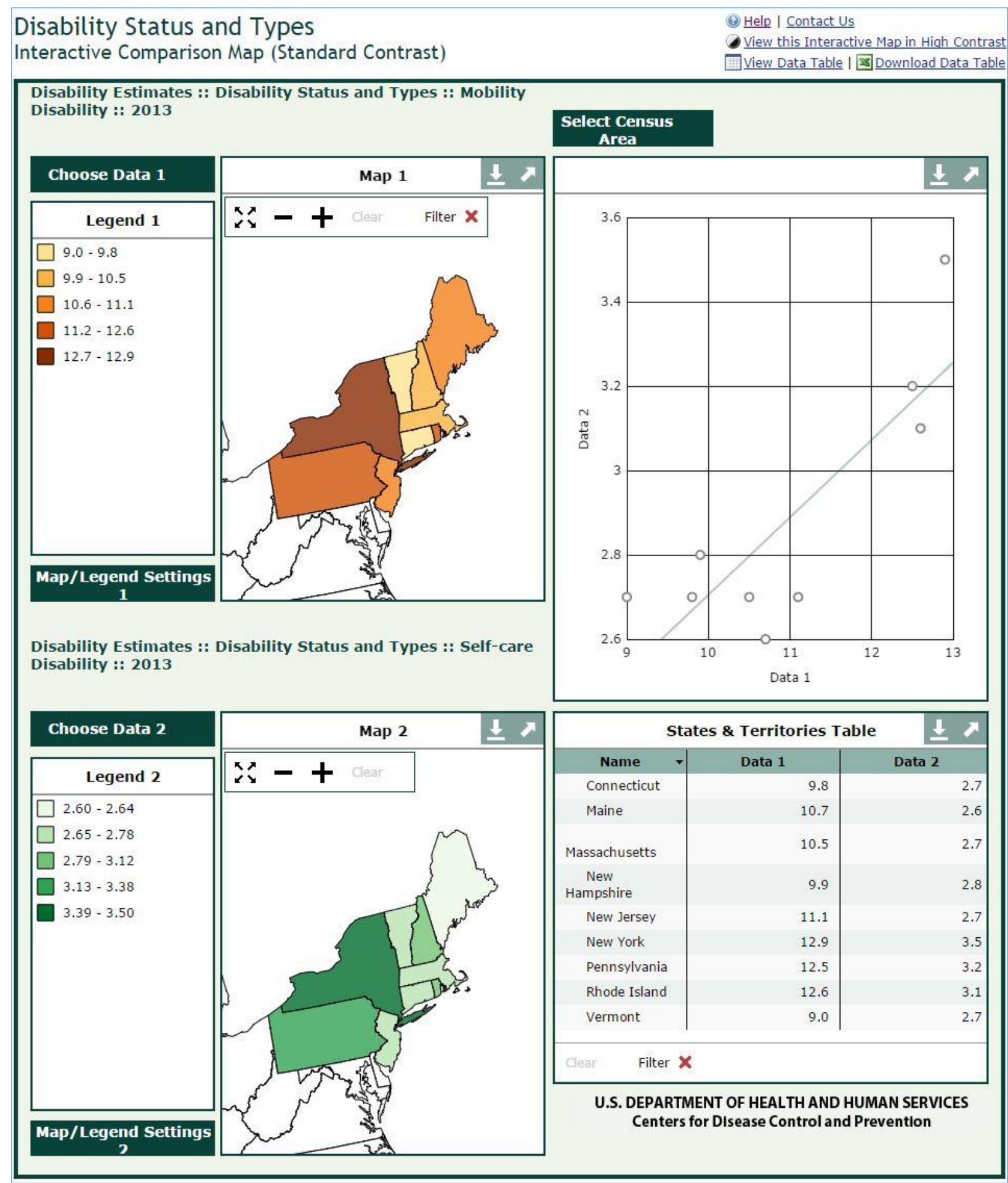

Figure B-6. Example of the "Interactive Comparison Map" option for the Northeast Census Region. 


\section{$\underline{\text { State Profiles Option }}$}

The second major feature (option) of the DHDS tool is a function that allows users to view disability-related data on multiple topics for a selected geographic area. Topics available for selections under the "State Profiles" feature are shown in Figure B-7, including multiple topics under each of the main subjects: Disability Status and Types Profiles, Limitation Status Profiles, and Psychological Distress Profiles.

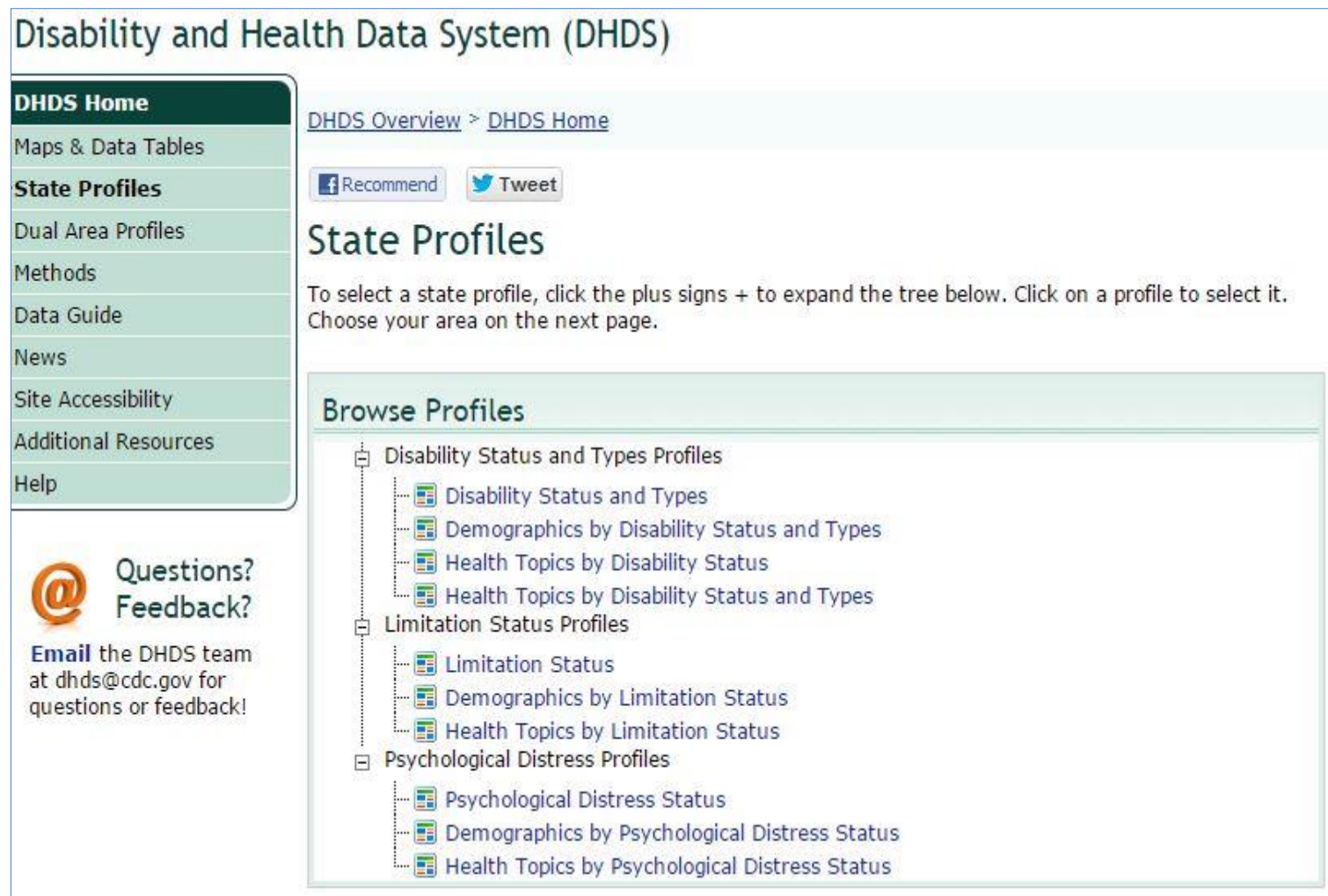

Figure B-7. Information available for viewing under the "State Profiles" feature in DHDS. 


\section{$\underline{\text { Dual Area Profiles Option }}$}

This option allows a user to compare profiles for two user-specified areas. Three kinds of Disability Status and Type Profiles are available for selections, as shown in Figure B-9, which include Disability Status and Types, Demographics by Disability Status and Types, and Health Topics by Disability Status and Types.

\section{Disability and Health Data System (DHDS)}

\begin{tabular}{|l|}
\hline DHDS Home \\
\hline Maps \& Data Tables \\
\hline State Profiles \\
Dual Area Profiles \\
Methods \\
Data Guide \\
News \\
Site Accessibility \\
\hline Additional Resources \\
Help \\
\hline \\
\hline
\end{tabular}

$\underline{\text { DHDS Overview }}>\underline{\text { DHDS Home }}$

ERecommend Tweet

\section{Dual Area Profiles}

Dual Area Profiles present data for a set of indicators for two areas at a time. To select a dual area profile, click the plus signs + to expand the tree below. Click on a profile to select it. Choose your two areas on the next page.

Browse Dual Area Profiles

$\square$ Disability Status and Types Profiles

....国 Disability Status and Types

... 国 Demographics by Disability Status and Types

... 国 Health Topics by Disability Status and Types

Email the DHDS team at dhds@cdc.gov for questions or feedback!

Figure B-9. Screenshot of the Dual Area Profiles option in the DHDS tool. 
After the two areas to be compared are specified, the profile associated with user-selected report type is displayed. At which time, the user could choose to print, email, and/or download the profile report. In the example shown on the top of Figure B-10, New York and the entire U.S. (including States and Territories) were chosen as the two areas for comparisons. Under the profile heading of "Disability Status and Types" is a list of report contents (see Figure B-10), followed by brief discussions on key statistics, which includes summary tables, for each disability type.

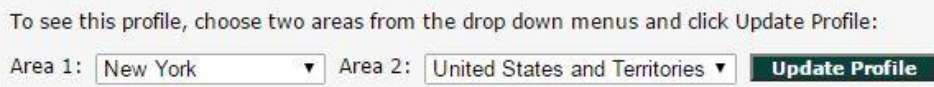

Disability Status and Types

(9) Help I Contact Us Dual Area Profile

- Introduction

- Any Disability

- Cognitive Disability

- Mobility Disability

- Vision Disability

- Self-care Disability

- Independent Living Disability

- No Disability

- Notes

\section{$\boxminus$ Introduction}

This profile provides 2013 data ${ }^{1}$ on disability status ${ }^{2}$ (any disability and no disability), and on disability types ${ }^{2}$ (cognitive, mobility, vision, self-care, and independent living disabilities) among adults ${ }^{3}$ in different age, sex, race/ethnicity, and veteran status groups ${ }^{4}$ in New York and United States \& Territories. In 2013

- $\mathbf{2 2 . 1} \%$ of adults in New York had any disability (cognitive, mobility, vision, self-care, or independent living disability) compared with $\mathbf{2 2 . 4} \%$ in United States \& Territories

- $\mathbf{1 0 . 1} \%$ of adults in New York had a cognitive disability (serious difficulty concentrating, remembering, or making decisions) compared with $\mathbf{1 0 . 7} \%$ in United States \& Territories

- $12.9 \%$ of adults in New York had a mobility disability (serious difficulty walking or climbing stairs) compared with $13.1 \%$ in United States \& Territories

- $\mathbf{4 . 5} \%$ of adults in New York had a vision disability (serious difficulty seeing, even when wearing glasses) compared with $\mathbf{4 . 8} \%$ in United States \& Territories

- $3.5 \%$ of adults in New York had a self-care disability (any difficulty dressing or bathing) compared with $3.6 \%$ in United States \& Territories

- $6.7 \%$ of adults in New York had an independent living disability (any difficulty doing errands alone such as visiting a doctor's office or shopping) compared with $6.6 \%$ in United States \& Territories

Table 1. Any disability ${ }^{2}$ among age, sex, race/ethnicity, and veteran status groups

Figure B-10. Example of a Dual Area Profile report under the subject of "Disability Status and Types," where disability statistics for NYS and the entire U.S. were compared. 
Figure B-11 uses a New York - California dual-area comparison as an example to illustrate how information from dual areas is presented within a selected Profile Report. In this example, percentages associated with adults with a mobility disability by various demographic factors (e.g., age, gender, etc.) were provided. As illustrated in Figure B-11, the percentages for the two selected states are presented in a side-by-side column formatted table. For example, in 2013, over $15 \%$ of female adults that lived in NYS had a mobility disability, while less than $13 \%$ of female adults from California had a mobility disability. Note that, CDC/DHDS might place a "DS" in a table cell to signify such value was suppressed (i.e., data suppressed). In most cases, data could be suppressed due to large degree of uncertainty in the estimates (e.g., small sample size) or to avoid disclosure concerns.

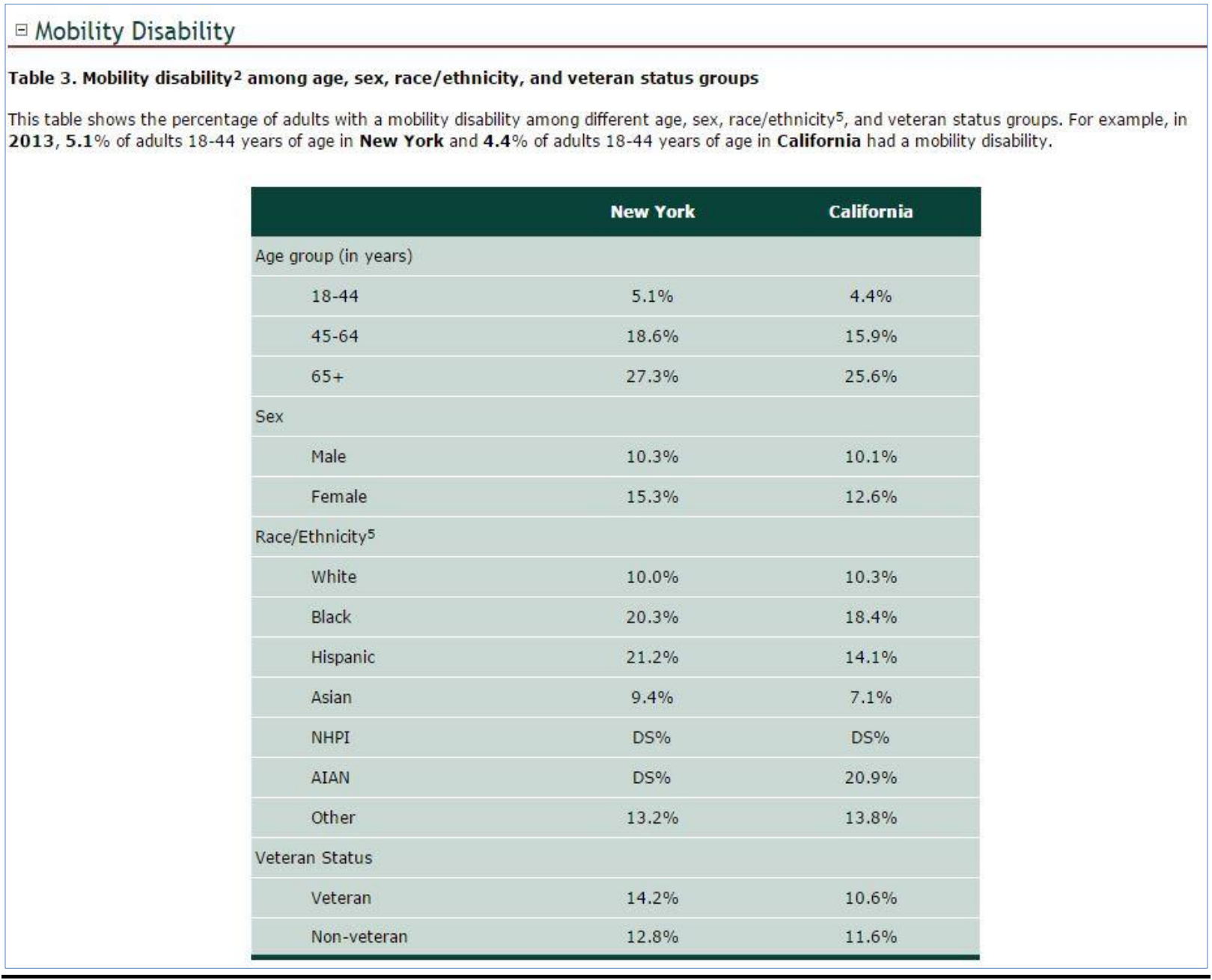

Figure B-11. Example of a summary table produced as a part of the "Dual Area Profiles" report. 


\section{APPENDIX C ADDITIONAL DISABILITY STATISTICS FROM ACS: ECONOMIC WELLBEING}

The economic wellbeing of the population with a disability was examined using information obtained from the 2009 ACS one-year Subject Table S1811 "Selected Economic Characteristics for the Civilian Noninstitutionalized Population by disability Status." Those data were typically reported for persons age 16 years and older, unless otherwise specified. The focus for this research was to utilize 2009 ACS statistics in identifying and quantifying gaps in earnings and poverty between people with and without a disability.

\section{EARNINGS GAPS}

\section{Median Earnings}

Median earning statistics for NYS residents that lived outside NYC (i.e., Rest of NYS) could not be derived using published information from the existing 2009 ACS tables. To estimate median earning for this specific region, data analysis of the 2009 ACS one-year data is required but is out of scope for this study. Therefore, the NYS region is used in this subsection for regional comparisons, instead of the Rest of NYS.

According to Census Bureau data, median earnings for the population ages 16 years and older in the U.S. were about $\$ 28,400$ in 2009 , while median earnings for the same age NYS residents were at $\$ 32,000$ a year. With a higher cost of living, NYC residents have higher median earnings of around $\$ 33,300$ for the same year.

People with disabilities were earning much less compared to their non-disabled colleagues. As presented in Table $\mathrm{C}-1$, for every dollar a typical non-disabled person age 16 years and over made in 2009, a typical disabled person would only be paid 68 cents in NYC. The situation was, in fact, worse for a typical disabled worker that lived elsewhere. Where, for each dollar a typical non-disabled worker (population age 16 years and over) made, a typical disabled person only received about 66 cents.

Table C-1. Median Earnings in 2009 by Disability Status and Region

\begin{tabular}{|l|c|c|c|}
\hline \multicolumn{1}{|c|}{ Disability status } & NYC (5 counties) & NYS & U.S. \\
\hline With a Disability & $\$ 22,919$ & $\$ 21,362$ & $\$ 18,865$ \\
\hline No Disability & $\$ 33,889$ & $\$ 32,542$ & $\$ 28,983$ \\
\hline Ratio & $68 \%$ & $66 \%$ & $65 \%$ \\
\hline
\end{tabular}

Furthermore, Figure C-1 clearly shows significant earning gaps existing between disabled and non-disabled people, and within gender. Using the median earning of a typical "male with no disability" as the base for comparisons, Figure C-1 indicates that a "male with a disability" earned only about $64-67 \%$ of what their non-disabled counterpart did, depending on where they 
lived. Moreover, a "female with a disability" earned even less, only about 45-59\% of what their "male with no disability" neighbors earned in 2009.

The gender gaps in median earnings are smaller for people that lived in NYC than those who lived elsewhere. However, earning gaps between disabled and non-disabled populations (within gender) remained significant regardless of resident locations. This can be observed from Figure $\mathrm{C}-1$, where the two male lines (blue and purple) are relatively parallel, with an approximately $35 \%$ in distance for all regions. Similarly, the distance between the two female lines (green and red) stays roughly at $25 \%$ across the regions.

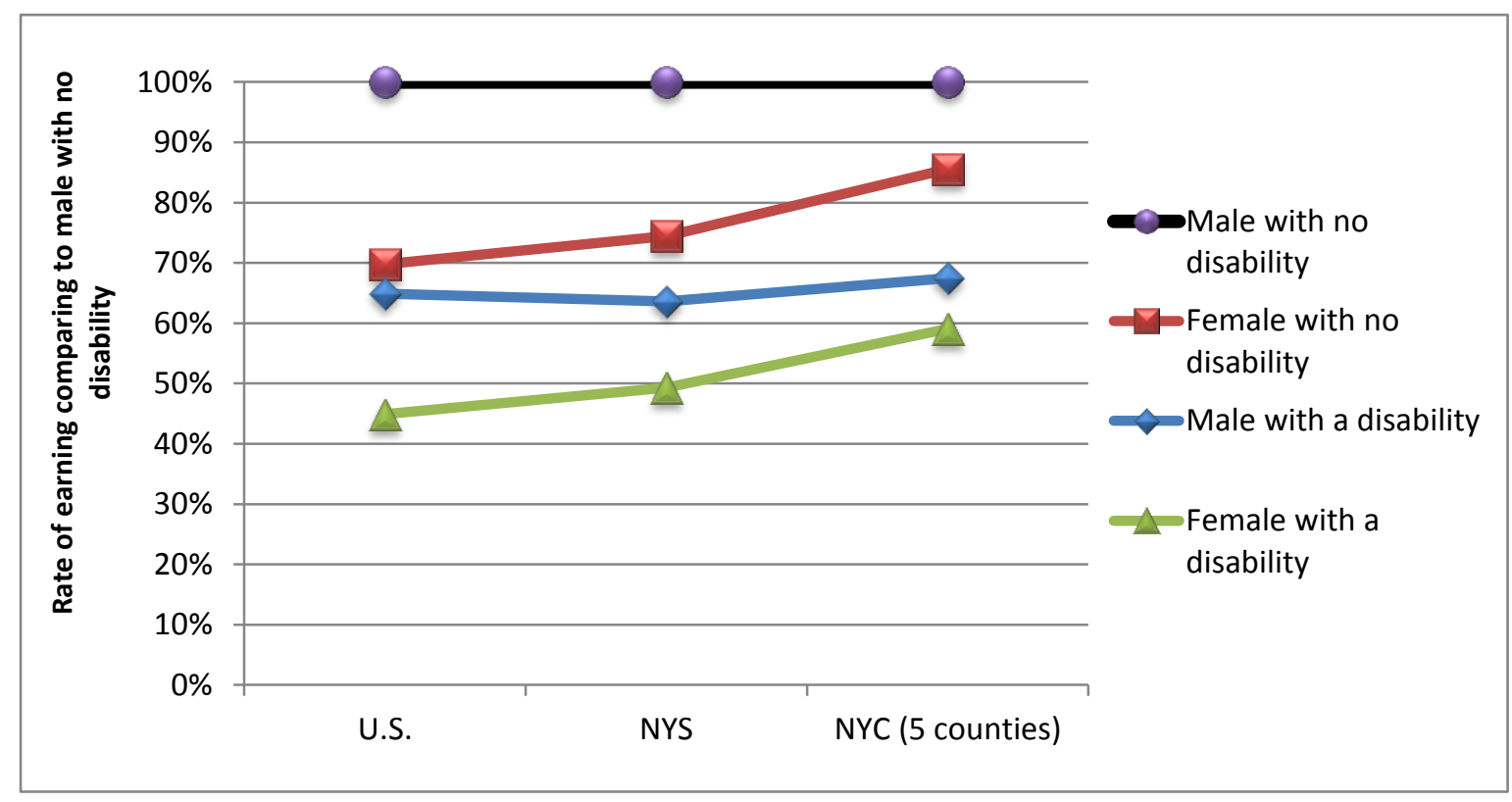

\section{Figure C-1. Median earning rates by disability status, gender, and region (where "male no disability" $=100 \%$ ).}

\section{Annual Earnings}

Figure C-2 compares the disabled versus non-disabled distribution of 12-month earnings for the population age 16 years and older who reported earnings for 2009. Clearly, in all regions examined, there is a significant difference in income distributions between people with and without a disability. The shares of very-low income (under $\$ 15,000$ ) groups in the disabled populations are $13 \%-15 \%$ higher than that in corresponding non-disabled populations.

Specifically, more than a-third (36\%) of disabled workers who lived in NYC earned less than $\$ 15,000$ in 2009 ; while only $23 \%$ of their non-disabled counterparts made this level of earnings in the same year. Outside NYC, 42\%-44\% of disabled workers earned less than $\$ 15,000$ in 2009 while about $27 \%-29 \%$ of their non-disabled neighbors made the same amount of earnings.

Figure C-2 also shows that percentages of non-disabled workers earning $\$ 75,000$ or more are nearly twice as high as the percentages of those with disabilities making $\$ 75,000$ or more in 
earnings. The earnings gap between people with and without a disability is clearly visible by looking at the median earning line plotted in Figure C-2. The median earnings for all disabled groups fall on the "red boxes" which represents the earnings level of " $\$ 15,000$ to $\$ 24,999$;" while all non-disabled groups have median earnings on the "green boxes" representing earnings of " $\$ 25,000$ to $\$ 49,000 . "$

\begin{tabular}{|c|c|c|c|c|c|c|c|}
\hline & \multirow{12}{*}{ 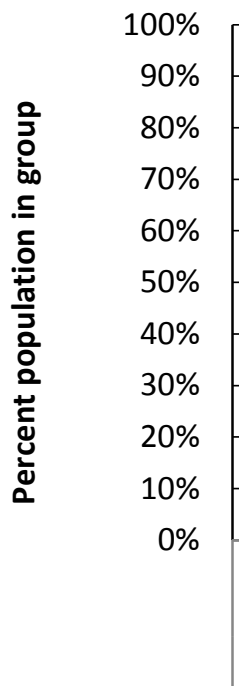 } & & & & & & \\
\hline & & & & & & & \\
\hline & & & & & & & \\
\hline & & & & & & & \\
\hline & & & & & & & \\
\hline & & & & & & & \\
\hline & & & & & & & \\
\hline & & & & & & & \\
\hline & & & & & & & \\
\hline & & & & & & & \\
\hline & & $\begin{array}{c}\text { With a } \\
\text { Disability }\end{array}$ & $\begin{array}{c}\text { No } \\
\text { Disability }\end{array}$ & $\begin{array}{c}\text { With a } \\
\text { Disability }\end{array}$ & $\begin{array}{c}\text { No } \\
\text { Disability }\end{array}$ & $\begin{array}{c}\text { With a } \\
\text { Disability }\end{array}$ & $\begin{array}{c}\text { No } \\
\text { Disability }\end{array}$ \\
\hline & & & & Res & NYS & Res & U.S. \\
\hline$\square 75,00$ & more & $10.3 \%$ & $17.2 \%$ & $8.4 \%$ & $15.8 \%$ & $6.4 \%$ & $12.4 \%$ \\
\hline$\$ 50,00$ & $\$ 74,999$ & $10.6 \%$ & $15.5 \%$ & $10.0 \%$ & $15.3 \%$ & $9.0 \%$ & $13.5 \%$ \\
\hline$\square \$ 25,00$ & $\$ 49,999$ & $25.7 \%$ & $29.2 \%$ & $24.9 \%$ & $28.2 \%$ & $24.4 \%$ & $29.5 \%$ \\
\hline$\square 15,00$ & $\$ 24,999$ & $17.0 \%$ & $14.8 \%$ & $15.3 \%$ & $13.3 \%$ & $16.7 \%$ & $15.9 \%$ \\
\hline Under & 000 & $36.4 \%$ & $23.3 \%$ & $41.5 \%$ & $27.4 \%$ & $43.6 \%$ & $28.7 \%$ \\
\hline - Mediar & rnings & $50 \%$ & $50 \%$ & $50 \%$ & $50 \%$ & $50 \%$ & $50 \%$ \\
\hline
\end{tabular}

Figure C-2. Annual earnings of workers age 16 years and older by disability status and region.

\section{POVERTY GAPS}

The poverty rate is an indicator that measures the percentage of people whose income falls below the poverty threshold. It is generally used to make comparisons on economic wellbeing among different communities. Based on 2009 ACS data, Figure C-3 shows that poverty rates, measured as percent of population with income below $100 \%$ of the poverty level, for populations with a disability were about twice as high as their non-disabled neighbors in all regions.

Specifically, $30 \%$ of the NYC population with a disability had income below $100 \%$ of the poverty level, while only about $15 \%$ of non-disabled NYC residents fell in this range of poverty. Outside NYC, a disabled New Yorker has an $18 \%$ likelihood of having income under $100 \%$ of the poverty level, but only $8 \%$ of their non-disabled counterparts fell in this same level of poverty. A similar pattern also existed among the U.S. population that lived outside NYS. 


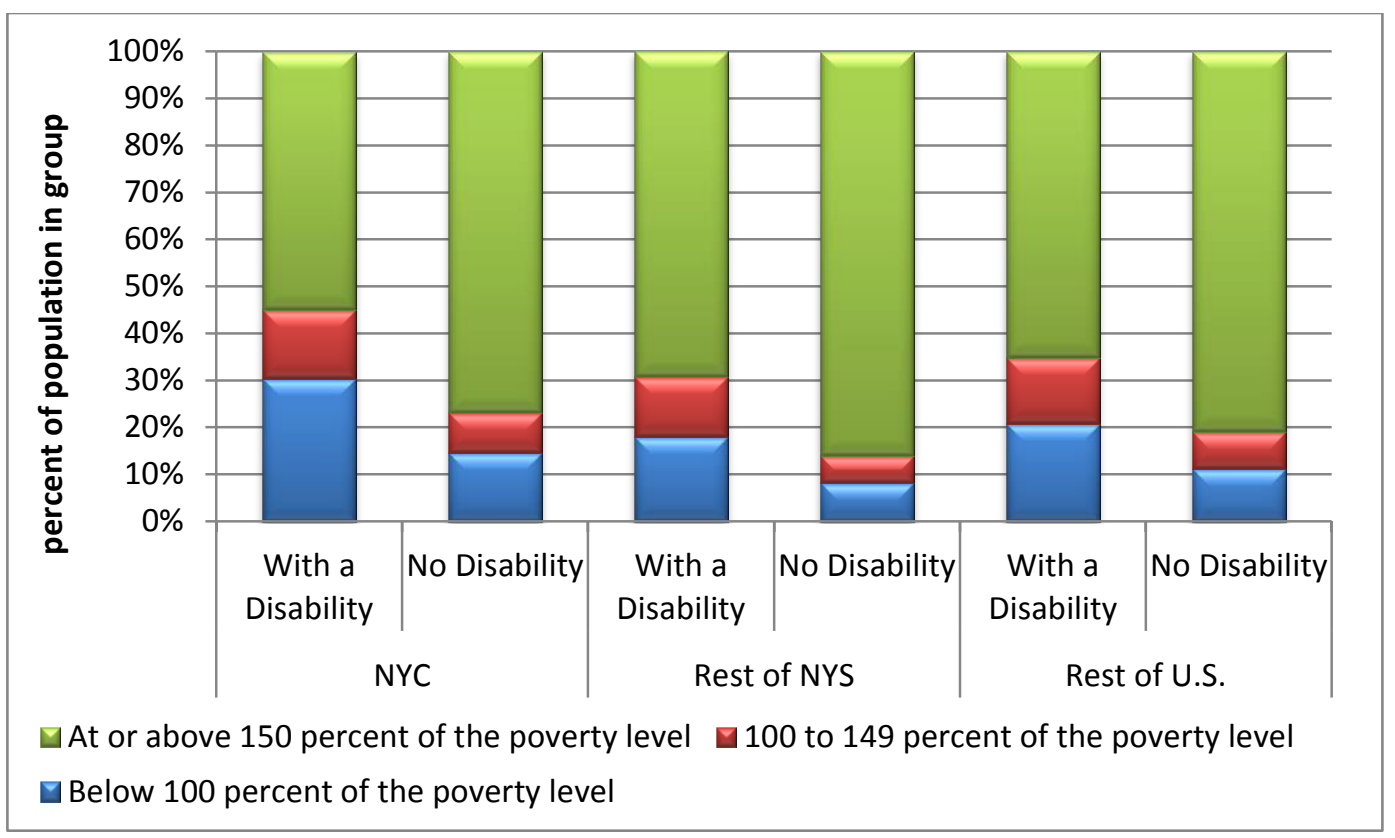

Figure C-3. 2009 poverty rates by disability status and region.

\section{EDUCATIONAL GAPS}

Information on the educational level by disability status was gathered by the 2009 ACS for the population age 25 years and over. According to data shown in Figure C-4, 38\% of disabled NYC residents age 25 years and older were not high school graduates, while only $18 \%$ of their counterpart non-disabled NYC residents had the same low-level education. This educational gap is also seen among people that lived outside NYC. About $24 \%$ of disabled New Yorkers age 25 years and older that lived outside NYC had less than high school graduate education versus only $8 \%$ of their non-disabled counterparts. Outside NYS, people holding this lowest educational level accounted for $27 \%$ for the disabled and $12 \%$ for the non-disabled group of their corresponding population. .

With the median level line plotted in the same chart, an educational gap between a typical disabled person and a non-disabled person can be easily observed. During 2009, for all regions the median educational level for a $25+$ years old person with a disability fell in the "high school graduate" group; while the median educational level for a non-disabled person was a level higher with "some college or associate degree," regardless of where the person lived. 


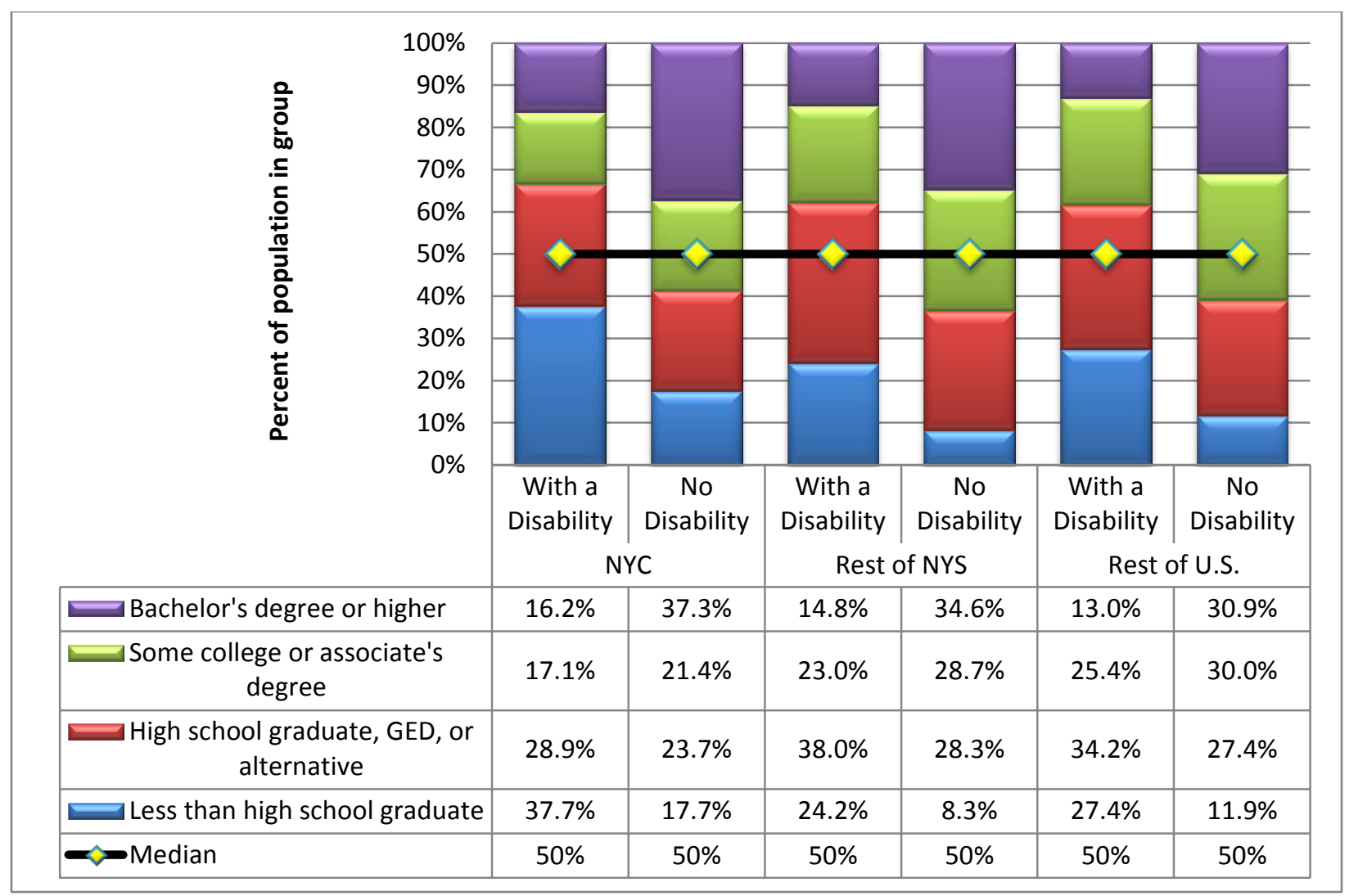

Figure C-4. Education distribution for population age 25 years and older by disability status and region.

\section{RECEIPT OF FOOD STAMPS/SNAP}

Table C-2 summarizes statistics as extracted from the 2009 ACS Table B22010 entitled "Receipt of food stamps/SNAP in the past 12 months by disability status for households." The term SNAP is defined as "Supplemental Nutrition Assistance Program" and it is offered by the Food and Nutrition Service of the U.S. Department of Agriculture. It is formerly known as the Food Stamp Program, which provides nutritional assistance to eligible low-income individuals and families.

Table C-2. Number of Households by Food Stamps/SNAP Receipt Status, Disability Status, and Region for 2009

\begin{tabular}{|c|c|c|c|}
\hline Household type & NYC & $\begin{array}{c}\text { Rest of } \\
\text { NYS }\end{array}$ & Rest of U.S. \\
\hline Total & $3,087,496$ & $4,100,059$ & $113,616,229$ \\
\hline Household received Food Stamps/SNAP & 531,751 & 359,777 & $11,707,519$ \\
\hline Households with 1+ persons with a disability & 236,306 & 184,506 & $5,333,607$ \\
\hline Households with no persons with a disability & 295,445 & 175,271 & $6,373,912$ \\
\hline Household did not receive Food Stamps/SNAP & $2,555,745$ & $3,740,282$ & $101,908,710$ \\
\hline Households with 1+ persons with a disability & 427,579 & 780,295 & $22,331,514$ \\
\hline Households with no persons with a disability & $2,128,166$ & $2,959,987$ & $79,577,196$ \\
\hline
\end{tabular}


Based on Table C-2, of those nearly 114 million households in the U.S. during 2009, about $10 \%$ (nearly 12 million) were SNAP recipients. Of the households that received SNAP assistance, about $46 \%$ (over 5 million households) were disabled households (defined as household with one or more persons with a disability). On the other hand, only about $22 \%$ of households that did not receive SNAP (22 million of the 102 million households) were disabled households. This is consistent with earlier findings (Section 3.4) indicating that having a disability has a negative impact on one's earning/income. Furthermore, a disabled person is more likely to be in a lowincome group, thus a disabled-household is more likely to be a recipient of SNAP assistance.

Figure C-5 provides additional statistics on this subject. Approximately $36 \%$ of all disabled households in NYC received SNAP in 2009 while only $12 \%$ of non-disabled households in NYC received SNAP during the same year. Outside NYC regions, the shares of households receiving SNAP were $19 \%$ and $6 \%$ for disabled and non-disabled households, respectively.

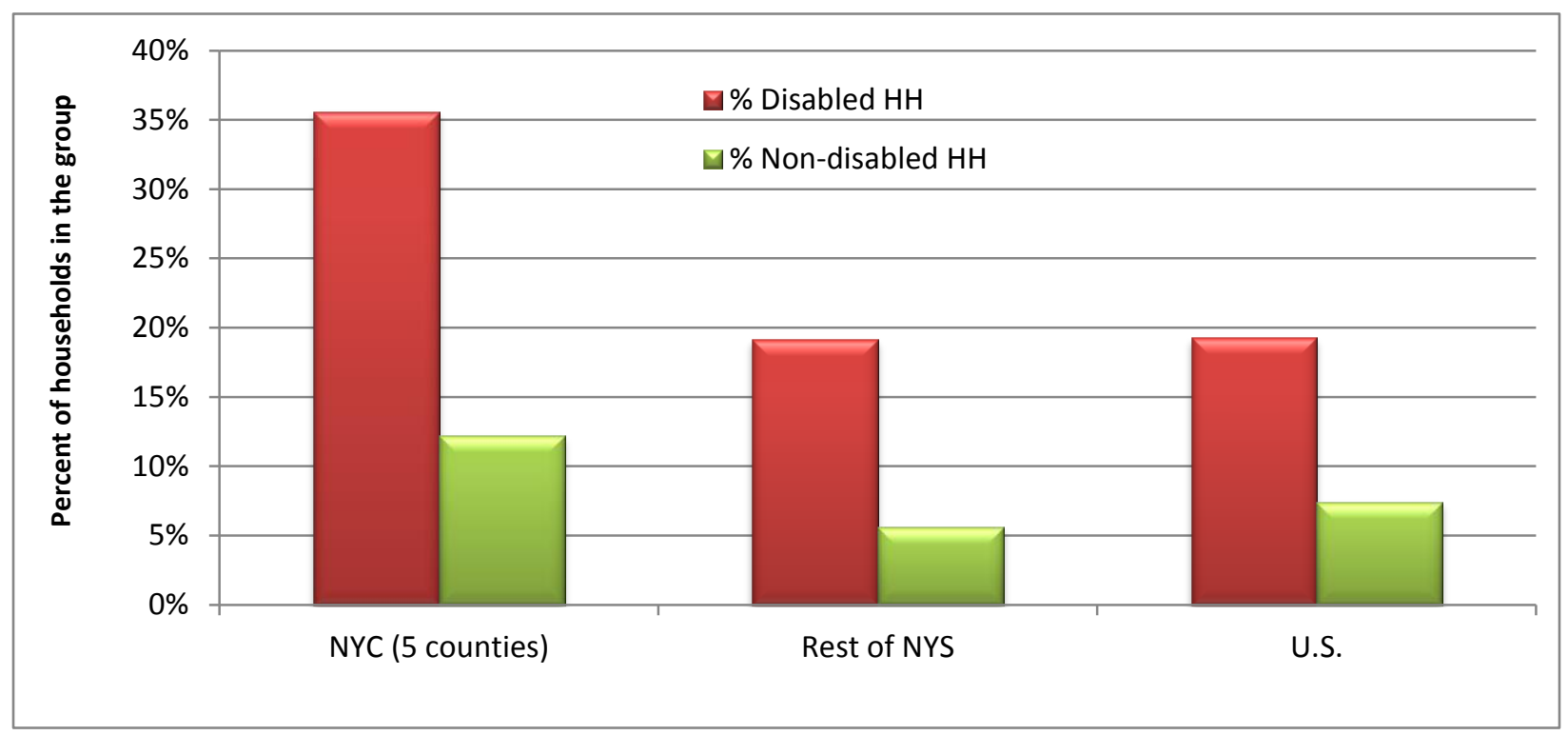

Figure C-5. Share of households (HH) that received Food Stamp/SNAP by disability status in 2009. 


\section{APPENDIX D SUPPLEMENTAL STATISTICS FROM 2009 NHTS}

Table D-1. Travel Statistics by Household Size, Disability Status, and Region (2009 NHTS)

\begin{tabular}{|c|c|c|c|c|c|c|c|c|}
\hline \multirow[b]{2}{*}{ Household size } & \multicolumn{2}{|c|}{ Rest of U.S. } & \multicolumn{2}{|l|}{ NYS } & \multicolumn{2}{|c|}{ NYC (5-county) } & \multicolumn{2}{|c|}{ Manhattan } \\
\hline & Non-disabled & Disabled & Non-disabled & Disabled & Non-disabled & Disabled & Non-disabled & Disabled \\
\hline \multicolumn{9}{|c|}{ PT/Person } \\
\hline 1-person HHs & 4.1 & 2.5 & 4.0 & 2.3 & 4.0 & 2.2 & 4.6 & 2.4 \\
\hline 2-person $\mathrm{HHs}$ & 4.0 & 3.0 & 3.9 & 2.8 & 3.7 & 2.5 & 4.2 & 3.4 \\
\hline 3 or more person $\mathrm{HHs}$ & 3.9 & 3.3 & 3.8 & 3.1 & 3.6 & 2.8 & 4.1 & 2.4 \\
\hline \multicolumn{9}{|c|}{ PMT/Person } \\
\hline 1-person HHs & 31.7 & 14.5 & 23.2 & 9.0 & 14.5 & 5.8 & 12.4 & 3.5 \\
\hline 2-person HHs & 41.5 & 31.0 & 29.0 & 15.3 & 18.1 & 6.3 & 20.3 & 6.7 \\
\hline 3 or more person $\mathrm{HHs}$ & 38.5 & 30.7 & 28.3 & 19.3 & 18.6 & 11.7 & 27.0 & 6.0 \\
\hline \multicolumn{9}{|c|}{ Average PT Length } \\
\hline 1-person HHs & 7.9 & 6.2 & 6.2 & 4.4 & 4.0 & 3.2 & 2.9 & 1.6 \\
\hline 2-person HHs & 10.5 & 10.6 & 7.8 & 5.8 & 5.2 & 2.9 & 5.0 & 2.6 \\
\hline 3 or more person $\mathrm{HHs}$ & 10.1 & 9.6 & 7.9 & 7.0 & 5.7 & 5.2 & 6.8 & 2.5 \\
\hline \multicolumn{9}{|c|}{ VT/Driver } \\
\hline 1-person HHs & 3.4 & 2.2 & 2.1 & 1.6 & 0.9 & 0.5 & 0.5 & 0.3 \\
\hline 2-person HHs & 3.0 & 2.5 & 2.2 & 1.8 & 0.8 & 0.8 & 0.3 & 0.4 \\
\hline 3 or more person $\mathrm{HHs}$ & 3.2 & 2.7 & 2.6 & 1.9 & 1.5 & 0.9 & 1.0 & 0.1 \\
\hline \multicolumn{9}{|c|}{ VMT/Driver } \\
\hline 1-person HHs & 26.1 & 15.0 & 16.1 & 10.6 & 5.5 & 3.5 & 3.9 & 2.4 \\
\hline 2-person HHs & 29.6 & 24.9 & 19.1 & 12.2 & 7.5 & 3.5 & 7.4 & 1.4 \\
\hline 3 or more person $\mathrm{HHs}$ & 31.7 & 27.3 & 22.8 & 15.3 & 11.0 & 4.9 & 15.3 & 0.3 \\
\hline \multicolumn{9}{|c|}{ Average VT Length } \\
\hline 1-person HHs & 7.8 & 6.8 & 7.7 & 6.7 & 6.2 & 8.1 & 7.7 & 8.1 \\
\hline 2-person HHs & 10.1 & 10.1 & 8.9 & 7.1 & 9.6 & 4.9 & 29.2 & 10.3 \\
\hline 3 or more person $\mathrm{HHs}$ & 10.0 & 10.2 & 8.9 & 8.0 & 7.7 & 5.5 & 15.0 & 2.7 \\
\hline
\end{tabular}

Note: Highlighted cells are estimates based on very small sample size, thus are subjected to higher uncertainties. 
Table D-2. Mode Shares by Household Size, Disability Status, and Region (2009 NHTS)

\begin{tabular}{|c|c|c|c|c|c|c|c|c|}
\hline \multirow[b]{2}{*}{ Mode } & \multicolumn{2}{|c|}{ Rest of U.S. } & \multicolumn{2}{|c|}{ NYS } & \multicolumn{2}{|c|}{ NYC (5-county) } & \multicolumn{2}{|c|}{ Manhattan } \\
\hline & $\begin{array}{l}\text { Non- } \\
\text { disabled }\end{array}$ & Disabled & $\begin{array}{l}\text { Non- } \\
\text { disabled }\end{array}$ & Disabled & $\begin{array}{l}\text { Non- } \\
\text { disabled }\end{array}$ & Disabled & $\begin{array}{l}\text { Non- } \\
\text { disabled }\end{array}$ & Disabled \\
\hline \multicolumn{9}{|c|}{ One-person households } \\
\hline POV-Driver & $77.6 \%$ & $56.1 \%$ & $45.3 \%$ & $36.1 \%$ & $17.9 \%$ & $9.4 \%$ & $9.3 \%$ & $6.0 \%$ \\
\hline POV-Passenger & $6.3 \%$ & $19.1 \%$ & $5.1 \%$ & $14.9 \%$ & $3.3 \%$ & $11.5 \%$ & $2.0 \%$ & $4.9 \%$ \\
\hline Taxi & $0.1 \%$ & $1.3 \%$ & $1.4 \%$ & $7.0 \%$ & $2.7 \%$ & $10.7 \%$ & $5.0 \%$ & $9.7 \%$ \\
\hline Public & $2.1 \%$ & $4.4 \%$ & $15.6 \%$ & $11.6 \%$ & $28.9 \%$ & $22.3 \%$ & $25.4 \%$ & $23.0 \%$ \\
\hline Walk & $11.7 \%$ & $13.6 \%$ & $30.9 \%$ & $27.4 \%$ & $45.9 \%$ & $42.2 \%$ & $56.4 \%$ & $56.4 \%$ \\
\hline Other & $2.2 \%$ & $5.6 \%$ & $1.7 \%$ & $2.9 \%$ & $1.3 \%$ & $3.9 \%$ & $1.9 \%$ & $0.0 \%$ \\
\hline \multicolumn{9}{|c|}{ Two-person households } \\
\hline POV-Driver & $69.3 \%$ & $62.0 \%$ & $49.6 \%$ & $42.5 \%$ & $17.2 \%$ & $17.9 \%$ & $5.4 \%$ & $5.9 \%$ \\
\hline POV-Passenger & $17.6 \%$ & $24.6 \%$ & $14.6 \%$ & $17.0 \%$ & $11.2 \%$ & $7.1 \%$ & $5.6 \%$ & $7.2 \%$ \\
\hline Taxi & $0.1 \%$ & $0.4 \%$ & $1.3 \%$ & $2.2 \%$ & $3.0 \%$ & $3.4 \%$ & $4.3 \%$ & $6.2 \%$ \\
\hline Public & $1.0 \%$ & $2.1 \%$ & $9.3 \%$ & $10.5 \%$ & $22.0 \%$ & $20.2 \%$ & $17.3 \%$ & $19.9 \%$ \\
\hline Walk & $9.8 \%$ & $7.8 \%$ & $23.1 \%$ & $26.3 \%$ & $44.1 \%$ & $49.2 \%$ & $65.6 \%$ & $59.0 \%$ \\
\hline Other & $2.2 \%$ & $3.0 \%$ & $2.2 \%$ & $1.6 \%$ & $2.6 \%$ & $2.1 \%$ & $1.9 \%$ & $1.8 \%$ \\
\hline \multicolumn{9}{|c|}{ Three or more-person households } \\
\hline POV-Driver & $56.1 \%$ & $52.0 \%$ & $44.6 \%$ & $38.1 \%$ & $23.1 \%$ & $18.1 \%$ & $13.3 \%$ & $2.0 \%$ \\
\hline POV-Passenger & $28.7 \%$ & $31.3 \%$ & $20.3 \%$ & $20.5 \%$ & $15.2 \%$ & $13.9 \%$ & $18.7 \%$ & $0.0 \%$ \\
\hline Taxi & $0.1 \%$ & $0.0 \%$ & $0.8 \%$ & $0.6 \%$ & $1.7 \%$ & $1.2 \%$ & $5.8 \%$ & $7.2 \%$ \\
\hline Public & $1.2 \%$ & $1.4 \%$ & $8.9 \%$ & $16.7 \%$ & $20.5 \%$ & $35.2 \%$ & $15.5 \%$ & $45.8 \%$ \\
\hline Walk & $9.3 \%$ & $10.4 \%$ & $20.3 \%$ & $17.7 \%$ & $36.1 \%$ & $28.5 \%$ & $43.8 \%$ & $43.9 \%$ \\
\hline Other & $4.6 \%$ & $4.9 \%$ & $5.1 \%$ & $6.4 \%$ & $3.4 \%$ & $3.1 \%$ & $3.0 \%$ & $1.1 \%$ \\
\hline
\end{tabular}

Note: Highlighted cells are estimates based on very small sample size, thus are subjected to higher uncertainties. 